\title{
Estudio de la fauna de macromamíferos del yacimiento de Praileaitz I (Deba, Gipuzkoa)
}

\author{
Praileaitz I (Deba, Gipuzkoa) aztarnategiaren makrougaztun-faunaren ikerketa \\ Faunal study of large mammals from Praileaitz I site (Deba, Gipuzkoa)
}

PALABRAS CLAVE: Macromamíferos, Paleolítico Medio-Superior, País Vasco.

GAKO-HITZAK: Ugaztun Handiak, Goi-Erdi Paleolitikoa, Euskal Herria.

KEYWORDS: Large Mammals, Middle Late Paleolithic, Country Basque.

Pedro CASTAÑOS ${ }^{(1)}$, Jone CASTAÑOS ${ }^{(2)}$

\section{RESUMEN}

Se estudia la fauna de macromamíferos del yacimiento de Praileaitz I (Deba, Gipuzkoa) en los distintos sectores del yacimiento. Se discute el origen de la tafocenosis a partir de la fragmentación y marcas de los huesos así como de la proporción de carnívoros y representación anatómica de algunas especies. Se atribuye la mayor parte de la muestra a la actividad depredadora de varios carnívoros entre los que destaca el lobo. Se establece una hipótesis sobre la secuencia temporal de la ocupación del yacimiento.

Se ofrece un estudio métrico y su correspondiente discusión para diferenciar especies de úrsidos (oso pardo y oso de las cavernas), félidos (lince nórdico y lince de las cavernas) y cánidos (cuon y lobo). Se confirma la importancia de las muestras de las dos últimas especies en la Región Cantábrica.

\section{LABURPENA}

Praileatz I (Deba, Gipuzkoa) aztarnategiko makrougaztun-fauna ikertzen da sektoreka. Tafozenosiaren jatorria eztabaidatzen da hezurren zatiketaren eta marken proportzioan oinarrituta, baita haragijaleen eta espezie batzuen irudikapen anatomikoenean ere. Laginaren zati handiena egozten zaio hainbat haragijaleren predatzaile-jarduerari, batez ere otsoari. Hipotesi bat zabaltzen da aztarnategiaren okupazioaren denbora-sekuentziari buruz.

Ikerketa metriko bat eskaintzen da, eta berari dagokion eztabaida ursido-espezieak (hartz arrea eta haitzuloetako hartza), felidoak (ipar -katamotza eta haitzuloetako katamotza) eta kanidoak (dolea eta otsoa) desberdintzeko. Hemen baieztatzen da azken bi espezieren laginen garrantzia Kantauri zonaldean.

\section{ABSTRACT}

Large mammals from several sectors of Praile Aitz I cave (Deba, Gipuzkoa) is studied. Skeletal profiles, long bone fragmentation and tooth marks shows that ungulate carcasses have been transported and consumed in the cave by several carnivores on all the wolf. A hypothesis about the temporary occupation of the site is stablised.

A metric study and discussion to differentiate species of Ursids (cave bear and brown bear), Felids (boreal lynx and cave lynx) and Canids (wolf and dhole) is offered. The importance of the last two species in the Cantabrian Region is confirmed.

\section{1.- INTRODUCCIÓN}

En la Región Cantábrica la mayor parte de las acumulaciones de fauna en cavidades kársticas son de origen antrópico. Sólo un reducido número de tafonemas tienen un carácter exclusivamente paleontológico. A veces la cueva ha actuado como una trampa natural. Es el caso de Liñares (LÓPEZ, 2003) en Galicia, Jou Puerta y Rexidora (ALVAREZ-LAÓ, 2014 y 2015 respectivamente) en Asturias, Punta Lucero (CASTAÑOS, 1988), Lezika (Castaños et al., 2009), Kiputz IX (CASTAÑOS et al., 2014) y Artazu VII (SUÁREZ et al., 2016) en el País Vas- co. Son menos los casos en los que el agente acumulador del conjunto de huesos es un depredador animal.

El objetivo inicial del presente trabajo era el estudio arqueozoológico de los macromamíferos recuperados en los distintos sectores de la cueva de Praileaitz I con el fin de establecer las bases de subsistencia de origen animal de los cazadores que utilizaron la cavidad a juzgar por el rico ajuar de colgantes descubiertos. Sin embargo, desde el comienzo del análisis de los restos, resultó obvio que la mayor parte de la fauna presente en la cueva no procedía de actividades humanas tal como

\footnotetext{
(1)Sociedad de Ciencias Aranzadi. Geo-Q, Santimami Auzoa, 41, E-48940 Leioa, pedrocastanos@yahoo.es (2) Departamento de Estratigrafía y Paleontología Facultad de Ciencia y Tecnología, Universidad del País Vasco/ Euskal Herriko Unibertsitatea, Apartado 644, E-48080, Bilbao.
} 
se justificará al tratar el tema de la génesis de esta acumulación ósea.

Por esta razón los aspectos estrictamente arqueozoológicos han pasado a un lugar secundario dando prioridad al estudio tafonómico y paleontológico de la muestra. La riqueza en materiales de algunas especies poco abundantes en la Región Cantábrica (lobo, cuon y zorro) hace del conjunto de Praileaitz I una muestra de especial interés desde el punto de vista morfométrico.

Por otra parte, la compleja distribución de los restos en los distintos sectores de la cavidad y su problemática cronológica exigen un tratamiento específico de los distintos conjuntos según su ubicación dentro del yacimiento: abrigo exterior, vestíbulo (con la galería noroeste individualizada), pasillo, primera sala interior y segunda sala interior.

\section{2.- METODOLOGÍA}

Cada resto ha sido objeto de un estudio individualizado en el que se ha procedido a la identificación a nivel anatómico y taxonómico cuando esto ha sido posible. Para ello se han utilizado los correspondientes materiales de comparación de nuestra colección privada y en algunos casos las osteotecas de la Sociedad de Ciencias Aranzadi y del Laboratorio de Arqueozoología de la Universidad Autónoma de Madrid. En cada resto identificado se ha especificado la bilateralidad, la edad, el sexo, el tipo de fragmentación y marcas así como las correspondientes medidas cuando el estado del hueso o del diente lo han permitido.

En la representación de la densidad relativa de restos de fauna recuperados en cada cuadro se utilizan variaciones cromáticas intermedias entre el blanco (menor frecuencia de restos) y el negro (máxima frecuencia de restos). En cada sector se aplica un criterio diferente en cuanto al número de restos correspondiente a cada color que se ajusta al tamaño de las distintas muestras.

Los parámetros utilizados para la cuantificación de las distintas especies son los habituales: número de restos (NR) y número mínimo de individuos (NMI). Las ventajas y limitaciones de cada uno de ellos que ha sido muy debatida desde hace más de tres décadas, nos inclina a la utilización simultánea de los dos a fin de no perder la información complementaria proporcionada por cada uno de ellos. Hay algún autor (DAVIS, 1992) que en vez de ofrecer todos los restos identificables, seleccionan aquellos que consideran más diagnósticos. Personalmente pensamos que aunque los motivos para aplicar esta metodología no están faltos de razón, tienen un inconveniente fundamental: dificultan la comparación con la mayor parte de las muestras arqueozoológicas publicadas cuyos autores no siguen este protocolo.

En la representación anatómica de algunas especies (cabra, lobo y sarrio) además del número de restos de cada parte del esqueleto ofrecemos dos parámetros de uso habitual: el número mínimo de elementos (NME) (STINER, 1991) y el número mínimo de unidades anatómicas (MAU) (BINFORD, 1984). El número de restos (NR) correspondiente a cada parte del esqueleto es conveniente convertirlo en el número mínimo de huesos distintos (NME) que dichos restos representan. Para ello se agrupan aquellos fragmentos que pudieran pertenecer a un mismo hueso y todos ellos se consideran un solo NME. De esta forma se corrigen los efectos de distorsión que algunas partes anatómicas pueden proyectar por el elevado número de restos que generan al fragmentarse (dentadura). A partir de este parámetro se estima el número mínimo de individuos (MAU) presentes en cada parte del esqueleto al dividir el NME entre la frecuencia de ese elemento en el esqueleto. Es otra forma de compensar las diferencias entre aquellas regiones esqueléticas cuya presencia en un mismo individuo es única (axis,

\begin{tabular}{|l|l|l|l|}
\hline A & Anchura & EPA & Espesor proceso ancóneo \\
\hline AA & Anchura acetabulum & L & Longitud \\
\hline AD & Anchura mínima diáfisis & LA & Longitud cavidad glenoidea \\
\hline Ad & Anchura distal & Ldo & Longitud dorsal \\
\hline AM & Anchura máxima & LM & Longitud máxima \\
\hline Ap & Anchura proximal & LmC & Longitud mínima cuello \\
\hline AS & Anchura cavidad glenoidea & LMl & Longitud máxima lateral \\
\hline AScd & Anchura superficie caudal & LMm & Longitud máxima mesial \\
\hline AScr & Anchura superficie craneal & LMP & Longitud máxima proceso articular \\
\hline ASp & Anchura superficie proximal & LMpe & Longitud máxima periférica \\
\hline AT & Anchura tróclea & LO & Longitud olécranon \\
\hline DMB & Diámetro máximo base & LSD & Longitud superficie plantar \\
\hline DmB & Diámetro mínimo base & h & hembra \\
\hline EC & Espesor caput & $\mathrm{m}$ & macho \\
\hline El & Espesor lateral & $\mathrm{X}$ & media aritmética \\
\hline EmO & Espesor mínimo olécranon & $\mathrm{S}$ & desviación típica \\
\hline
\end{tabular}

Tabl. 1. Abreviaturas de las medidas utilizadas. / Abbreviations of the measures used. 


\begin{tabular}{|l|c|c|c|c|c|c|c|}
\hline & $\begin{array}{c}\text { Rellano } \\
\text { exterior }\end{array}$ & $\begin{array}{c}\text { Galería } \\
\text { NW }\end{array}$ & Vestíbulo & Pasillo & Sala 1 & Sala 2 & Total \\
\hline NR identificados & 748 & 1119 & 2373 & 82 & 267 & 648 & $\mathbf{5 2 3 7}$ \\
& $15,4 \%$ & $35,0 \%$ & $20,3 \%$ & $9,0 \%$ & $13,0 \%$ & $22,3 \%$ & $20,5 \%$ \\
\hline NR no & 4106 & 2072 & 9299 & 826 & 1780 & 2257 & $\mathbf{2 0 3 5 0}$ \\
identificados & $84,6 \%$ & $65,0 \%$ & $79,7 \%$ & $90,0 \%$ & $87,0 \%$ & $77,7 \%$ & $79,5 \%$ \\
\hline Total NR & $\mathbf{4 8 5 4}$ & $\mathbf{3 2 0 1}$ & $\mathbf{1 1 6 7 2}$ & $\mathbf{9 0 8}$ & $\mathbf{2 0 4 7}$ & $\mathbf{2 9 0 5}$ & $\mathbf{2 5 5 8 7}$ \\
\hline \%NR & $\mathbf{1 9 , 0}$ & $\mathbf{1 2 , 5}$ & $\mathbf{4 5 , 6}$ & $\mathbf{3 , 5}$ & $\mathbf{8 , 0}$ & $\mathbf{1 1 , 4}$ & \\
\hline
\end{tabular}

Tabl. 2. Número de restos (NR) y porcentajes de la porción identificada y no identificada de cada sector excavado. / Number of remains (NR) and percentages of the portion identified and not identified for each sector excavated.

atlas) o doble (todos los huesos pares) y otras (vértebras y costillas) de elevado número de elementos.

A partir del número mínimo de individuos por cada porción anatómica (MAU) y para evaluar de forma conjunta la posible variabilidad en la representación anatómica, es útil agrupar los datos en cinco regiones anatómicas clásicas en un animal tetrápodo: cabeza, tronco, miembro anterior (escápula, húmero, radio, ulna), miembro posterior (pelvis, fémur, tibia) y patas (carpo, tarso, metapodios y falanges). La frecuencia relativa de cada región anatómica se obtiene sumando las MAU de los huesos de cada región.

Los histogramas con las frecuencias relativas de las especies se han estimado a partir del porcentaje del número de restos, prescindiendo en las figuras de aquellas especies cuyo tamaño de muestra no supere los cinco restos.

Las medidas recogidas en el estudio de las distintas especies presentes se han tomado con un calibre de puntas finas de la marca Mitutoyo. Todas ellas se han obtenido siguiendo la metodología ya clásica de A.v.d. DRIESCH (1976) utilizada en la mayoría de análisis de faunas ibéricas con las correspondientes abreviaturas adaptadas al castellano (Tabl. 1). Se expresan en mm con un error estimado de $0,5 \mathrm{~mm}$ en todas las que superan los $20 \mathrm{~mm}$ (salvo los metapodios de Lagomorfos) y de 0,05 mm en las demás. En el texto se utilizan resúmenes estadísticos mientras que las medidas aisladas se recogen en un anexo final.

\section{3.- MATERIAL}

La excavación de Praileaitz I ha proporcionado 25587 restos de macromamíferos de los cuales han sido susceptibles de identificación 5237 que representan el $20,5 \%$ del total recuperado. Todo el sustrato ha sido cribado con una luz de malla de $5 \mathrm{~mm}$ y se ha recogido todo el material óseo. Este conjunto de fauna está distribuido de forma desigual entre los seis sectores diferenciados durante la excavación (Tabl. 2).

La muestra más numerosa corresponde al vestíbulo. Si se le añade el conjunto de la sala noroeste, se obtiene más de la mitad $(58,1 \%)$ de todos los restos recuperados. El abrigo exterior es el siguiente sector desde el punto de vista cuantitativo. Finalmente la muestra más pequeña procede del pasillo y desde aquí hay un crecimiento progresivo del número de restos hasta la sala más profunda (Fig. 1).

\section{$\%$ NR}

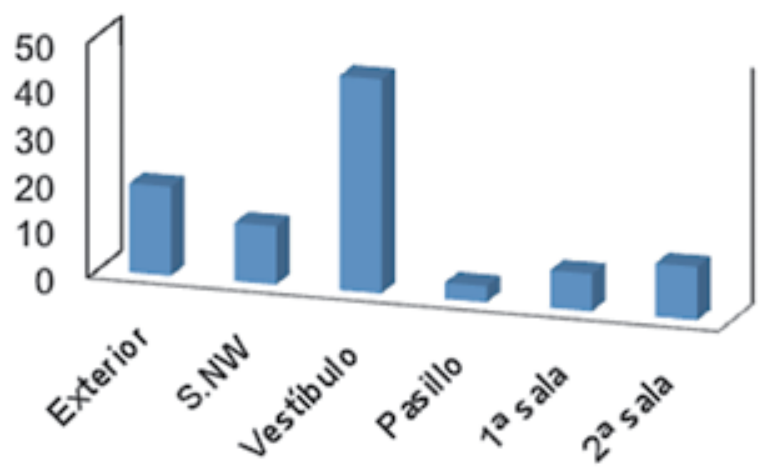

Fig. 1. Histograma con porcentajes de restos de cada sector. / Histogram with percentages of remains of each sector.

La porción indeterminable oscila entre el $65 \%$ y el 92,9\% siendo la más alta la del tránsito entre el vestíbulo y la primera sala interior (pasillo), y la más baja, la de la galería noroeste.

El grado de fragmentación del material recuperado en Praileaitz ocupa una posición intermedia si se compara con otros conjuntos más o menos próximos en el espacio y en el tiempo (Tabl. 3). Este yacimiento presenta porcentajes de material identificado mayores que los de otros yacimientos del Paleolítico Superior Cantábrico, como Cobrante (CASTAÑOS, 2009) o el nivel VI de Ekain y IV de Amalda (ALTUNA, MARIEZKURRENA, 1984 y ALTUNA, 1990). Sin embargo, queda más próximo a otros como el nivel $\mathrm{V}$ de Erralla (ALTUNA, MARIEZKURRENA, 1985), el intervalo III-V (Aziliense) del citado Ekain y el nivel Solutrense del yacimiento cántabro de El Pendo (CASTAÑOS, 2001).

Los 5224 restos identificados a nivel anatómico y taxonómico han permitido registrar la presencia de 22 especies de macromamíferos y una de roedor (Tabl. 4). 


\begin{tabular}{|l|c|}
\hline & \%NR identif. \\
\hline Cobrante & 3,7 \\
\hline Amalda IV & 7,2 \\
\hline Ekain VI & 7,5 \\
\hline Praileaitz I & $\mathbf{2 0 , 6}$ \\
\hline Pendo & 24,4 \\
\hline Erralla V & 29,9 \\
\hline Ekain III-V & 27,3 \\
\hline
\end{tabular}

Tabl. 3. Porcentajes de restos (NR) identificados de varias muestras del Paleolítico Superior Cantábrico. / Identified remain percentages of several upper Palaeolithic Cantabrian sites.

La inclusión de la marmota se debe al tamaño de esta especie de micromamífero que puede ser objeto de captura por los grupos de cazadores paleolíticos. En las tablas se incluye su número de restos pero se prescinde del número mínimo de individuos.

Estas especies pueden asociarse en dos grupos zoológicos: 8 ungulados y 14 carnívoros. Entre los primeros se encuentran la mayor parte de los taxones habituales en las listas de fauna del Paleolítico Superior Cantábrico: caballo, grandes bóvidos (bisonte/uro), cabra, sarrio, ciervo, reno y corzo. Sólo llama la atención la ausencia total del jabalí. No obstante, los grandes bóvidos y el reno quedan escasamente representados así como el caballo y el corzo cuyas frecuencias son residuales.

Los carnívoros están peor representados en cuanto a número de restos pero muestran un índice alto de variabilidad específica con 14 especies entre las que están presentes tanto el oso pardo como el de las cavernas y dos especies de lince, el boreal y el de las cavernas. Destacan en este grupo por el número de restos los cánidos (lobo, cuon y zorro) y los félidos (leopardo, lince y gato montés). El grupo de los mustélidos (tejón, turón y armiño) presentan frecuencias prácticamente testimoniales.

Hay especies como el tejón y el turón que sólo aparecen en el abrigo exterior. Otras como el caballo, el corzo, el armiño y la comadreja sólo tienen restos en el vestíbulo. Un tercer grupo (gato montés, marmota y grandes bóvidos) falta en el pasillo y en la primera sala interior. Y el resto de taxones están presentes en todos los sectores.

\section{4.- DESCRIPCIÓN DETALLADA DE CADA CON- JUNTO}

\subsection{Rellano exterior}

A la izquierda de la entrada y en el exterior de la cueva hay un pequeño abrigo que fue objeto de una excavación de cinco bandas a cada lado $\left(A, B, C, D, A^{\prime}\right)$ y $(1,3$,

\begin{tabular}{|c|c|c|c|c|c|c|c|}
\hline & Exterior & Galería NW & Vestíbulo & Pasillo & Sala 1 & Sala 2 & TOTAL \\
\hline Equus ferus & & & 4 & & & & 4 \\
\hline Bovini sp. & 18 & 1 & 5 & & & 4 & 28 \\
\hline Capra pyrenaica. & 182 & 454 & 1115 & 47 & 119 & 366 & 2283 \\
\hline Rupicapra pyrenaica & 256 & 103 & 300 & 3 & 18 & 30 & 710 \\
\hline Cervus elaphus & 76 & 142 & 321 & 7 & 45 & 63 & 654 \\
\hline Rangifer tarandus & 2 & 2 & 3 & 3 & 1 & 1 & 12 \\
\hline Capreolus capreolus & & & 1 & & & & 1 \\
\hline Ursus arctos & & & 14 & & & 7 & 21 \\
\hline Ursus spelaeus & 26 & 2 & 6 & & & 60 & 94 \\
\hline Ursus sp. & & & & & & 18 & 18 \\
\hline Crocuta crocuta & 9 & & & & & 5 & 14 \\
\hline Panthera pardus & 8 & 13 & 6 & 1 & 2 & & 30 \\
\hline Lynx lynx & 7 & 4 & 24 & & & 2 & 37 \\
\hline Lynx spelaeus & & & 3 & & & & 3 \\
\hline Lynx sp. & & & 23 & 2 & 8 & & 33 \\
\hline Felis silvestris & 1 & & 2 & & & 1 & 4 \\
\hline Canis lupus & 96 & 182 & 242 & 6 & 13 & 19 & 558 \\
\hline Cuon alpinus & 7 & 8 & 17 & & & & 32 \\
\hline Vulpes vulpes & 42 & 198 & 281 & & 61 & 69 & 651 \\
\hline Meles meles & 2 & & & & & & 2 \\
\hline Mustela nivalis & & & 2 & & & 2 & 4 \\
\hline Mustela putorius & 1 & & & & & & 1 \\
\hline Mustela erminea & & 1 & 2 & & & & 3 \\
\hline Marmota marmota & 15 & 19 & 2 & & & 1 & 37 \\
\hline TOTAL & 748 & 1119 & 2373 & 69 & 267 & 648 & 5224 \\
\hline
\end{tabular}

Tabl. 4. Distribución de los restos identificados por especies y sectores. / Identified remain distribution by species and sectors. 
$5,7,9)$ aunque sólo hay restos de fauna en 21 cuadros. Este detalle es consecuencia de la presencia de un gran bloque que ocupaba una parte significativa del área excavada y de la forma irregular de la pared.

Si se representa la cantidad de restos de cada cuadro mediante una escala cromática se puede visualizar la distribución de la densidad de fauna en todos los sectores excavados. Así, en el sondeo correspondiente al abrigo exterior, la mayor densidad de restos y por ende la mayor riqueza taxonómica procede de los cuadros situados en la zona más próxima a la pared y a la entrada de la cavidad (bandas 3 y 5) (Fig. 2). A medida que nos alejamos de la pared (bandas 7 y 9) o nos desplazamos hacia la izquierda (banda D) la densidad de evidencias faunísticas disminuye significativamente.

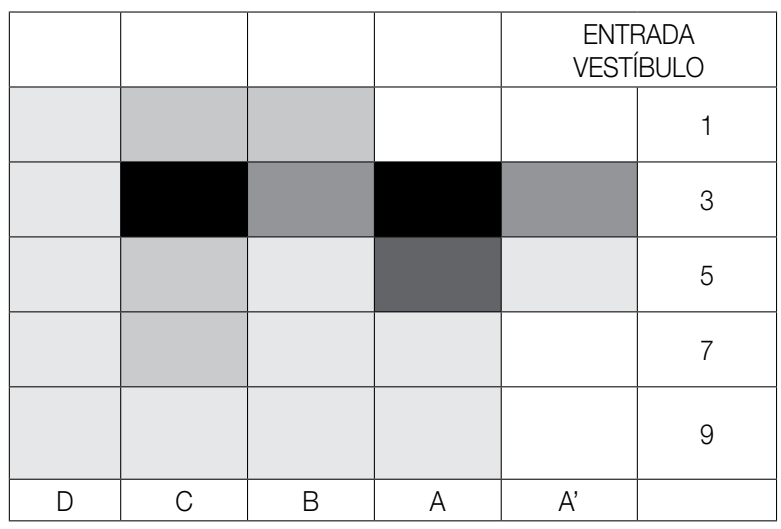

Fig. 2. Densidad de restos de fauna de los cuadros en el rellano exterior. / Faunal remains density in the boxes of the external sector.

La muestra de huesos desde el punto de vista vertical se reparte en 13 lechos distintos; los escasos restos de industria han permitido establecer dos paquetes claramente diferenciados: uno superior, que se puede situar en torno al Aziliense y Magdaleniense Final, y otro inferior, de carácter más antiguo, con una datación del $35010 \pm$ 280 BP. Los restos procedentes de este sector serán estudiados como un conjunto paleontológico aparte y sin aparente relación con el material procedente del interior de la cueva.

En este sector se han recuperado 4854 restos de macromamíferos de los cuales han sido susceptibles de identificación a nivel anatómico y taxonómico 748 que suponen el $15,4 \%$ de todo el material de fauna obtenido (Tabl. 5). En este conjunto hay restos que pertenecen a 16 especies distintas repartidas en dos grupos zoológicos: cinco ungulados (grandes bóvidos, cabra montesa, sarrio, ciervo y reno) y diez carnívoros (oso de las cavernas, hiena, leopardo, lince nórdico, gato montés, lobo, cuon, zorro, tejón y turón) además de la marmota.

La escasez de evidencias de naturaleza antrópica dificulta una agrupación de los lechos a horizontes culturales a diferencia de lo que ocurre en el interior de la cavidad. La aparición del reno, la hiena y el leopardo

\begin{tabular}{|l|c|c|c|c|}
\hline & \multicolumn{2}{|c|}{$\mathbf{1 - 6}$} & \multicolumn{2}{c|}{$\mathbf{7 - 1 3}$} \\
\hline & NR & NMI & NR & NMI \\
\hline Bovini sp. & 6 & 2 & 12 & 2 \\
\hline C. pyrenaica & 26 & 3 & 156 & 8 \\
\hline R. pyrenaica & 37 & 3 & 219 & 7 \\
\hline C. elaphus & 27 & 3 & 49 & 2 \\
\hline R. tarandus & & & 2 & 1 \\
\hline U. spelaeus & 3 & 1 & 23 & 3 \\
\hline C. crocuta & & & 9 & 3 \\
\hline P. pardus & & & 8 & 2 \\
\hline L. lynx & 1 & 1 & 6 & 1 \\
\hline F. silvestris & & & 1 & 1 \\
\hline C. lupus & 26 & 2 & 70 & 3 \\
\hline C. alpinus & 1 & 1 & 6 & 2 \\
\hline V. vulpes & 8 & 1 & 34 & 2 \\
\hline M. meles & & & 2 & 1 \\
\hline M. putorius & & & 1 & 1 \\
\hline M. marmota & & & 15 & \\
\hline Identificados & 135 & 17 & 613 & 39 \\
\hline No identificados & 928 & & 3178 & \\
\hline Total NR & $\mathbf{1 0 6 3}$ & & $\mathbf{3 7 9 1}$ & \\
\hline
\end{tabular}

Tabl. 5. Distribución del número de restos (NR) y del número mínimo de individuos (NMI) de las distintas especies del rellano exterior. / Number of remains (NR) and minimum number of individuals (NMI) of the external sector species.

junto con la marmota a partir del lecho 7, nos ha parecido un criterio razonable para dividir toda la muestra en dos subconjuntos. Por un lado los seis primeros lechos atribuibles a la segunda mitad del Paleolítico Superior, y los más profundos, más propios de un intervalo que puede oscilar entre el final del Musteriense y el Solutrense a tenor de lo que se observa en un buen número de yacimientos de la Región Cantábrica.

La riqueza taxonómica de este sector es importante si se tiene en cuenta su extensión y escasa potencia. Están presentes la mayoría de los ungulados habituales en las relaciones de fauna de yacimientos del Paleolítico Superior de la Región Cantábrica. Sólo faltan el caballo, el corzo y el jabalí. Los dos primeros sin embargo están presentes en el interior de la cueva.

Entre los rasgos diferenciales de este sector puede señalarse la frecuencia más elevada de grandes bóvidos (Bovini) que sólo se repite en la galería noroeste y en el vestíbulo con efectivos casi residuales. Por otra parte es la única muestra en la que el ungulado mejor representado es el sarrio (Rupicapra pirenaica) a diferencia de lo que ocurre en el resto de sectores en los que la cabra montesa (Capra pirenaica) es el herbívoro con mayor frecuencia (Fig. 3). Este dato resulta coherente con el momento en 


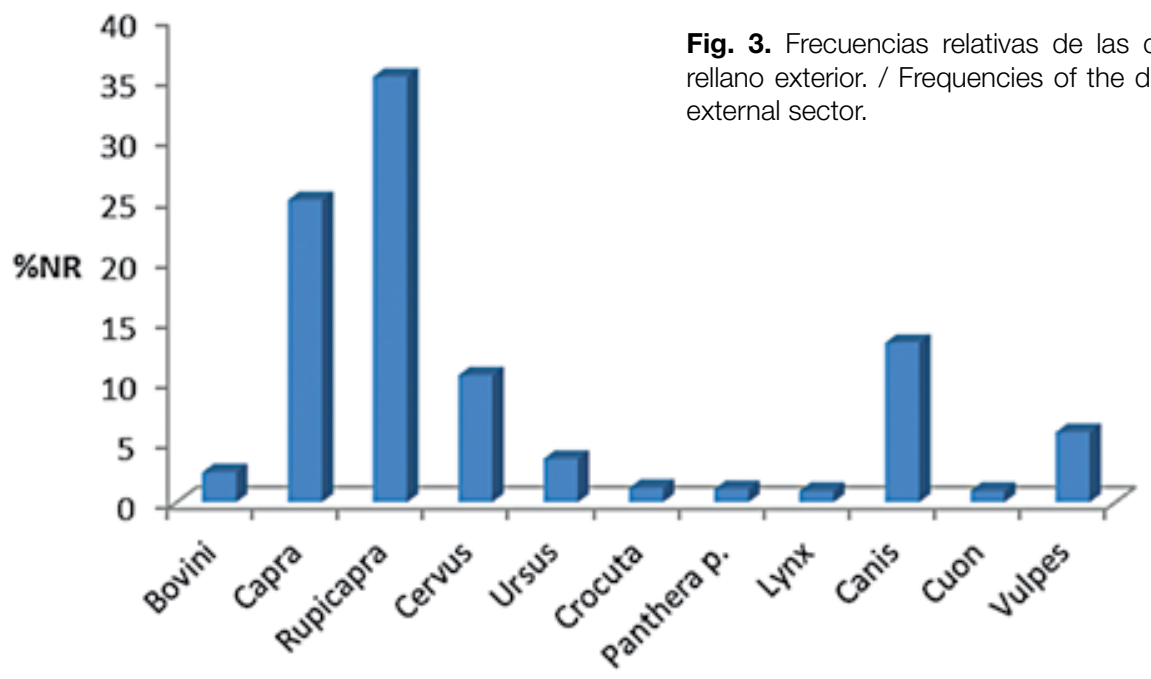

el que se observa un incremento de esta especie en el Cantábrico oriental y que coincide con el inicio del Paleolítico Superior (ALTUNA, 1992; CASTAÑOS, ALVAREZ, 2012). Precisamente la única fecha de carbono 14 de esta muestra, realizada sobre un fragmento de ulna de leopardo, da 35010 \pm 280 B.P. (BETA 341895) dato que corresponde cronológicamente al Chatelperroniense.

\subsection{Vestíbulo}

Este sector contiene la muestra de fauna más rica de todo el yacimiento y también la estratigrafía más completa. La distribución horizontal de la fauna en este sector sigue una distribución normal o curva gaussiana en la dirección longitudinal de la cueva (Fig. 4). Este fenómeno es consecuencia por una parte de la sección en planta de esta primera cámara que se estrecha tanto en la proximidad de la entrada como cerca del pasillo que da acceso a las dos salas interiores. Esta contracción espacial reduce en los extremos el número de cuadros y por tanto también el de restos. A esta circunstancia hay que añadir que la densidad de restos en estas bandas de posición extrema es significativamente menor que en las del centro de la cámara.

La muestra aquí recogida está constituida por 11672 restos de los que han sido identificados 2373 que representan un 20,3\% del total. La distribución cronológica presenta diferencias significativas en cuanto a la cantidad de restos recuperados. Las muestras correspondientes al Epipaleolítico $(7,8 \%)$ y al Magdaleniense Superior Final $(4,2 \%)$ son más reducidas que las del Magdaleniense Inferior (37,6\%) y Solutrense (50,5\%) (Tabl. 6).

Se hallan representadas 19 especies de macromamíferos (8 ungulados y 11 carnívoros) a los que hay que añadir la presencia de 2 restos de marmota. En el grupo de ungulados aparecen por vez primera y única vez el caballo (Equus caballus) y el corzo (Capreolus capreolus). Su presencia con menos de 5 restos es residual así

\begin{tabular}{|l|l|l|l|l|l|l|c|}
\hline & 16 & 14 & 12 & 10 & 8 & 6 & 4 \\
\hline B & & & \multicolumn{2}{|c|}{ PASILLO } & & & \\
\hline C & & & & & & & \\
\hline D & & & & & & & \multirow{2}{*}{ GALERÍA } \\
E & & & & & & & NW \\
\hline F & & & & & & & \\
\hline G & & & & & & & \\
\hline H & & & & & & & \\
\hline I & & \multicolumn{2}{|c|}{ EXTERIOR } & & & & \\
\hline
\end{tabular}

Fig. 4. Densidad de restos de fauna en los cuadros del vestíbulo. / Faunal remains density in the boxes of the vestíbule.

como las de los grandes bóvidos y el reno (Rangifer tarandus). La cabra montesa es el herbívoro que ocupa la primera posición en cuanto a número de restos, tal como se repetirá ya en el resto de sectores. El ciervo, que ocupa el segundo lugar en el Magdaleniense Inferior, pasa al tercer puesto en el Solutrense (Fig. 5).

Entre los carnívoros hay también algunas variaciones. Desaparecen con relación al abrigo exterior la hiena (Crocuta crocuta), el tejón (Meles meles) y el turón (Mustela putorius). En contrapartida aparecen por vez primera el oso pardo (Ursus arctos) que prácticamente reemplaza al oso de las cavernas (Ursus spelaeus) en el Magdaleniense Inferior, ya que éste sólo presenta un resto. En el Solutrense aparece el lince de las cavernas (Lynx spelaea) que se añade al lince nórdico (Lynx lynx) quedando un conjunto de restos de lince sin atribución específica. 


\begin{tabular}{|c|c|c|c|c|c|c|c|c|}
\hline & \multicolumn{2}{|c|}{ Epipaleolítico } & \multicolumn{2}{|c|}{ Magd. Superior Final } & \multicolumn{2}{|c|}{ Magd. Inferior } & \multicolumn{2}{|c|}{ Solutrense } \\
\hline & NR & NMI & NR & NMI & NR & NMI & NR & NMI \\
\hline E. ferus & 1 & 1 & & & 1 & 1 & 2 & 1 \\
\hline Bovini sp. & 1 & 1 & & & 2 & 1 & 2 & 1 \\
\hline C. pyrenaica & 87 & 6 & 92 & 2 & 359 & 6 & 577 & 7 \\
\hline R. pyrenaica & 20 & 2 & 4 & 1 & 76 & 3 & 200 & 4 \\
\hline C. elaphus & 35 & 2 & 17 & 1 & 126 & 5 & 143 & 4 \\
\hline R. tarandus & 1 & 1 & 1 & 1 & & & 1 & 1 \\
\hline C. capreolus & & & 1 & 1 & & & & \\
\hline U. arctos & & & & & 14 & 2 & & \\
\hline U. spelaeus & & & & & 1 & 1 & 5 & 3 \\
\hline P. pardus & & & & & & & 6 & 1 \\
\hline L. Iynx & & & & & 3 & 1 & 21 & 2 \\
\hline L. spelaeus & & & & & & & 3 & 1 \\
\hline Lynx sp. & 6 & 2 & & & 8 & 1 & 9 & 1 \\
\hline F. silvestris & & & & & 2 & 1 & & \\
\hline C. lupus & 7 & 1 & 4 & 1 & 66 & 3 & 165 & 3 \\
\hline C. alpinus & & & & & 12 & 2 & 5 & 2 \\
\hline V. vulpes & 38 & 2 & 22 & 1 & 85 & 4 & 136 & 4 \\
\hline M. nivalis & & & 1 & 1 & 1 & 1 & & \\
\hline M. erminea & 2 & 1 & & & & & & \\
\hline M. marmota & & & & & 1 & & 1 & \\
\hline Identificados & 198 & 19 & 142 & 9 & 757 & 32 & 1276 & 35 \\
\hline No identificados & 707 & & 346 & & 3633 & & 4613 & \\
\hline Total NR & 905 & & 488 & & 4390 & & 5889 & \\
\hline
\end{tabular}

Tabl. 6. Distribución del número de restos (NR) y del número mínimo de individuos (NMI) de las distintas especies del vestíbulo. / Number of remains (NR) and minimum number of individuals (NMI) of the vestibule species.

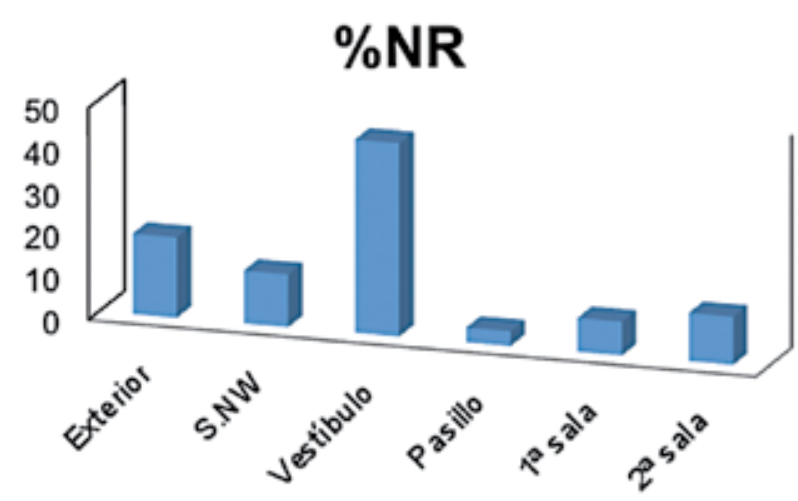

Fig. 5. Frecuencias relativas de las distintas especies en los dos niveles más antiguos del vestíbulo. / Relative frequencies species in the tow oldest levels of the vestibule.

La desaparición de los dos mustélidos se compensa con la presencia por vez primera de otros dos de menor porte como son la comadreja (Mustela nivalis) y el armiño (Mustela erminea). El lobo (Canis lupus) y el zorro (Vulpes vulpes) se intercambian los dos primeros puestos entre los carnívoros al pasar de un nivel a otro.

\subsection{Galería noroeste}

Se denomina así a un divertículo de la cavidad al oeste del vestíbulo y que comunica con el mismo en los cuadros 4E y 4D (Fig. 6). Tiene dos zonas bien diferenciadas en cuanto a la densidad de evidencias y posible

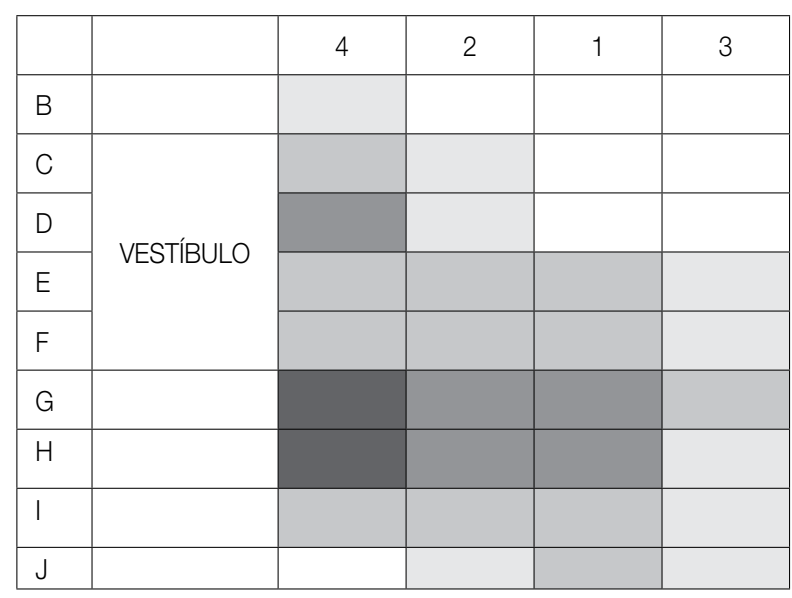

Fig. 6. Densidad de restos de fauna en los cuadros de la galería noroeste. / Faunal remains density in the boxes of the NW gallery. 
origen de la fauna. El área próxima al vestíbulo (banda 4) se caracteriza por la mayor concentración tanto de restos de fauna como de industria lítica. Por el contrario al fondo de la galería (banda 3) los materiales arqueológicos y paleontológicos son más escasos.

La muestra de fauna de esta galería parece tener carácter mixto. La parte más próxima a la gran sala del vestíbulo (banda 4) puede constituir una extensión del sustrato del propio vestíbulo. Pero la porción más alejada (banda 3) presenta algunos rasgos diferenciales. Por una parte contiene alguna evidencia de industria gravetiense. Además la presencia de la marmota y una mayor fre-

\begin{tabular}{|l|c|}
\hline & NR \\
\hline Bovini sp. & 1 \\
\hline C. pyrenaica & 454 \\
\hline R. pyrenaica & 103 \\
\hline C. elaphus & 142 \\
\hline R. tarandus & 2 \\
\hline U. spelaeus. & 2 \\
\hline P. pardus & 13 \\
\hline L. lynx & 4 \\
\hline C. lupus & 182 \\
\hline C. alpinus & 8 \\
\hline V. vulpes & 198 \\
\hline M. erminea & 1 \\
\hline M. marmota & 19 \\
\hline Identificados & 1119 \\
\hline No identificados & 2072 \\
\hline Total NR & $\mathbf{3 2 0 1}$ \\
\hline
\end{tabular}

Tabl. 7. Distribución del número de restos (NR) y del número mínimo de individuos (NMI) de las distintas especies de la galería noroeste. / Number of remains (NR) and minimum number of individuals (NMI) of the NW gallery species. cuencia relativa del leopardo difieren del contenido taxonómico de la gran sala del vestíbulo. Estos dos detalles pueden indicar que una parte de la de fauna proceda de una galería colmatada próxima más antigua. La imposibilidad de atribuir los restos a una u otra fuente, nos obliga a considerarlas como un todo y a prescindir de la estimación del número mínimo de individuos.

Se han recogido 3201 restos de los que han sido identificados 1119 que representan un 35\% del total. A pesar de ser el tercer conjunto en cantidad de restos y el segundo en número de restos identificados, la variedad taxonómica se reduce a 13 especies de macromamíferos (Tabl. 7).

Presenta los mismos ungulados que el abrigo exterior. Entre los carnívoros han desaparecido el oso pardo, la hiena y el lince de las cavernas, con la comadreja como único representante de los mustélidos. También está presente la marmota. Los carnívoros más abundantes son el zorro y el lobo (Fig. 7). Hay una datación de radiocarbono de $25.320 \pm 140$ B.P. (GrA 28025) del nivel VI de esta galería (cuadro $2 \mathrm{G}$ ) que indica la presencia de material más antiguo que el del nivel Solutrense del vestíbulo.

\subsection{El tránsito entre el vestíbulo y la primera sala interior: pasillo}

Con esta denominación nos referimos al estrecho conducto que une el vestíbulo con la primera sala interior. Abarca cuatro bandas literales (A-A'-B'-C') y seis numéricas (6 a 16) y de los 24 cuadros sólo 17 contienen fauna. En general los cuadros con más densidad de fauna corresponden a los del centro del pasillo en sentido longitudinal (Fig. 8). Sin embargo hay una excepción en la banda $A^{\prime}$ que apenas tiene restos en todos sus cuadros. Como antes se indicaba parece que esta área correspondiera a la frontera o límite entre las áreas de expansión del vestíbulo y de la primera sala interior. Además se observa que la penetración de materiales en la zona del pasillo fue más intensa desde la sala interna que desde el vestíbulo.

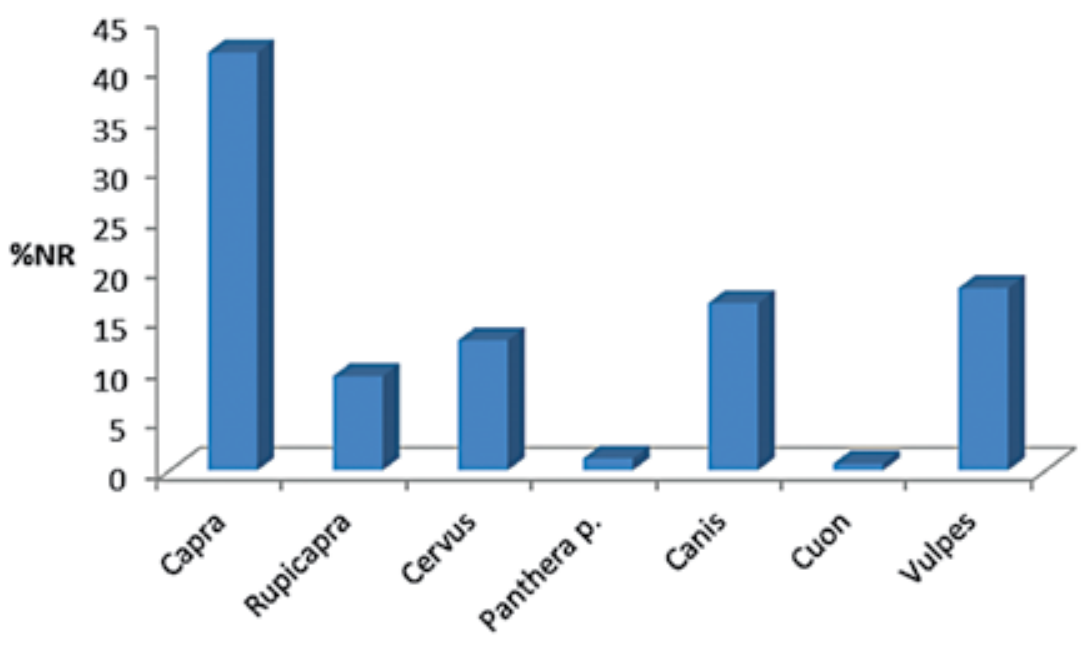

Fig. 7. Frecuencia relativa de las distintas especies en la galería noroeste. / Relative frequencies species in the NW gallery. 


\begin{tabular}{|c|c|c|c|c|c|c|}
\hline & 16 & 14 & 12 & 10 & 8 & 6 \\
\hline & & $1^{a}$ sala & & & & \\
\hline$C^{\prime}$ & & & & & & \\
\hline $\mathrm{B}^{\prime}$ & & & & & & \\
\hline$A^{\prime}$ & & & & & 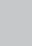 & \\
\hline A & & & & & & \\
\hline & & & VES & & & \\
\hline
\end{tabular}

Fig. 8. Densidad de restos de fauna en los cuadros del pasillo. / Faunal remains density in the boxes of the passage.

Es el sector con menos contenido faunístico del yacimiento. Se han recuperado 908 restos de los que sólo se han podido identificar 82 que representan tan sólo el 9\% del total (Tabl. 8). Sólo contienen fauna los dos niveles más antiguos del vestíbulo.

\begin{tabular}{|l|c|c|c|c|}
\hline & \multicolumn{2}{|c|}{ Magd. Inferior } & \multicolumn{2}{c|}{ Solutrense } \\
\hline & NR & NMI & NR & NMI \\
\hline C. pyrenaica & 17 & 2 & 29 & 2 \\
\hline R. pyrenaica & 3 & 1 & & \\
\hline C. elaphus & 4 & 1 & 3 & 1 \\
\hline R. tarandus & 2 & 1 & 1 & 1 \\
\hline P. pardus & 1 & 1 & & \\
\hline Lynx sp. & 1 & 1 & 1 & 1 \\
\hline C. lupus & 2 & 1 & 4 & 1 \\
\hline V. vulpes & 5 & 1 & 9 & 1 \\
\hline Identificados & 35 & 9 & 47 & 7 \\
\hline No identificados & 325 & & 501 & \\
\hline Total NR & $\mathbf{3 6 0}$ & & $\mathbf{5 4 8}$ & \\
\hline
\end{tabular}

Tabl. 8. Distribución del número de restos (NR) y del número mínimo de individuos (NMI) de las distintas especies del pasillo. / Number of remains (NR) and minimum number of individuals (NMI) of the NW gallery species.
El reducido tamaño de la muestra se traduce en una disminución de la variedad taxonómica. Sólo hay ocho especies: cuatro ungulados (cabra, sarrio, ciervo y reno) y otros tantos carnívoros (leopardo, lince, lobo y zorro). Faltan las especies con frecuencias más bajas (caballo, gran bóvido, corzo, hiena, lince, gato montés, cuon y los mustélidos, así como la marmota). Sin embargo, llama la atención la presencia del reno que también es una especie escasa.

\subsection{Primera sala interior}

Se denomina así a una amplia sala abovedada de forma casi circular y que presenta una superficie de unos $49 \mathrm{~m}^{2}$. Está comunicada hacia el vestíbulo con el pasillo anteriormente descrito y hacia dentro con otra sala más profunda (Fig. 9). Incluye ocho bandas numéricas (8 a 22) y seis literales ( $D^{\prime}$ a l').

La distribución horizontal de los restos presenta una asimetría en dicho reparto favorable al lado derecho de la cámara. En efecto la zona con la mayor concentración

\begin{tabular}{|l|l|l|l|l|l|l|l|l|}
\hline & 22 & 20 & 18 & 16 & 14 & 12 & 10 & 8 \\
\hline & & & $2^{\mathrm{a}}$ sala & & & & & \\
\hline$I^{\prime}$ & & & & & & & & \\
\hline$H^{\prime}$ & & & & & & & & \\
\hline G' $^{\prime}$ & & & & & & & & \\
\hline F' $^{\prime}$ & & & & & & & \\
\hline E' $^{\prime}$ & & & & & & & \\
\hline$D^{\prime}$ & & & & & & \multicolumn{3}{|c|}{ PASILLO } \\
\hline & & & & & & \\
\hline
\end{tabular}

Fig. 9. Densidad de restos de fauna en los cuadros de la primera sala. / Faunal remains density in the boxes of the first chamber. 
de evidencias corresponde a la entrada y lado derecho de la misma. Cuanto más al fondo y a la izquierda nos desplazamos, el número de restos se hace más escaso.

\begin{tabular}{|l|c|c|c|c|}
\hline & \multicolumn{2}{|c|}{ Magd. Inferior } & \multicolumn{2}{c|}{ Solutrense } \\
\hline & NR & NMI & NR & NMI \\
\hline C. pyrenaica & 90 & 4 & 29 & 2 \\
\hline R. pyrenaica & 15 & 2 & 3 & 1 \\
\hline C. elaphus & 39 & 3 & 6 & 1 \\
\hline R. tarandus & 1 & 1 & & \\
\hline P. pardus & 2 & 1 & & \\
\hline Lynx sp. & 6 & 1 & 2 & 1 \\
\hline C. lupus & 10 & 1 & 3 & 1 \\
\hline V. vulpes & 48 & 2 & 13 & 1 \\
\hline Identificados & 211 & 15 & 56 & 7 \\
\hline No identificados & 1425 & & 355 & \\
\hline Total NR & $\mathbf{1 6 3 6}$ & & $\mathbf{4 1 1}$ & \\
\hline
\end{tabular}

Tabl. 9. Distribución del número de restos (NR) y del número mínimo de individuos (NMI) de la primera sala interior. / Distribution of the number of remains (NR) and the minimum number of individuals (NMI) from the first chamber.

Esta sala ha proporcionado 2047 restos que representan un $8,2 \%$ de todo el yacimiento y sólo están pre- sentes ocho especies: cuatro ungulados (cabra, sarrio, ciervo y reno) y otros tantos carnívoros (leopardo, lince, lobo y zorro) (Tabl. 9).

A pesar de contener una muestra de fauna muy superior al pasillo, es el sector con menor variedad taxonómica. El conjunto con más restos de fauna es el del Magdaleniense Inferior (79,9\%).

\subsection{Segunda sala interior}

Es la zona excavada más profunda de la cueva con una extensión de 42 cuadros excavados formados por una banda de siete unidades literales (J' a P') y otras tantas numéricas (10 a 22). En posición algo centrada existe un gran bloque estalagmítico que reduce significativamente el número de restos de los cuadros que ocupa (14L', 16L', 14M', 16M'). Salvo esta anomalía la densidad de restos es máxima en el centro de la sala y disminuye progresivamente hacia la periferia (Fig. 10).

Este sector ha proporcionado 2905 restos de los cuales han sido identificados 648 que representan un $22,3 \%$ del total de la muestra. La fauna de esta segunda sala apenas supera $(11,3 \%)$ la décima parte de todo el yacimiento. Hay 14 especies de macromamíferos representadas (6 ungulados y 8 carnívoros) además de la marmota (Tabl. 10).

\begin{tabular}{|c|c|c|c|c|c|c|c|}
\hline \multirow{2}{*}{$P^{\prime}$} & 22 & 20 & 18 & 16 & 14 & 12 & 10 \\
\hline & & & & & & & \\
\hline \multicolumn{8}{|c|}{$\mathrm{O}^{\prime}$} \\
\hline \multicolumn{8}{|c|}{$N^{\prime}$} \\
\hline \multicolumn{8}{|c|}{$M^{\prime}$} \\
\hline \multicolumn{8}{|l|}{$\mathrm{L}^{\prime}$} \\
\hline \multicolumn{8}{|c|}{$K^{\prime}$} \\
\hline \multicolumn{8}{|c|}{$J^{\prime}$} \\
\hline & & & & & |a sale & & \\
\hline
\end{tabular}

Fig. 10. Densidad de restos de fauna en los cuadros de la segunda sala. / Faunal remains density in the boxes of the second chamber.

La cronología del material de esta última sala presenta problemas. Por una parte, hay cinco dataciones que corresponden al Epipaleolítico. Sin embargo, una datación mediante racemización de aminoácidos realizada directamente sobre un canino de oso de las cavernas proporciona una fecha de 50100 B.P. (LEB 8819), por tanto, mucho más antigua. Además de este último dato conviene resaltar que este sector ha proporcionado la muestra más numerosa de restos de oso de las cavernas y la presencia de especies como la hiena y la marmota incompatibles con una cronología epipaleolítica (Fig. 11).

Teniendo en cuenta la información precedente es razonable suponer que una parte de la fauna se remonte al Musteriense cuando esta sala pudo ser utilizada como lugar de hibernación. Y que posteriormente a lo largo de milenios fuera un cubil sucesivo o alternativo de otros carnívoros como la hiena, el lobo o el zorro. La presencia humana además de esporádica pudo circunscribirse al 


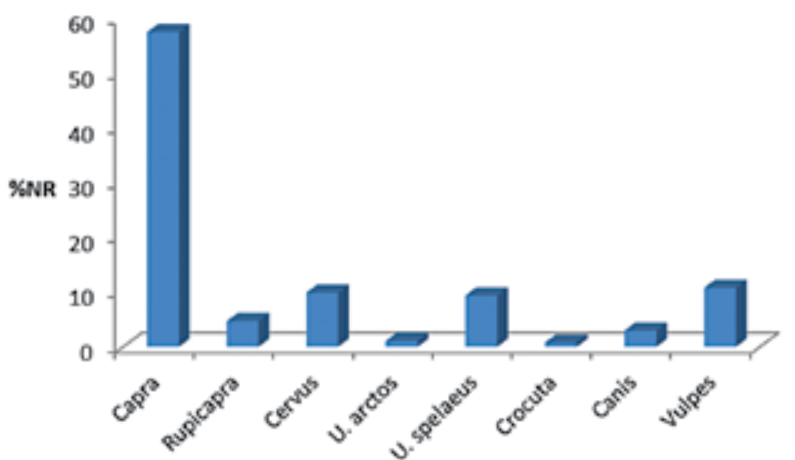

Fig. 11. Frecuencia relativa de las especies en la segunda sala interior. / Relative frequencies species in second chamber.

\begin{tabular}{|l|c|}
\hline & NR \\
\hline Bovini sp. & 4 \\
\hline C. pyrenaica & 366 \\
\hline R. pyrenaica & 30 \\
\hline C. elaphus & 63 \\
\hline R. tarandus & 1 \\
\hline U. arctos & 7 \\
\hline U. spelaeus & 60 \\
\hline Ursus sp. & 18 \\
\hline C. crocuta & 5 \\
\hline L. lynx & 2 \\
\hline F. silvestris & 1 \\
\hline C. Iupus & 19 \\
\hline V. vulpes & 69 \\
\hline M. nivalis & 2 \\
\hline M. marmota & 1 \\
\hline Identificados & 648 \\
\hline No identificados & 2257 \\
\hline Total NR & $\mathbf{2 9 0 5}$ \\
\hline
\end{tabular}

Tabl. 10. Distribución del número de restos (NR) y del número mínimo de individuos (NMI) de la segunda sala interior. / Distribution of the number of remains (NR) and the minimum number of individuals (NMI) from the second chamber.

Epipaleolítico (niveles II al VII) y al Solutrense (nivel IX). Por esta razón no se ofrece la estimación del número mínimo de individuos de cada especie.

\section{5.- GÉNESIS DE LA TAFOCENOSIS}

La primera cuestión a la que se debe responder ante una acumulación de fauna en un yacimiento es el carácter antrópico o no de la misma. Aspectos como el tipo de fragmentación, la distribución anatómica de los restos, la edad de los animales, la proporción de huesos de carnívoros y las marcas de mordeduras o de descarnado y troceado son la base empírica sobre la que se pueden emitir hipótesis sobre el o los agentes responsables de la génesis de la fauna recuperada.

\subsection{Fragmentación y marcas en huesos largos}

Determinados patrones de fragmentación de los huesos largos en los que predominan los fragmentos de diáfisis que no conservan el contorno completo del hueso ("cilindros"), marcas del impacto de percusiones, incisiones en los huesos producidas por los instrumentos líticos utilizados para la extracción de órganos y paquetes musculares, son habituales en huesos de animales cazados y consumidos por los humanos. En la fauna de Praileaitz I estos rasgos son casi inexistentes. Así, la mayor parte de los huesos largos de los ungulados se caracterizan por estar completos, tener una o las dos epífisis sin fusionar y presentar marcas de mordidas sobre todo en los extremos. Más del $80 \%$ de los huesos y dientes corresponden a individuos infantiles o juveniles de ciervo, cabra y sarrio. Hay una gran cantidad de huesos completos de aves y concentraciones de micromamíferos que parecen proceder de egagrópilas de rapaces. Todo ello nos inclina a suponer que la mayor parte de la tafocenosis poco o nada tiene que ver con una acumulación de huesos resultante del aprovechamiento de ungulados cazados y consumidos como consecuencia de una ocupación humana estable de la cueva. Más parece que procede de carnívoros y aves que utilizan habitualmente la cavidad como refugio.

\subsection{Proporción carnívoros/ungulados}

Otro elemento importante a tener en cuenta al respecto es la relación entre el número de restos de ungulados y el de carnívoros. En los asentamientos de ocupación de los cazadores del Paleolítico los restos de carnívoros son siempre muy reducidos ya que el objetivo prioritario de las capturas son los ungulados del entorno.

\begin{tabular}{|l|c|c|c|}
\hline & \% Ungulata & \% Carnivora & NR total \\
\hline Labeko Koba Sima $^{1}$ & 56,8 & 43,2 & 577 \\
\hline${\text { Unikoté } \boldsymbol{~}^{2}}^{\text {Praileaitz I-Exterior }}$ & 57,7 & 42,3 & 988 \\
\hline Praileaitz I-Vestíbulo $^{1}$ & 74,2 & 25,8 & 771 \\
\hline${\text { Labeko Koba IX } \text { inf. }^{1}}_{\text {Axlor D }^{3}}$ & 69 & 31 & 3480 \\
\hline Covalejos $^{3}$ & 95,1 & 4,9 & 1219 \\
\hline 1: Altuna \& Mariezkurrena (2000); 2: Michel (2005) ; 3: Castaños (inédito) & 0,12 & 793 \\
\hline
\end{tabular}

Tabl. 11. Proporción de ungulados y carnívoros en varios yacimientos. / Proportion of ungulates and carnivores in several sites. 
Fig. 12. Porcentajes de restos de ungulados y carnívoros en varios yacimientos. / Percentages of ungulate and carnivore remains at several sites. (LK.S: Labeko koba- Sima; UK: Unikoté; PA.E: Praileaitz I-Exterior; PAV: Praileaitz I-Vestíbulo; AX.D: Axlor.D; CO: Covalejos)
¿ Ungulados a Carnvioros

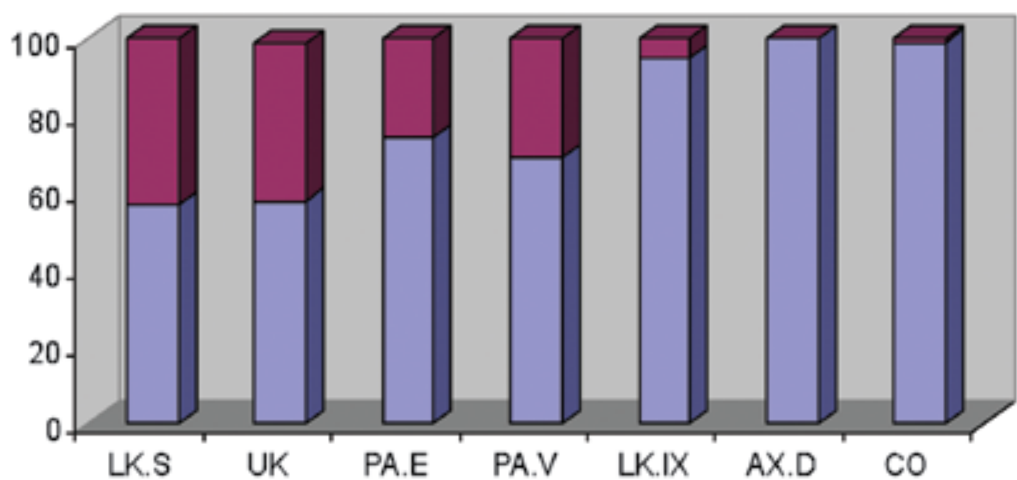

La proporción de ungulados y carnívoros en el entorno más próximo en el espacio y en el tiempo de Praileaitz I (Tabl. 11) nos da una nueva clave para el tema que nos ocupa. Hay dos muestras atribuidas a ocupaciones de grandes carnívoros (Sima de Labeko koba y Unikoté I) frente a otras tres de niveles musterienses cuyas tafocenosis son de origen fundamentalmente antrópico (Covalejos, Axlor y nivel IX de Labeko koba). En estas últimas la proporción de restos de carnívoros no supera en el mejor de los casos el 5\%. Los dos conjuntos de Praileaitz I (zona exterior y vestíbulo) presentan frecuencias relativas de carnívoros muy próximas a las de los cubiles de hiena y muy alejadas de los lugares de ocupación humana del Paleolítico Medio. Si utilizáramos muestras del Paleolítico Superior las diferencias serían aún más claras (Fig. 12).

\begin{tabular}{|c|c|c|c|c|c|c|c|c|}
\hline & \multicolumn{4}{|c|}{ Rupicapra rupicapra } & \multicolumn{4}{|c|}{ Canis lupus } \\
\hline & NR & NME & MAU & Regiones & NR & NME & MAU & Regiones \\
\hline Clavija ósea & 2 & 1 & 0,5 & \multirow{6}{*}{$\begin{array}{c}\text { Cabeza } \\
11,1\end{array}$} & & & & \multirow{6}{*}{$\begin{array}{c}\text { Cabeza } \\
1,66\end{array}$} \\
\hline Cráneo & 4 & 2 & 2 & & & & & \\
\hline Maxilar & 5 & 2 & 1 & & & & & \\
\hline Dient. ais. sup. & 26 & 26 & 1,85 & & 9 & 9 & 0,37 & \\
\hline Mandíbula & 13 & 7 & 3,5 & & 1 & 1 & 0,5 & \\
\hline Dient. ais. inf. & 45 & 45 & 2,25 & & 19 & 19 & 0,79 & \\
\hline Atlas & & & & \multirow{5}{*}{$\begin{array}{c}\text { Tronco } \\
2,22\end{array}$} & 2 & 2 & 2 & \multirow{5}{*}{$\begin{array}{c}\text { Tronco } \\
3,4\end{array}$} \\
\hline Axis & 1 & 1 & 1 & & 1 & 1 & 1 & \\
\hline Sacro & & & & & & & & \\
\hline Vértebra & 3 & 3 & 0,11 & & 11 & 11 & 0,4 & \\
\hline Costilla & 3 & 3 & 0,11 & & & & & \\
\hline Escápula & 9 & 5 & 2,5 & \multirow{4}{*}{$\begin{array}{c}\text { Miembro } \\
\text { anterior } \\
9,5\end{array}$} & 1 & 1 & 0,5 & \multirow{4}{*}{$\begin{array}{c}\text { Miembro } \\
\text { anterior } \\
2,5\end{array}$} \\
\hline Húmero & 8 & 7 & 3,5 & & 2 & 2 & 1 & \\
\hline Radio & 7 & 4 & 2 & & 1 & 1 & 0,5 & \\
\hline Ulna & 3 & 3 & 1,5 & & 1 & 1 & 0,5 & \\
\hline Pelvis & 6 & 3 & 1,5 & \multirow{4}{*}{$\begin{array}{c}\text { Miembro } \\
\text { posterior } \\
8,0\end{array}$} & & & & \multirow{4}{*}{$\begin{array}{l}\text { Miembro } \\
\text { posterior }\end{array}$} \\
\hline Fémur & 5 & 3 & 1,5 & & & & & \\
\hline Rótula & 3 & 3 & 1,5 & & & & & \\
\hline Tibia & 8 & 7 & 3,5 & & & & & \\
\hline Carpo & 5 & 5 & 0,41 & \multirow{10}{*}{$\begin{array}{l}\text { Patas } \\
18,27\end{array}$} & 15 & 15 & 1,07 & \multirow{10}{*}{$\begin{array}{c}\text { Patas } \\
4,62\end{array}$} \\
\hline Metacarpo & 6 & 5 & 2,5 & & 1 & 1 & 0,1 & \\
\hline Calcáneo & 4 & 4 & 2 & & 2 & 2 & 1 & \\
\hline Astrágalo & 4 & 3 & 1,5 & & 1 & 1 & 0,5 & \\
\hline Resto tarso & 5 & 5 & 2,5 & & 3 & 3 & 0,3 & \\
\hline Metatarso & 4 & 3 & 1,5 & & 1 & 1 & 0,1 & \\
\hline Metap. indet. & 12 & 7 & & & 1 & 1 & & \\
\hline Falange 1 & 25 & 25 & 3,12 & & 12 & 12 & 0,6 & \\
\hline Falange 2 & 21 & 21 & 2,62 & & 10 & 10 & 0,5 & \\
\hline Falange 3 & 17 & 17 & 2,12 & & 9 & 9 & 0,45 & \\
\hline Total & 256 & & & & 103 & & & \\
\hline
\end{tabular}

Tabl. 12. Distribución anatómica de los restos de sarrio y lobo en el abrigo exterior. / Skeletal remain distribution of Chamois and Wolf in external sector. 


\subsection{Representación anatómica en algunas es- pecies}

En las acumulaciones de fauna de origen antrópico es habitual un predominio de fragmentos procedentes de las extremidades frente a una baja proporción de elementos correspondientes al tronco (vértebras, costillas, esternón). La frecuencia de elementos de la cabeza depende de la proporción de piezas dentarias aisladas que se han desprendido de los huesos maxilares. A partir del número mínimo de unidades anatómicas (MAU) se puede estimar la frecuencia relativa de cinco regiones del cuerpo: cabeza, tronco, miembro anterior (escápula-húmero-radio-ulna), miembro posterior (pelvis-fémur-tibia) y patas (carpotarso-metapodios-falanges) en cabra, sarrio y lobo.

En primer lugar se analizan las posibles diferencias entre ungulados y carnívoros. Para ello se han elegido las especies más frecuentes: cabra y sarrio frente al lobo. En el abrigo exterior se han elegido el sarrio y el lobo (Tabl. 12).

A partir de estos datos se aprecian diferencias significativas (Fig. 13). Mientras en el sarrio se observa una baja representación del esqueleto del tronco, en el lobo, el costillar y el espinazo igualan al miembro anterior y pa-

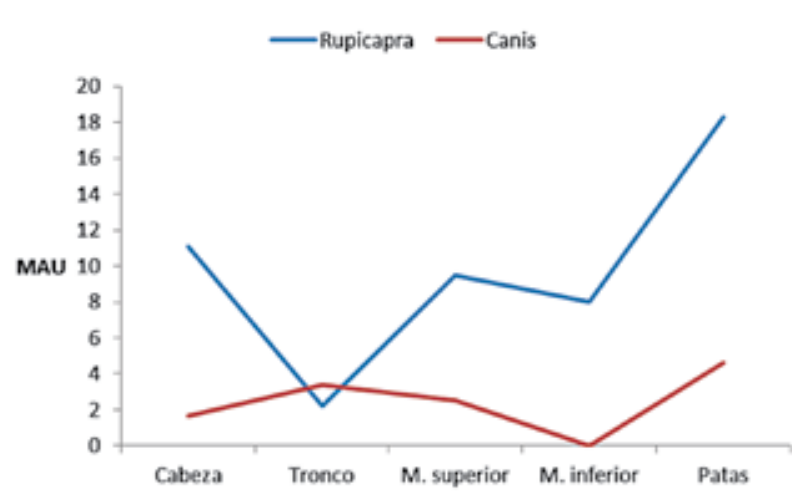

Fig. 13. Distribución anatómica de sarrio y lobo en el rellano exterior. / Skeletal distribution of Chamois and Wolf in external sector.

tas que son las regiones mejor representadas. Esto parece indicar que en el depredador se conserva el esqueleto más completo que en la presa en la que dominan sobre todo los elementos más distales de las patas.

Un fenómeno similar se observa entre el lobo y la cabra montesa en el nivel Solutrense del vestíbulo (Tabl. 13).

\begin{tabular}{|c|c|c|c|c|c|c|c|c|}
\hline & \multicolumn{4}{|c|}{ Capra pirenaica (Solutrense) } & \multicolumn{4}{|c|}{ Canis lupus } \\
\hline & NR & NME & MAU & Regiones & NR & NME & MAU & Regiones \\
\hline Clavija ósea & 1 & 1 & 0,5 & \multirow{7}{*}{$\begin{array}{c}\text { Cabeza } \\
28,87\end{array}$} & & & & \multirow{7}{*}{$\begin{array}{c}\text { Cabeza } \\
4,53\end{array}$} \\
\hline Cráneo & 6 & 6 & 6 & & 1 & 1 & 1 & \\
\hline Maxilar & 7 & 6 & 3 & & 1 & 1 & 0,5 & \\
\hline Dient. ais. sup. & 83 & 83 & 5,92 & & 23 & 23 & 0,95 & \\
\hline Mandíbula & 19 & 13 & 6,5 & & 2 & 2 & 1 & \\
\hline Dient. ais. inf. & 119 & 119 & 5,95 & & 26 & 26 & 1,08 & \\
\hline Hioides & 2 & 2 & 1 & & & & & \\
\hline Atlas & & & & \multirow{4}{*}{$\begin{array}{c}\text { Tronco } \\
2,59\end{array}$} & 2 & 2 & 2 & \multirow{4}{*}{$\begin{array}{c}\text { Tronco } \\
3,89\end{array}$} \\
\hline Axis & 1 & 1 & 1 & & 1 & 1 & 1 & \\
\hline Vértebra & 34 & 34 & 1,25 & & 23 & 23 & 0,85 & \\
\hline Costilla & 13 & 9 & 0,34 & & 2 & 1 & 0,04 & \\
\hline Escápula & 7 & 6 & 3 & \multirow{4}{*}{$\begin{array}{c}\text { Miembro } \\
\text { anterior } \\
18,0\end{array}$} & & & & \multirow{4}{*}{$\begin{array}{c}\text { Miembro } \\
\text { anterior } \\
3,17\end{array}$} \\
\hline Húmero & 16 & 13 & 6,5 & & 2 & 2 & 1 & \\
\hline Radio & 14 & 14 & 7 & & 4 & 4 & 2 & \\
\hline Ulna & 4 & 3 & 1,5 & & 1 & 1 & 0,5 & \\
\hline Pelvis & 8 & 5 & 2,5 & \multirow{4}{*}{$\begin{array}{c}\text { Miembro } \\
\text { posterior } \\
14,5\end{array}$} & & & & \multirow{4}{*}{$\begin{array}{c}\text { Miembro } \\
\text { posterior } \\
1,5\end{array}$} \\
\hline Fémur & 12 & 11 & 5,5 & & 2 & 2 & 1 & \\
\hline Rótula & 5 & 5 & 2,5 & & & & & \\
\hline Tibia & 11 & 8 & 4 & & 1 & 1 & 0,5 & \\
\hline Carpo & 31 & 31 & 2,58 & \multirow{11}{*}{$\begin{array}{l}\text { Patas } \\
37,83\end{array}$} & 10 & 10 & 0,83 & \multirow{11}{*}{$\begin{array}{c}\text { Patas } \\
6,53\end{array}$} \\
\hline Metacarpo & 14 & 13 & 6,5 & & 10 & 10 & 1 & \\
\hline Calcáneo & 8 & 8 & 4 & & 3 & 3 & 1,5 & \\
\hline Astrágalo & 7 & 7 & 3,5 & & 1 & 1 & 0,5 & \\
\hline Resto tarso & 7 & 7 & 3,5 & & 2 & 2 & 0,2 & \\
\hline Metatarso & 12 & 9 & 4,5 & & 4 & 4 & 0,4 & \\
\hline Metap. indet. & 20 & 11 & & & 6 & 6 & & \\
\hline Falange 1 & 50 & 50 & 6,25 & & 26 & 26 & 1,3 & \\
\hline Falange 2 & 38 & 38 & 4,75 & & 11 & 11 & 0,55 & \\
\hline Falange 3 & 18 & 18 & 2,25 & & 5 & 5 & 0,25 & \\
\hline Sesamoideo & 10 & 10 & & & 1 & 1 & & \\
\hline Total & 577 & 541 & & & 170 & 169 & & \\
\hline
\end{tabular}

Tabl. 13. Distribución anatómica de los restos de cabra y de lobo en Solutrense del vestíbulo. / Skeletal remain distribution of wild goat and Wolf in the Solutrean of vestibule. 
De nuevo se observa una diferencia clara entre la distribución anatómica del herbívoro (cabra) y la del depredador (lobo). En éste, salvo una disminución de frecuencia en el miembro inferior, el resto de regiones anatómicas están igualmente representadas. Sin embargo, la cabra presenta una baja frecuencia de elementos del tronco y elevadas proporciones tanto de la cabeza como de las patas. En el caso del esqueleto cefálico, la causa es el alto número de piezas aisladas (Fig. 14).

Lo observado entre el sarrio y el lobo en el abrigo exterior y entre éste mismo y la cabra en el nivel Solutrense, nos permite suponer que en el carnívoro se conserva la mayor parte del esqueleto en la cueva y por tanto que el animal murió en el mismo cubil que utilizaba de refugio. Sin embargo, el esqueleto de las dos presas no parece llegar completo a la cavidad, a la vista de la ausencia casi completa del espinazo y costillar. Sin embargo, aparecen con cierta profusión huesos de las extremidades que parecen indicar un acarreo de esta región corporal hasta la cueva.

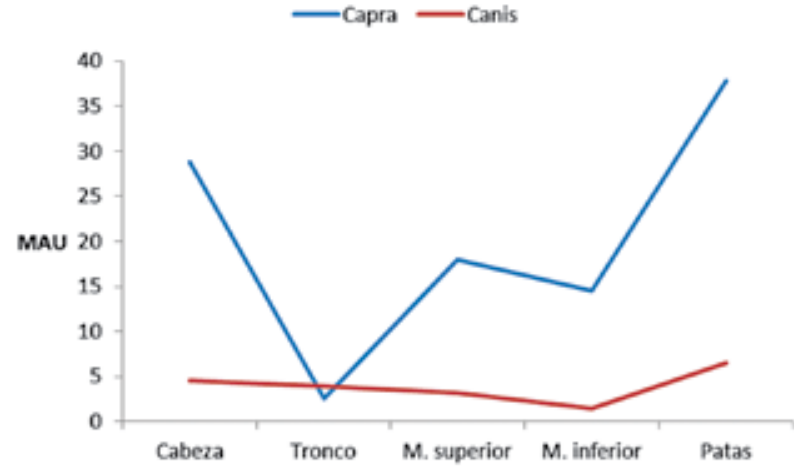

Fig. 14. Distribución anatómica de cabra y lobo en el Solutrense del vestíbulo. / Skeletal distribution of wild goat and Wolf in the Solutrean of vestibule.

Las diferencias observadas en la distribución anatómica entre el lobo y los dos ungulados más frecuentes, se producen cuando la comparación se realiza entre los

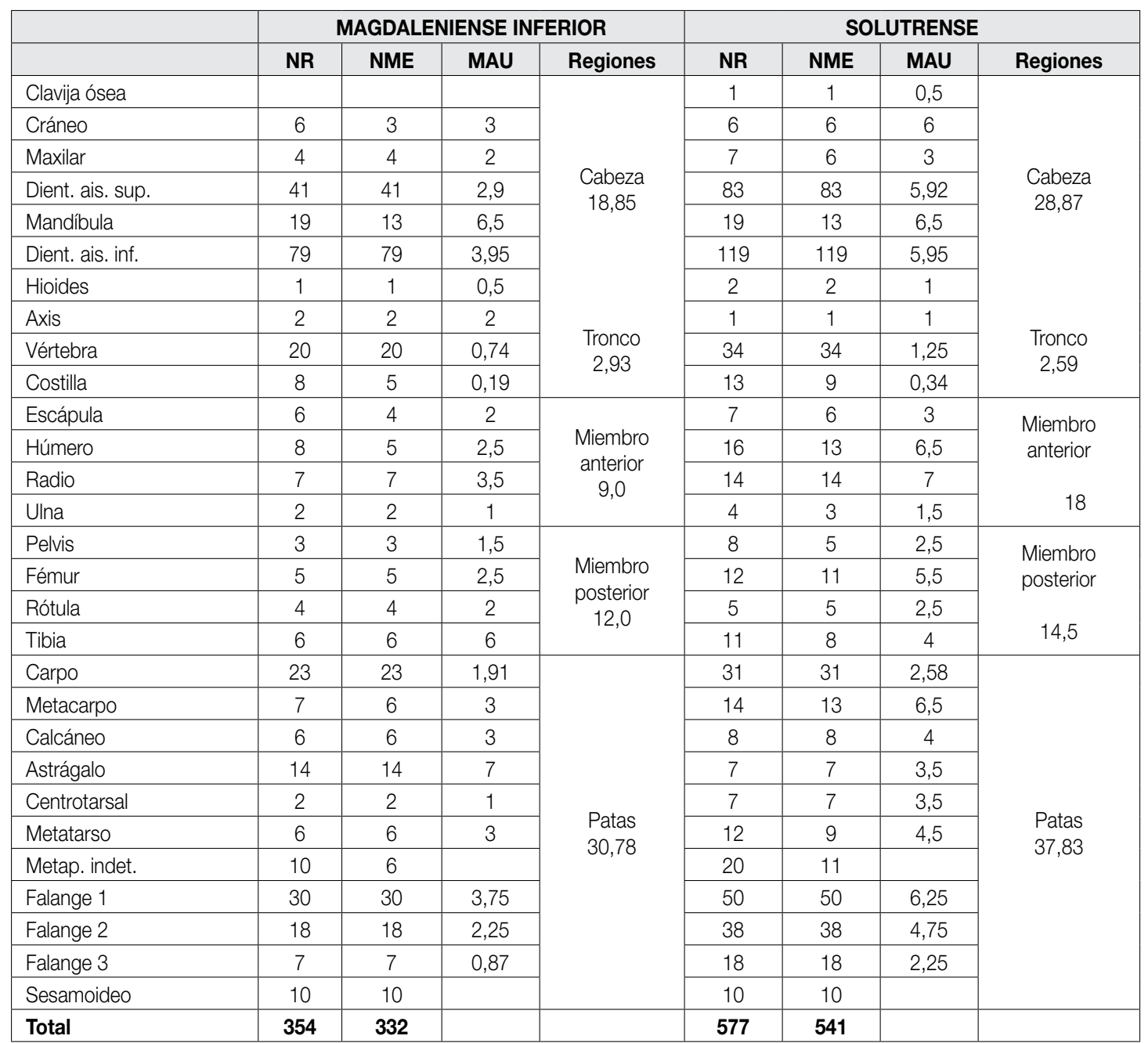

Tabl. 14. Distribución anatómica de los restos de cabra montesa del vestíbulo en Magdaleniense Inferior y Solutrense. / Skeletal remain distribution of wild goat in the lower Magdalenian and Solutrean. 


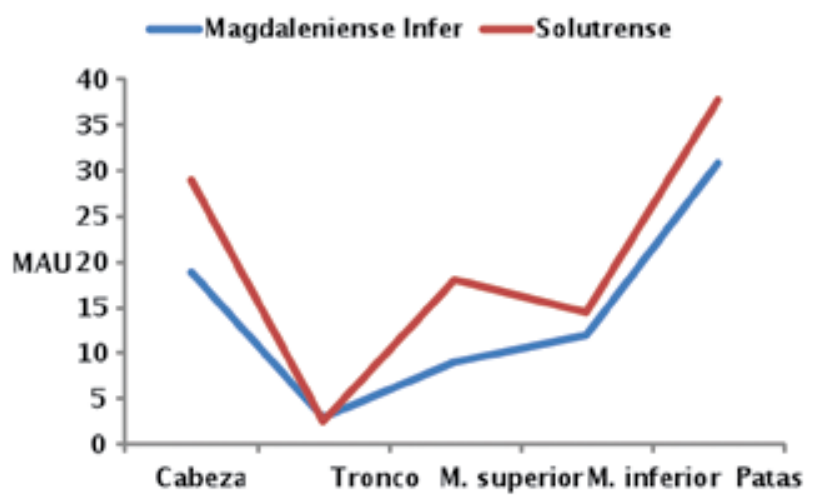

Fig. 15. Distribución anatómica de la cabra montesa en el Magdaleniense Inferior y Solutrense del vestíbulo. / Skeletal distribution of wild goat in upper Magdalenian and Solutrean of vestibule.

propios ungulados. Así ocurre si se compara las muestras de cabra correspondientes al Magdaleniense Inferior y Solutrense del vestíbulo (Tabl. 14). Salvo una pequeña desviación en el miembro superior, los dos modelos son muy similares (Fig. 15)

\begin{tabular}{|c|c|c|c|c|}
\hline & NR & NME & MAU & Regiones \\
\hline Clavija ósea & 1 & 1 & 0,5 & \multirow{6}{*}{$\begin{array}{c}\text { Cabeza } \\
12,25\end{array}$} \\
\hline Cráneo & 2 & 2 & 2 & \\
\hline Maxilar & 3 & 3 & 1,5 & \\
\hline Dient. ais. sup. & 39 & 39 & 2,8 & \\
\hline Mandíbula & 12 & 7 & 3,5 & \\
\hline Dient. ais. inf. & 39 & 39 & 1,95 & \\
\hline \multicolumn{4}{|l|}{ Sacro } & \multirow{3}{*}{$\begin{array}{c}\text { Tronco } \\
0,33\end{array}$} \\
\hline Vértebra & 6 & 6 & 0,22 & \\
\hline Costilla & 3 & 3 & 0,11 & \\
\hline Escápula & 4 & 3 & 1,5 & \multirow{3}{*}{$\begin{array}{c}\text { Miembro anterior } \\
6,0\end{array}$} \\
\hline Húmero & 11 & 7 & 3,5 & \\
\hline Radio & 3 & 2 & 1 & \\
\hline \multicolumn{4}{|l|}{ Pelvis } & \multirow{4}{*}{$\begin{array}{c}\text { Miembro posterior } \\
4,0\end{array}$} \\
\hline Fémur & 3 & 2 & 1 & \\
\hline Rótula & 6 & 6 & 3 & \\
\hline Tibia & 4 & 2 & & \\
\hline Carpo & 14 & 14 & 1,16 & \multirow{9}{*}{$\begin{array}{c}\text { Patas } \\
6,55\end{array}$} \\
\hline Metacarpo & 1 & 1 & 0,5 & \\
\hline Calcáneo & 1 & 1 & 0,5 & \\
\hline Astrágalo & 6 & 4 & 2 & \\
\hline Centrotarsal & 1 & 1 & 0,5 & \\
\hline Metap. indet. & 7 & 4 & & \\
\hline Falange 1 & 4 & 4 & 0,5 & \\
\hline Falange 2 & 11 & 11 & 1,37 & \\
\hline Falange 3 & 1 & 1 & 0,12 & \\
\hline Total & 182 & 163 & & \\
\hline
\end{tabular}

Tabl. 15. Distribución anatómica de los restos de cabra montesa del rellano exterior. / Skeletal remain distribution of wild goat in external sector.
Esta semejanza desde el punto de vista diacrónico se repite cuando comparamos muestras de sarrio y cabra (Tabl. 15) del abrigo exterior y de los dos niveles más antiguos del vestíbulo.

El modelo de distribución anatómica de los dos ungulados más frecuente en el yacimiento es muy similar independientemente del sector o de la cronología de las muestras (Fig. 16). Y a su vez difiere sustancialmente del que presenta el lobo tanto en el abrigo exterior como en el Solutrense del vestíbulo.

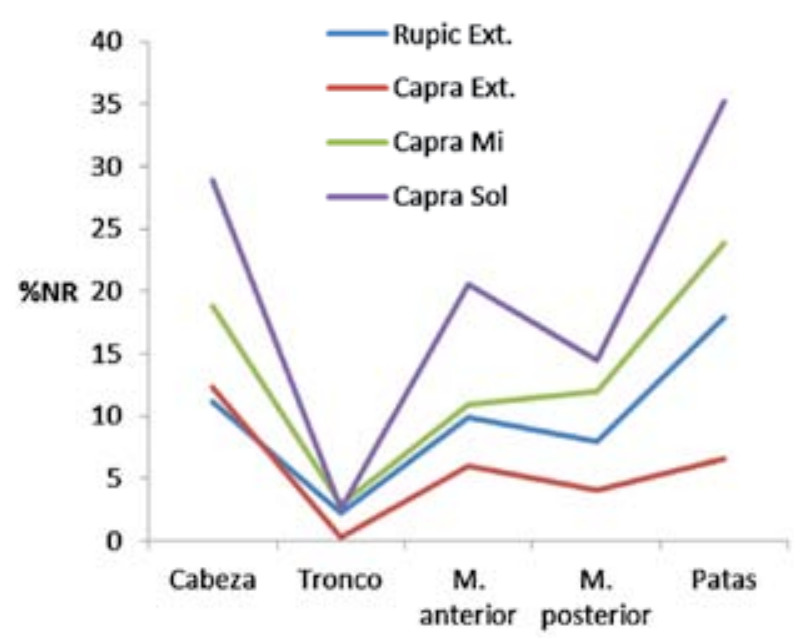

Fig. 16. Distribución anatómica de cabra y sarrio en distintos niveles y sectores. / Skeletal distribution of Chamois and wild goat in several levels an sectors.

\subsection{Fauna asociada al hogar en la entrada del vestíbulo}

La muestra de fauna procedente del Magdaleniense Inferior del hogar (cuadros 10E-10F) está constituida por 36 restos identificados y 9 sin identificar. Están representadas dos especies de ungulados (cabra montesa y ciervo) y tres carnívoros (oso pardo, lobo y zorro). La cabra, con 17 restos, es el herbívoro más frecuente seguida del oso, con una docena de restos. Estos huesos presentan el mismo patrón de fragmentación que el resto de fauna recuperada en el yacimiento. Por tanto no son de origen antrópico. Tampoco muestran evidencia alguna de calcinación. Esto permite suponer que el uso de este sector como hogar ha sido esporádico.

La fauna correspondiente a los cuadros $12 \mathrm{E}$ y $12 \mathrm{~F}$ próxima al hogar presenta algunos rasgos interesantes. En primer lugar está dividida estratigráficamente en dos conjuntos separados por la caída de un gran bloque. Por una parte queda una muestra de huesos aplastados (lecho 11) y sellados que corresponden al nivel del Magdaleniense Inferior. Presentan un mayor grado de fragmentación por razones obvias y varios huesos con claras mordeduras de carnívoros. Hay una en el extremo proximal de una falange primera de ciervo que ha 
destruido la epífisis correspondiente. Otras se observan en dos falanges primeras de cabra cuya epífisis proximal aún no estaba fusionada. $Y$ en un metacarpo de sarrio hay varias mordeduras en el extremo distal que no han conseguido aún separar la epífisis. Todas ellas indican una acumulación de huesos con poca o ninguna relación con actividades humanas.

Sin embargo, en el lecho 11 del cuadro $12 \mathrm{~F}$ se conserva el único resto con marcas claras de origen antrópico de toda la muestra. Se trata de dos marcas de percusión en el borde de fractura de un húmero de ciervo. El resto es un fragmento de diáfisis que no conserva el perímetro completo de la caña del hueso (cilindro) y que coincide con el modelo de fracturación típico de los procesos de extracción de la médula habituales en muestras de origen antrópico.

También se ha recuperado aquí uno de los escasos restos de caballo de todo el yacimiento. Se trata de un fragmento de cráneo (P.A.12E.285.32b) que conserva parte del arco zigomático posterior más el borde orbita- rio. Se ha documentado en el nivel IV correspondiente al Magdaleniense Inferior. Es probable que este espécimen sea parte de un cráneo completo traído a la cueva por un agente antrópico y no por un carnívoro.

A los detalles descritos se une una proporción de restos de carnívoros $(14,2 \%)$ inferior a la de los distintos sectores del yacimiento cuyo índice de carnivorismo oscila entre el 25,6\% del vestíbulo (en el que se halla enclavado este conjunto) y el 37,5\% de la galería noroeste.

En definitiva, el tipo predominante de fragmentación, la presencia de mordeduras de carnívoros sobre todo en los extremos de huesos largos, la elevada proporción de ungulados infantiles y juveniles, los altos índices de carnivorismo y la diferencia significativa de la representación anatómica entre ungulados y carnívoros, son rasgos tafonómicos de la muestra faunística recuperada en Praileaitz I. Todos ellos indican que la mayor parte de los restos de macrofauna del yacimiento no son consecuencia de actividades humanas sino de prácticas depredadoras de distintos carnívoros, que a lo largo de milenios

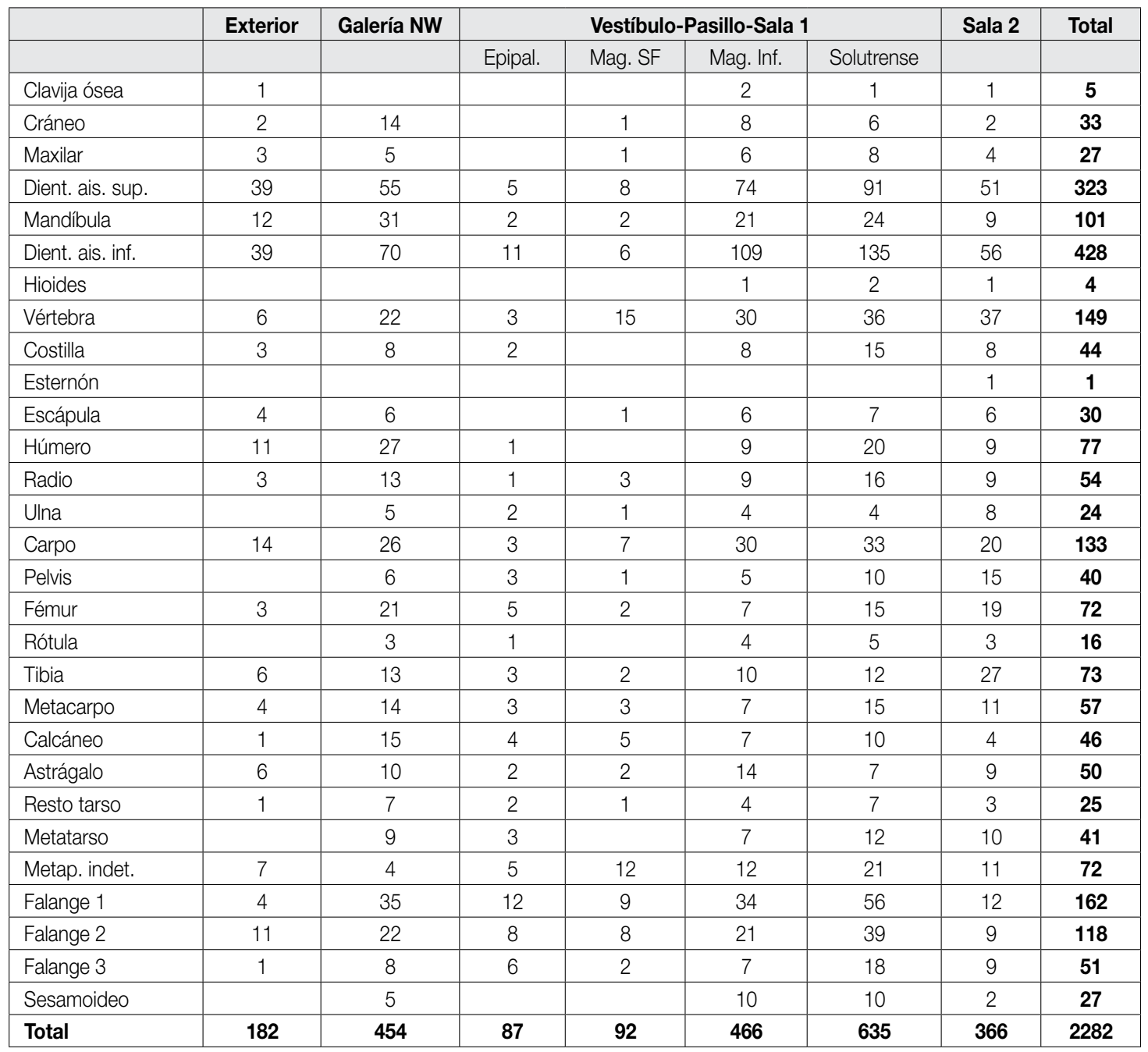

Tabl. 16. Distribución anatómica de los restos de cabra montesa. / Skeletal remain distribution of wild goat. 
han utilizado la cueva como cubil. La presencia humana en la cavidad ha sido muy esporádica y probablemente se ha circunscrito sobre todo a la zona próxima a la gran piedra en forma de asiento y al hogar correspondiente. Se trataría de un sector privilegiado de actividad humana aunque no se puede considerar un lugar de habitación al uso.

\section{6.- ESTUDIO DE LAS ESPECIES PRESENTES}

\subsection{Herbívoros}

\section{Cabra montesa Capra pyrenaica}

La cabra con 2282 restos es la especie mejor representada del yacimiento. Sus conjuntos más abundantes proceden de los niveles Solutrense y Magdaleniense Inferior, considerando conjuntamente los materiales del vestíbulo, pasillo y primera sala interior (Tabl. 16). Estos mismos sectores presentan las muestras más pequeñas de esta especie en los niveles Epipaleolítico y Magdaleniense Superior Final. Hay también un interesante conjunto de cabra en la galería noroeste y en la sala más profunda de la cavidad.

Desde el punto de vista de la representación anatómica están presentes todos los huesos del esqueleto salvo el maleolar. La proporción relativa de las distintas regiones del cuerpo y su significado tafonómico es una cuestión que ya se ha comentado más arriba.

A partir del estado de reemplazo de la dentadura de leche y del grado de desgaste del último molar inferior, se han podido estimar las edades de casi medio centenar de individuos de los distintos sectores (Tabl. 17). Se observa un claro predominio de animales inmaduros (infantiles, juveniles y subadultos) que representan en conjunto un $77,3 \%$ frente a una quinta parte de adultos jóvenes. Sólo hay un adulto maduro y no se observa ningún individuo senil. Esta estructura de la edad queda confirmada en el esqueleto postcraneal con una elevada proporción de huesos largos que tienen sin fusionar las dos epífisis o una de ellas.

\begin{tabular}{|c|c|c|c|c|c|c|}
\hline & Exterior & Galería NW & Vestíbulo & Sala 2 & Total & Cohortes \\
\hline $0-3$ meses & & 1 & & & 1 & \multirow{3}{*}{$\begin{array}{c}\text { Infantiles } \\
18,2 \%\end{array}$} \\
\hline 4 meses & & & 1 & 2 & 3 & \\
\hline 4-7 meses & & 2 & 2 & & 4 & \\
\hline 7-10 meses & 2 & 3 & 5 & 2 & 12 & \multirow{2}{*}{$\begin{array}{c}\text { Juveniles } \\
29,5 \%\end{array}$} \\
\hline 10-18 meses & & 1 & & & 1 & \\
\hline 18-23 meses & 2 & 1 & 4 & 2 & 9 & \multirow{3}{*}{$\begin{array}{c}\text { Subadultos } \\
29,5 \%\end{array}$} \\
\hline 23-28 meses & & 1 & 1 & & 2 & \\
\hline 31-35 meses & 1 & & & 1 & 2 & \\
\hline $\mathrm{M} 3+$ & 1 & 2 & 3 & 3 & 9 & \multirow{2}{*}{$\begin{array}{c}\text { Adultos } \\
22,7\end{array}$} \\
\hline M3++ & 1 & & & & 1 & \\
\hline Total & 7 & 11 & 16 & 10 & 44 & \\
\hline
\end{tabular}

Tabl. 17. Estructura de edad de la cabra montesa. / Age structure of the wild goat.

Debido a la distribución anatómica de la cabra anteriormente descrita, las medidas obtenidas para esta especie son fundamentalmente de la dentición, del tarso y de las falanges (Anexo I). Se ofrecen aparte los resúmenes estadísticos de las medidas más frecuentes, prescindiendo de las falanges (Tabl. 18).
Fig. 17. Diagrama de dispersión del astrágalo con la separación de sexos de la cabra. / Scatterplot of talus with sexual segregation of wild goat.

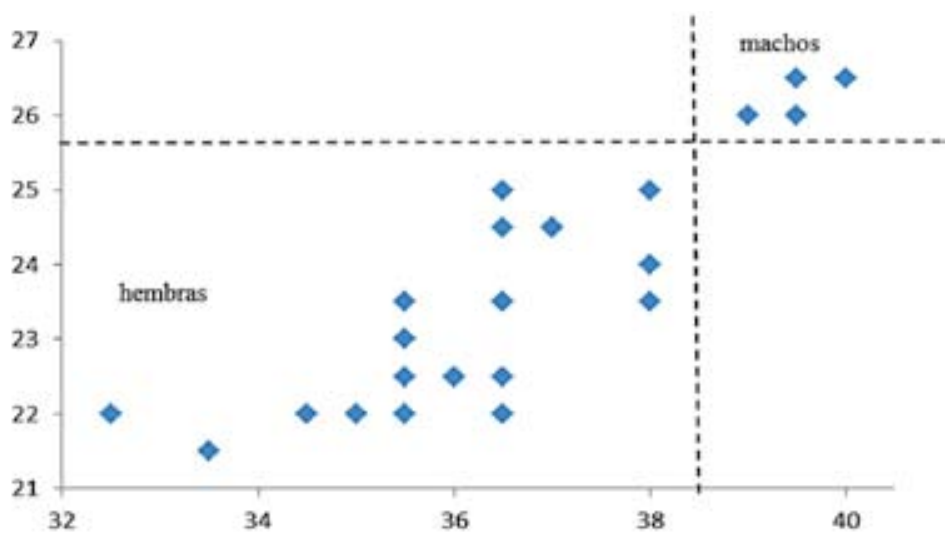




\begin{tabular}{|c|c|c|c|c|}
\hline & $\mathbf{n}$ & Variación & Media & $\mathbf{s}$ \\
\hline \multicolumn{5}{|c|}{ Mandíbula } \\
\hline LP2-M3 & 3 & $78-91,5$ & 85,8 & \\
\hline LP2-P4 & 3 & $24,4-27$ & 26,1 & \\
\hline LM1-M3 & 3 & $52,5-62$ & 58,3 & \\
\hline LM3 & 16 & $21,5-31,5$ & 26,5 & \\
\hline \multicolumn{5}{|c|}{ Escápula } \\
\hline LMP & 2 & $38,5-39,5$ & 39 & \\
\hline LS & 2 & $35,5-34,5$ & 35 & \\
\hline AS & 2 & $26,5-27$ & 26,75 & \\
\hline $\mathrm{LmC}$ & 2 & $26-26.5$ & 26,25 & \\
\hline \multicolumn{5}{|l|}{ Húmero } \\
\hline AT & 4 & 36,5 & 43 & \\
\hline \multicolumn{5}{|l|}{ Radio } \\
\hline Ap & 4 & $36,5-42$ & 39,75 & \\
\hline ASp & 4 & $34,5-41$ & 38,25 & 2,3 \\
\hline $\mathrm{Ad}$ & 2 & $33,5-35,5$ & 34,5 & \\
\hline \multicolumn{5}{|c|}{ Metacarpo } \\
\hline LM & 4 & $129-157,5$ & 137,25 & \\
\hline $\mathrm{Ap}$ & 9 & $29-36,5$ & 31,55 & 2,39 \\
\hline$A D$ & 4 & $17,8-21,5$ & 19,0 & \\
\hline $\mathrm{Ad}$ & 4 & $32-38$ & 33,75 & \\
\hline Ed & 4 & $19,4-21,5$ & 19,97 & \\
\hline \multicolumn{5}{|l|}{ Fémur } \\
\hline EC & 5 & $20,5-26,5$ & & \\
\hline \multicolumn{5}{|l|}{ Tibia } \\
\hline $\mathrm{Ad}$ & 4 & $28-31$ & 30,0 & \\
\hline \multicolumn{5}{|c|}{ Astrágalo } \\
\hline LMl & 25 & $32,5-40$ & 36,74 & 1,82 \\
\hline $\mathrm{LMm}$ & 25 & $31,5-37,5$ & 34,27 & 1,7 \\
\hline El & 25 & $18-31,5$ & 20,52 & 2,48 \\
\hline $\mathrm{Ad}$ & 24 & $21,5-26,5$ & 23,66 & 1,53 \\
\hline \multicolumn{5}{|c|}{ Calcáneo } \\
\hline LM & 3 & $68-75$ & 71,16 & \\
\hline AM & 3 & $21-22,5$ & 22 & \\
\hline \multicolumn{5}{|c|}{ Centrotarsal } \\
\hline $\mathrm{AM}$ & 14 & $28,5-35$ & 30,64 & 2,13 \\
\hline \multicolumn{5}{|c|}{ Metatarso } \\
\hline LM & 5 & $135-179$ & 164,83 & \\
\hline Ap & 8 & $24-32$ & 26,25 & 2,48 \\
\hline$A D$ & 4 & $15,2-21$ & 17,22 & \\
\hline $\mathrm{Ad}$ & 6 & $30-36$ & 33,08 & 2,33 \\
\hline$E d$ & 6 & $17,6-23$ & 20,2 & 1,86 \\
\hline
\end{tabular}

Tabl. 18. Resúmenes estadísticos de las medidas más frecuentes de cabra. / Univariate statistics of them measures more frequently of the wild goat.

En general los valores medios de esta muestra coinciden con los de otros yacimientos paleolíticos tanto de la Región cantábrica como del SO de Francia y del norte de Huesca.

En la cabra el dimorfismo sexual es bastante marcado y ello permite sexar la mayor parte de los huesos a partir de sus medidas. Así se ha hecho siguiendo los cri- terios de autores que han estudiado muestras de cabra montesa próximas en el espacio y en el tiempo a las de Praileaitz I (DELPECH, 1975; ALTUNA, 1978) y se recoge en las medidas aisladas (Anexo I). A partir del astrágalo que es el hueso con mayor número de medidas, se observa en esta muestra un claro predominio de hembras y probablemente juveniles frente a los machos (Fig. 17). 


\section{Sarrio o Rebeco Rupicapra pyrenaica}

El sarrio o rebeco ha proporcionado 710 restos distribuidos de forma desigual entre los distintos sectores de la cueva (Tabl. 19). La muestra más numerosa corresponde al abrigo exterior donde es la especie mejor representada. También hay dos conjuntos importantes en el nivel Solutrense del vestíbulo y en la galería noroeste. En el resto de los sectores o niveles las muestras son muy reducidas.

\begin{tabular}{|c|c|c|c|c|c|c|c|c|}
\hline & \multirow[t]{2}{*}{ Exterior } & \multirow[t]{2}{*}{ Galería NW } & \multicolumn{4}{|c|}{ Vestíbulo-Pasillo-Sala 1} & \multirow[t]{2}{*}{ Sala 2} & \multirow[t]{2}{*}{ Tota } \\
\hline & & & Epipal. & Mag. SF & Mag. Inf. & Solutrense & & \\
\hline Clavija ósea & 2 & 2 & & & 2 & 4 & & 10 \\
\hline Maxilar & 5 & & 1 & & & 1 & & 7 \\
\hline Dient. ais. sup. & 28 & 8 & & & 4 & 6 & 5 & 51 \\
\hline Dient. ais. inf. & 45 & 22 & 5 & & 27 & 47 & 7 & 153 \\
\hline Vértebra & 4 & 4 & 4 & & & 10 & 1 & 23 \\
\hline Costilla & 3 & 1 & 1 & & 4 & 3 & 1 & 13 \\
\hline Escápula & 9 & 3 & & & & 1 & & 13 \\
\hline Carpo & 5 & 6 & 3 & & & 3 & & 17 \\
\hline Pelvis & 6 & 1 & & & 1 & 7 & & 15 \\
\hline Fémur & 5 & 3 & & & 4 & 4 & & 16 \\
\hline Rótula & 3 & & & & & & & 3 \\
\hline Tibia & 8 & 6 & & & 3 & 7 & 3 & 27 \\
\hline Metacarpo & 6 & 5 & 1 & 1 & 2 & 2 & & 17 \\
\hline Calcáneo & 4 & & & & 1 & 6 & 2 & 13 \\
\hline Astrágalo & 4 & 3 & & & 5 & 5 & & 17 \\
\hline Resto tarso & 5 & 1 & & & 4 & 8 & 1 & 19 \\
\hline Total & 256 & 103 & 20 & 4 & 94 & 203 & 30 & 710 \\
\hline
\end{tabular}

Tabl. 19. Distribución anatómica de los restos de sarrio. / Skeletal remain distribution of the Chamois.

Desde el punto de vista anatómico están presentes casi todos los huesos del esqueleto salvo el hioides, esternón y maleolar. Hay una baja representación de huesos del tronco y de los huesos más largos de las extremidades.

La estimación de la edad se ha realizado a partir del estado de erupción de los dientes permanentes y del grado de desgaste del tercer molar inferior (Tabl. 20). Se sigue el patrón de ejemplares cantábricos actuales (PÉREZ-BARBERÍA, 1994). El resultado difiere de lo observado en la cabra ya que en esta especie los individuos adultos suponen más de la mitad $(57,1 \%)$ del total. Entre ellos hay tres de edad avanzada.

Las medidas aisladas (Anexo II) son algo más escasas que en la cabra. Sus resúmenes estadísticos (Tabl. 21) indican que entran en el dominio de variación del sarrio del Pleistoceno Final de la Región Cantábrica. El dimorfismo sexual en esta especie no es tan marcado desde el punto de vista osteométrico como en la cabra.

\section{Grandes Bóvidos Bos primigenius/Bison priscus}

Lo grandes bóvidos (uro y bisonte estepario) con 23 restos están escasamente representados en Praileaitz I. Teniendo en cuenta su tamaño y que el principal agente acumulador es el lobo, era lógico este resultado.

La mayor parte de los restos son fragmentos de huesos de pequeño tamaño como las falanges (Tabl. 22). Su presencia se reduce al abrigo exterior y a tres niveles del vestíbulo. Debido al tamaño y anatomía de los restos conservados, no ha sido posible atribuir los restos a ninguno de los géneros. 


\begin{tabular}{|c|c|c|c|c|c|c|}
\hline & Exterior & Galería NW & $\begin{array}{l}\text { Vestíbulo } \\
\text { Solutrense }\end{array}$ & Sala 2 & Total & \\
\hline 4-9 meses & 1 & & 1 & 1 & 3 & $\begin{array}{c}\text { Infantiles } \\
14,3 \%\end{array}$ \\
\hline 9-13 meses & 1 & & & & 1 & \multirow{2}{*}{$\begin{array}{c}\text { Juveniles } \\
14,3 \%\end{array}$} \\
\hline 13-21 meses & 1 & 1 & & & 2 & \\
\hline 21-25 meses & & 2 & 1 & & 3 & $\begin{array}{c}\text { Subadultos } \\
14,3 \%\end{array}$ \\
\hline M3+ & 2 & 1 & 1 & 1 & 5 & \multirow{3}{*}{$\begin{array}{c}\text { Adultos } \\
57,1 \%\end{array}$} \\
\hline $\mathrm{M} 3++$ & 2 & & & 1 & 3 & \\
\hline $\mathrm{M} 3++$ & 2 & & 2 & & 4 & \\
\hline Total & 9 & 4 & 5 & 3 & 21 & \\
\hline
\end{tabular}

Tabl. 20. Estructura de edad del sarrio o rebeco. / Age structure of the Chamois.

\begin{tabular}{|c|c|c|c|c|}
\hline & $\mathrm{n}$ & Variación & Media & s \\
\hline \multicolumn{5}{|c|}{ Clavija ósea } \\
\hline & 2 & $13,3-15,6$ & 14,45 & \\
\hline & 2 & $20-22,5$ & 21,25 & \\
\hline \multicolumn{5}{|c|}{ Mandíbula } \\
\hline LP2-P4 & 2 & $22-23,5$ & 22,75 & \\
\hline LM3 & 7 & $15,8-20,0$ & 17,34 & 1,38 \\
\hline \multicolumn{5}{|c|}{ Húmero } \\
\hline AT & 4 & $29,5-34,0$ & 31,12 & \\
\hline \multicolumn{5}{|l|}{ Radio } \\
\hline Ap & 2 & $28,5-29,5$ & 29 & \\
\hline ASp & 2 & & 28 & \\
\hline $\mathrm{Ad}$ & 3 & $25,5-29,0$ & 27 & \\
\hline \multicolumn{5}{|c|}{ Metacarpo } \\
\hline LM & 3 & $131-156,5$ & 145,16 & \\
\hline$A p$ & 5 & $23,5-30,0$ & 25,5 & 2,3 \\
\hline$A D$ & 3 & $15,5-17,9$ & 16,63 & \\
\hline $\mathrm{Ad}$ & 3 & $27-32,5$ & 29,5 & \\
\hline $\mathrm{Ed}$ & 3 & $16,8-19,5$ & 17,93 & \\
\hline \multicolumn{5}{|l|}{ Fémur } \\
\hline EC & 2 & & 21,5 & \\
\hline \multicolumn{5}{|l|}{ Tibia } \\
\hline $\mathrm{Ad}$ & 4 & $27-33,5$ & 29,25 & \\
\hline \multicolumn{5}{|c|}{ Astrágalo } \\
\hline LMl & 14 & $28-32,5$ & 31,1 & 1,1 \\
\hline LMm & 14 & $26,5-31,0$ & 29,71 & 1,1 \\
\hline El & 14 & $15-18,6$ & 17,36 & 0,79 \\
\hline $\mathrm{Ad}$ & 14 & $18-21,0$ & 20 & 0,81 \\
\hline \multicolumn{5}{|c|}{ Calcáneo } \\
\hline LM & 3 & $62,5-69,0$ & 65,66 & \\
\hline AM & 3 & $20-21,5$ & 21 & \\
\hline \multicolumn{5}{|c|}{ Centrotarsal } \\
\hline AM & 10 & $25,5-31,0$ & 27,6 & 1,75 \\
\hline \multicolumn{5}{|c|}{ Metatarso } \\
\hline Ap & 3 & $21,5-22,5$ & 22 & \\
\hline
\end{tabular}

Tabl. 21. Resúmenes estadísticos de las medidas más frecuentes de sarrio. Univariate statistics of them measures more frequently of the Chamois. 


\begin{tabular}{|l|c|c|c|c|c|}
\hline & Exterior & \multicolumn{3}{|c|}{ Vestíbulo } & Total \\
\hline & & Epipal. & Mag. Inf. & Solutrense & \\
\hline Dient. ais. sup. & 1 & & & & $\mathbf{1}$ \\
\hline Mandibula & 1 & & & & $\mathbf{1}$ \\
\hline Dient. ais. inf. & 1 & & & & $\mathbf{1}$ \\
\hline Vértebra & 2 & & & 1 & $\mathbf{3}$ \\
\hline Carpo & 3 & & & & $\mathbf{3}$ \\
\hline Húmero & 1 & & 1 & & $\mathbf{2}$ \\
\hline Fémur & & & & 1 & $\mathbf{1}$ \\
\hline Tibia & & & 1 & & $\mathbf{1}$ \\
\hline Resto tarso & & 1 & & & $\mathbf{1}$ \\
\hline Falange 1 & 4 & & & & $\mathbf{4}$ \\
\hline Falange 2 & 3 & & & & $\mathbf{3}$ \\
\hline Sesamoideo & 2 & & & $\mathbf{2}$ & $\mathbf{2 3}$ \\
\hline Total & $\mathbf{1 8}$ & $\mathbf{1}$ & $\mathbf{2}$ & & \\
\hline
\end{tabular}

Tabl. 22. Distribución anatómica de los restos de gran bóvido. / Skeletal remain distribution of the large bovine.

Las medidas son muy escasas y todas corresponden a las dos primeras falanges (Tabl. 23).

\begin{tabular}{|c|c|c|c|c|c|c|c|}
\hline \multicolumn{4}{|c|}{ Falange 1 } & \multicolumn{5}{c|}{ Falange 2 } \\
\hline & $\mathrm{LMpe}$ & 82,5 & 76,5 & $\mathrm{LM}$ & 44 & 54 & 48 \\
\hline & $\mathrm{Ap}$ & 41,5 & 45 & $\mathrm{Ap}$ & 34,5 & & \\
\hline & $\mathrm{AD}$ & 35 & & $\mathrm{AD}$ & 28 & & \\
\hline & $\mathrm{Ad}$ & 40,5 & & $\mathrm{Ad}$ & 29,5 & & \\
\hline & & $\mathrm{p}$ & & & $\mathrm{p}$ & & \\
\hline
\end{tabular}

Tabl. 23. Medidas aisladas de gran bóvido. / Measures isolated large bovid.

\section{Ciervo \\ Cervus elaphus}

El ciervo con 667 restos es el tercer herbívoro mejor representado del yacimiento. Sus muestras más ricas corresponden a los dos niveles más antiguos del vestíbulo (Magdaleniense Inferior y Solutrense) y a la galería noroeste (Tabl. 24). Excepto el esternón están presentes todos los huesos del esqueleto entre los que predominan los huesos cortos.

A partir del estado de sustitución en la dentición y del grado de desgaste, se ha estimado la edad de 20 individuos (Tabl. 25). Las tres cuartas partes de los individuos son inmaduros y el resto está compuesto por individuos de edad avanzada.

Estos datos indican que el patrón de elección de las presas por parte del depredador se centra fundamentalmente en animales jóvenes y en una pequeña proporción en individuos viejos que son los más fáciles de capturar. La ausencia de ciervos adultos está apuntando hacia un carnívoro de mediano tamaño como puede ser el lobo, cuon, lince y con menor probablilidad el zorro.

Las medidas de ciervo son más escasas (Anexo III) y sus valores medios (Tabl. 26) entran dentro del dominio de variación del ciervo del Paleolítico Superior Cantábrico.

\section{Reno \\ Rangifer tarandus}

El reno está presente con una docena de restos, más de la mitad de los cuales son falanges (Tabl. 27). Desde el punto de vista cronológico al menos seis de ellos proceden del Solutrense y del Magdaleniense Inferior. Este dato es coherente con la presencia de esta especie en yacimientos coetáneos próximos del entorno como Urtiagako Lezea (ALTUNA, 1999) y sobre todo Kiputz IX, que por el momento contiene la muestra más rica de esta especie en la Península lbérica (CASTAÑOS et al., 2006). 


\begin{tabular}{|c|c|c|c|c|c|c|c|c|}
\hline & \multirow[t]{2}{*}{ Exterior } & \multirow[t]{2}{*}{ Galería NW } & \multicolumn{4}{|c|}{ Vestíbulo-Pasillo-Sala 1} & \multirow[t]{2}{*}{ Sala 2} & \multirow[t]{2}{*}{ Total } \\
\hline & & & Epipal. & Mag. SF & Mag. Inf. & Solutrense & & \\
\hline Asta & & & 1 & & & & & 1 \\
\hline Cráneo & 1 & & & & 1 & 1 & 1 & 4 \\
\hline Maxilar & 1 & & 2 & & 6 & 4 & 1 & 14 \\
\hline Dient. ais. sup. & 16 & 14 & 1 & & 36 & 23 & 16 & 106 \\
\hline Mandíbula & 5 & 3 & 3 & & 1 & 3 & 5 & 20 \\
\hline Dient. ais. inf. & 9 & 8 & 3 & 2 & 19 & 9 & 9 & 59 \\
\hline Hioides & 1 & & & & & & 1 & 2 \\
\hline Vértebra & & 1 & 2 & 1 & 6 & 4 & & 14 \\
\hline Costilla & & & & 1 & 1 & & & 2 \\
\hline Escápula & 2 & 1 & 2 & & & 2 & 2 & 9 \\
\hline Húmero & 1 & 7 & 2 & 1 & 3 & 3 & 1 & 18 \\
\hline Radio & 1 & 7 & 2 & & 5 & 6 & 1 & 22 \\
\hline Ulna & 1 & 1 & 1 & 1 & 3 & & 1 & 8 \\
\hline Carpo & 7 & 13 & & 1 & 5 & 11 & 7 & 44 \\
\hline Pelvis & & & 3 & & 4 & 2 & & 9 \\
\hline Fémur & 3 & 4 & 2 & & 3 & 2 & 3 & 17 \\
\hline Rótula & & & & & 1 & 1 & & 2 \\
\hline Tibia & 3 & 4 & 1 & 2 & 4 & 3 & 3 & 20 \\
\hline Maleolar & & & & & 1 & 1 & & 2 \\
\hline Metacarpo & 3 & 5 & & 1 & 4 & 4 & 3 & 20 \\
\hline Calcáneo & & 4 & & & 2 & 2 & & 8 \\
\hline Astrágalo & 1 & 4 & & 1 & 4 & 5 & 1 & 16 \\
\hline Resto tarso & 1 & 5 & & 2 & 1 & 1 & 1 & 11 \\
\hline Metatarso & 1 & 2 & & & 2 & 5 & 1 & 11 \\
\hline Metap. indet. & 9 & 12 & 4 & & 6 & 11 & 9 & 51 \\
\hline Falange 1 & 3 & 17 & 1 & & 15 & 21 & 3 & 60 \\
\hline Falange 2 & 6 & 21 & 3 & 4 & 16 & 12 & 6 & 68 \\
\hline Falange 3 & 1 & 7 & 2 & & 15 & 11 & 1 & 37 \\
\hline Sesamoideo & & 2 & & & 5 & 4 & & 11 \\
\hline Total & 76 & 142 & 35 & 17 & 169 & 152 & 76 & 667 \\
\hline
\end{tabular}

Tabl. 24. Distribución anatómica de los restos de ciervo. / Skeletal remain distribution of the red deer.

\begin{tabular}{|c|c|c|c|c|c|c|c|}
\hline & Exterior & Galería NW & Vestíb & Sala 1 & Sala 2 & Total & Cohortes \\
\hline & & & M. inf. & Solutr. & & & \multirow{4}{*}{$\begin{array}{c}\text { Infantiles } \\
45 \%\end{array}$} \\
\hline Neonato & 1 & 1 & & & & 2 & \\
\hline 3 meses & 1 & 1 & & & & 2 & \\
\hline 3-6 meses & 1 & 1 & 1 & 1 & 1 & 5 & \\
\hline 6 meses & & & & 1 & & 1 & \multirow{2}{*}{$\begin{array}{c}\text { Juveniles } \\
15 \%\end{array}$} \\
\hline 6-12 meses & & & 2 & & & 2 & \\
\hline $\mathrm{M} 3+/-$ & & & & 1 & & 1 & \multirow{2}{*}{$\begin{array}{c}\text { Subadultos } \\
15 \%\end{array}$} \\
\hline $\mathrm{M} 3+$ & & & & 1 & 1 & 2 & \\
\hline $\mathrm{M} 3++$ & 2 & & 1 & 2 & & 5 & $\begin{array}{c}\text { Seniles } \\
25 \%\end{array}$ \\
\hline Total & 5 & 3 & 4 & 6 & 2 & 20 & \\
\hline
\end{tabular}

Tabl. 25. Estructura de edad del ciervo. / Age structure of the red deer. 


\begin{tabular}{|l|c|c|c|c|}
\hline & $\mathbf{n}$ & Variación & Media & s \\
\hline Mandíbula & & & & \\
\hline LM3 & 2 & $26,5-32,0$ & 29,25 & \\
\hline AM3 & 2 & $9,9-14,4$ & 12,15 & \\
\hline Ad & & & & \\
\hline Metacarpo & & & & \\
\hline Ad & 4 & $42-47,0$ & 44,5 & \\
\hline Ed & 4 & $27,5-31,0$ & 29,5 & \\
\hline Astrágalo & & & & \\
\hline LMl & 4 & $56-64,0$ & 59,25 & \\
\hline LMm & 4 & $53,5-59,0$ & 55,62 & \\
\hline El & 4 & $30,5-34,5$ & 32,25 & \\
\hline Ad & 4 & $36,5-40,5$ & 38,12 & \\
\hline Centrotarsal & & & & \\
\hline AM & 6 & $40-50,5$ & 45,91 & 4,06 \\
\hline
\end{tabular}

Tabl. 26. Resúmenes estadisticos de las medidas más frecuentes de ciervo. / Univariate statistics of them measures more frequently of the red deer.

\begin{tabular}{|l|c|c|c|c|c|c|c|}
\hline & Exterior & Galería NW & \multicolumn{3}{|c|}{ Vestíbulo-Pasillo-Sala 1 } & Sala 2 & Total \\
\hline & & & Mag. SF & Mag. Inf. & Solutrense & & \\
\hline Dient. ais. sup. & 1 & & & & & & $\mathbf{1}$ \\
\hline Mandíbula & & & & 1 & & & $\mathbf{1}$ \\
\hline Carpo & & & & & 1 & & $\mathbf{1}$ \\
\hline Metatarso & & 1 & & & & & $\mathbf{1}$ \\
\hline Metap. indet. & & & & & 1 & & $\mathbf{1}$ \\
\hline Falange 1 & 1 & & & 1 & & 1 & $\mathbf{3}$ \\
\hline Falange 2 & & 1 & 1 & 1 & & & $\mathbf{3}$ \\
\hline Falange 3 & & & & 1 & & & $\mathbf{1}$ \\
\hline Total & $\mathbf{2}$ & $\mathbf{2}$ & $\mathbf{1}$ & $\mathbf{4}$ & $\mathbf{2}$ & $\mathbf{1}$ & $\mathbf{1 2}$ \\
\hline
\end{tabular}

Tabl. 27. Distribución de los restos de reno. / Distribution of the remains of reindeer.

Corzo

\section{Capreolus capreolus}

Este pequeño cérvido sólo ha proporcionado un resto en el Magdaleniense Superior Final del vestíbulo. Se trata de un metacarpo completo que tiene las dos epífisis con mordeduras de un carnívoro.

\section{Caballo}

\section{Equus caballus}

El caballo es el ungulado con menor número de evidencias después del corzo. Sus cuatro restos se reparten por tres niveles del vestíbulo (Tabl. 28).

\begin{tabular}{|l|c|c|c|c|}
\hline & Epip. & Magd. Inf. & Solutr. & Total \\
\hline Cráneo & & 1 & & $\mathbf{1}$ \\
\hline Dient. ais. sup. & 1 & & & $\mathbf{1}$ \\
\hline Tibia & & & 1 & $\mathbf{1}$ \\
\hline Centrotarsal & & & 1 & $\mathbf{1}$ \\
\hline Total & $\mathbf{1}$ & $\mathbf{1}$ & $\mathbf{2}$ & $\mathbf{4}$ \\
\hline
\end{tabular}

Tabl. 28. Distribución de los restos de caballo. / Distribution of the remains of the horse.

\subsection{Carnívoros}

\section{Lobo y Cuon Canis lupus/Cuon alpinus}

Los cánidos son los depredadores con muestras más abundantes en el yacimiento. Además del zorro, están presentes otros dos géneros de mayor tamaño (lobo y cuon). La discriminación del material postcraneal no siempre es posible entre ellos por lo que se ofrecen los restos conjuntamente (Tabl. 29).

En el Anexo IV se ofrecen las medidas aisladas de lobo y en el Anexo $V$ las de cuon. Téngase en cuenta que dentro de las medidas poscraneales atribuidas al lobo bien puede estar incluida alguna de cuon, especialmente en las falanges. Además, y por la importancia cuantitativa de la muestra de lobo, se incluye el resumen estadístico de las medidas más frecuentes como contribución a la bioestratigrafía de esta especie (Tabl. 30).

El cuon o perro jaro (dhole) es una especie poco frecuente en el Pleistoceno Superior tanto de la Región Cantábrica como del resto de la Península Ibérica. A veces esto se debe a su dificultad de identificación. Sin 


\begin{tabular}{|c|c|c|c|c|c|c|c|c|}
\hline & \multirow[t]{2}{*}{ Exterior } & \multirow[t]{2}{*}{ Galería NW } & \multicolumn{4}{|c|}{ Vestíbulo-Pasillo-Sala 1} & \multirow[t]{2}{*}{ Sala 2} & \multirow[t]{2}{*}{ Total } \\
\hline & & & Epipal. & Mag. SF & Mag. Inf. & Solutrense & & \\
\hline Cráneo & & 1 & & & & 1 & & 2 \\
\hline Maxilar & & 2 & & & & 1 & & 3 \\
\hline Dient. ais. sup. & 8 & 21 & 1 & & 14 & 25 & 6 & 75 \\
\hline Mandíbula & 1 & 2 & & & 1 & 2 & 2 & 8 \\
\hline Dient. ais. inf. & 19 & 16 & & & 11 & 28 & 2 & 76 \\
\hline Vértebra & 14 & 30 & & 1 & 11 & 26 & 1 & 83 \\
\hline Costilla & & 3 & & & 1 & 2 & 1 & 7 \\
\hline Escápula & 1 & 1 & & & 1 & & & 3 \\
\hline Húmero & 2 & 4 & & & 1 & 2 & 2 & 11 \\
\hline Radio & 1 & 7 & & & & 5 & & 13 \\
\hline Ulna & 1 & 4 & & & & 1 & & 6 \\
\hline Carpo & 15 & 11 & & & 10 & 10 & & 46 \\
\hline Pelvis & & 2 & & & & & 1 & 3 \\
\hline Fémur & & 3 & & & 2 & 2 & & 7 \\
\hline Rótula & & & & & 1 & & & 1 \\
\hline Tibia & & 1 & & & 1 & 1 & & 3 \\
\hline Peroné & & 2 & & & & & & 2 \\
\hline Metacarpo & 1 & 14 & 1 & 2 & 4 & 10 & 1 & 33 \\
\hline Calcáneo & 3 & 2 & 1 & 1 & 1 & 3 & & 11 \\
\hline Astrágalo & 1 & 4 & & & 1 & 1 & & 7 \\
\hline Resto tarso & 3 & 2 & & & 1 & 2 & & 8 \\
\hline Metatarso & 1 & 14 & & & 2 & 4 & & 21 \\
\hline Metap. indet. & 1 & 4 & & & 3 & 6 & 1 & 15 \\
\hline Falange 1 & 12 & 20 & 1 & & 13 & 27 & 1 & 74 \\
\hline Falange 2 & 10 & 9 & & & 8 & 12 & & 39 \\
\hline Falange 3 & 9 & 9 & 3 & & 3 & 5 & 1 & 30 \\
\hline Sesamoideo & & 2 & & & & 1 & & 3 \\
\hline Totales & 103 & 190 & 7 & 4 & 90 & 177 & 19 & 590 \\
\hline
\end{tabular}

Tabl. 29. Distribución anatómica de los restos de lobo y cuon. / Skeletal remain distribution of the Wolf and cuon.

embargo, existen algunos criterios morfométricos recientemente revisados y ampliados con materiales de yacimientos ibéricos (PÉREZ RIPOLL et al., 2010). La muestra de cuon de Praileaitz I es después de la de Boquete de Zafarraya (BARROSO et al., 2006) la más abundante de la Península Ibérica. Consecuentemente su aportación a la tipificación osteométrica de la especie tiene cierta relevancia. Por esta razón procederemos a la descripción y discusión de algunos elementos anatómicos.
Fig. 18. Diagrama de dispersión de la anchura frente a la longitud del canino superior en lobo y en cuon. / Scatterplot of upper canine breadth vs the upper canine length measurements of wolf and cuon.

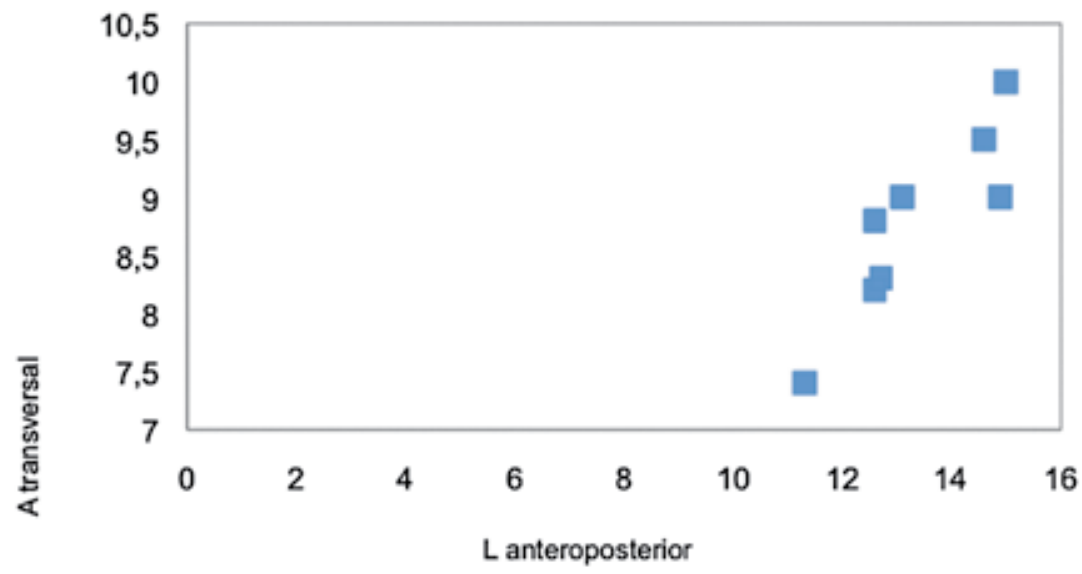




\begin{tabular}{|c|c|c|c|c|}
\hline & $\mathrm{n}$ & Variación & Media & s \\
\hline \multicolumn{5}{|c|}{ Maxilar: } \\
\hline LC & 7 & $12,6-15,0$ & 13,64 & 1,04 \\
\hline $\mathrm{AC}$ & 7 & $8,2-10,0$ & 8,97 & 0,58 \\
\hline LP3 & 6 & $15,5-17,9$ & 16,28 & 1,1 \\
\hline AP3 & 6 & $6,2-8,5$ & 7,15 & 0,83 \\
\hline LP4 & 5 & $20-26,0$ & 23,3 & 2,62 \\
\hline AP4 & 5 & $9,6-15,6$ & 13,46 & 2,19 \\
\hline LM1 & 2 & $15,9-17,2$ & 16,55 & \\
\hline AM1 & 2 & $18,4-21,2$ & 19,8 & \\
\hline LM2 & 3 & $8,5-9,1$ & 8,7 & \\
\hline AM2 & 3 & $12,2-13,6$ & 12,83 & \\
\hline \multicolumn{5}{|c|}{ Mandíbula } \\
\hline LC & 2 & $15,3-15,5$ & 15,4 & \\
\hline$A C$ & 2 & $10,2-10,5$ & 10,35 & \\
\hline LP2 & 3 & $10,5-13,8$ & 12 & \\
\hline AP2 & 3 & $5,4-6,7$ & 6,1 & \\
\hline LP3 & 4 & $12,3-14,6$ & 13,17 & \\
\hline AP3 & 4 & $5,6-7,4$ & 6,47 & \\
\hline LP4 & 6 & $15,2-17,6$ & 16,95 & 0,83 \\
\hline AP4 & 6 & $6,4-9,5$ & 8,85 & 1,1 \\
\hline LM1 & 9 & $27,6-30,5$ & 29,23 & 0,96 \\
\hline AM1 & 9 & $11,3-12,6$ & 12,18 & 0,39 \\
\hline LM2 & 3 & $12 / 12 / 07$ & 12,3 & \\
\hline AM2 & 3 & $7,4-9,7$ & 8,83 & \\
\hline \multicolumn{5}{|c|}{ Húmero } \\
\hline $\mathrm{Ad}$ & 2 & $36,7-45$ & 40,85 & \\
\hline \multicolumn{5}{|c|}{ Radio } \\
\hline LM & 2 & $220,5-221$ & 220,75 & \\
\hline$A p$ & 3 & $25-26,5$ & 25,66 & \\
\hline$A D$ & 2 & $17,1-17,6$ & 17,35 & \\
\hline $\mathrm{Ad}$ & 3 & $32-33,5$ & 32,66 & \\
\hline \multicolumn{5}{|c|}{ Mc 1} \\
\hline LM & 5 & $25-30,5$ & 28,5 & 1,92 \\
\hline \multicolumn{5}{|c|}{ Mc 2} \\
\hline LM & 6 & $76-91$ & 82 & 5,5 \\
\hline$A p$ & 6 & $9-14,6$ & 11,95 & 1,95 \\
\hline$A D$ & 6 & $8,8-10,0$ & 9,11 & 0,4 \\
\hline $\mathrm{Ad}$ & 6 & $11,8-12,4$ & 12,1 & 0,2 \\
\hline \multicolumn{5}{|c|}{ MC3 } \\
\hline LM & 5 & $79,5-93$ & 88,4 & 5,32 \\
\hline$A p$ & 5 & $9,9-11,9$ & 11,24 & 0,71 \\
\hline$A D$ & 5 & $7,4-9,3$ & 8,66 & 0,68 \\
\hline $\mathrm{Ad}$ & 5 & $10,8-12,3$ & 11,56 & 0,6 \\
\hline \multicolumn{5}{|l|}{ Mc4 } \\
\hline LM & 3 & $87-92$ & 90,66 & \\
\hline$A p$ & 3 & $10,5-11,0$ & 10,7 & \\
\hline$A D$ & 3 & $8,6-9,2$ & 8,93 & \\
\hline $\mathrm{Ad}$ & 3 & $11,6-12,6$ & 12,03 & \\
\hline \multicolumn{5}{|l|}{ Mc5 } \\
\hline LM & 3 & $73-76$ & 75,5 & \\
\hline$A p$ & 3 & $14,3-14,7$ & 14,53 & \\
\hline$A D$ & 3 & $9,0-10$ & 9,63 & \\
\hline $\mathrm{Ad}$ & 3 & $12,0-17$ & 14 & \\
\hline \multicolumn{5}{|c|}{ Astrágalo } \\
\hline LMl & 5 & $32,5-37$ & 34,5 & 1,61 \\
\hline \multicolumn{5}{|c|}{ Calcáneo } \\
\hline LM & 5 & $53,0-62$ & 57 & 3,24 \\
\hline \multicolumn{5}{|c|}{ Mt 3} \\
\hline LM & 2 & $98,0-99,5$ & 98,75 & \\
\hline \multicolumn{5}{|c|}{ Mt 4} \\
\hline LM & 4 & $87,0-102$ & 97 & \\
\hline \multicolumn{5}{|c|}{ Mt 5} \\
\hline LM & 2 & $90,0-91$ & 90,5 & \\
\hline
\end{tabular}

Tabl. 30. Resúmenes estadísticos de las medidas más frecuentes de lobo. / Univariate statistics of them measures more frequently of the Wolf. 


\section{Dentición superior}

Se conservan 8 caninos superiores completos. Uno de ellos, procedente del abrigo exterior, presenta una proporción entre la corona y la raíz más baja que en el lobo. Su longitud anteroposterior y su anchura transversal en la base de la corona quedan por debajo del dominio de variación de las de lobo. En el diagrama de dispersión entre ambas medidas esta pieza queda separada de las 7 restantes atribuidas al lobo (Fig. 18).

Algo semejante ocurre con dos terceros premolares y un primer molar del Magdaleniense Inferior del vestíbulo, así como con un cuarto premolar de la galería noroeste. Todos ellos quedan desde el punto de vista métrico por debajo de los valores mínimos del lobo.

\section{Dentición inferior}

Hay 5 mandíbulas de las cuales tres son de lobo y una conserva toda la serie yugal excepto el primer premolar. Las dos restantes son de cuon y pertenecen a un mismo individuo. De los tres caninos aislados, uno por sus dimensiones corresponde al perro jaro. Esta especie no ha proporcionado ningún ejemplar aislado de segundo premolar.

Se han recuperado 8 premolares terceros que además de la alta cúspide central (protocónido) presentan sendas cúspides menores por delante y por detrás de la principal. Cinco de los P3 aislados presentan dimensiones típicas del cuon .

Los últimos premolares además de la cúspide principal (protocónido) presentan en los ejemplares más pequeños una cúspide mesial y dos distales. Esta característica morfológica es típica del cuon. El diagrama de dispersión entre la longitud y anchura de esta pieza separa claramente las que corresponden a cada género (Fig. 19).

La carnicera inferior constituye la pieza dentaria con la morfología más interesante de cara a la diferenciación taxonómica. En todos los ejemplares más pequeños de la muestra, en el talónido del primer molar sólo hay una cúspide en posición central (hipocónido) mientras que en los especímenes más grandes se observan dos (hipocónido y entocónido). Esta es una característica morfológica típica del cuon. También el diagrama de dispersión de las dos dimensiones de esta pieza permite atribuir cada muela a los correspondientes géneros (Fig. 20).
Fig. 19. Diagrama de dispersión de la anchura frente a la longitud del P/4 en lobo y en cuon. / Scatterplot of P/4 breadth vs the P/4 length measurements of wolf and cuon.
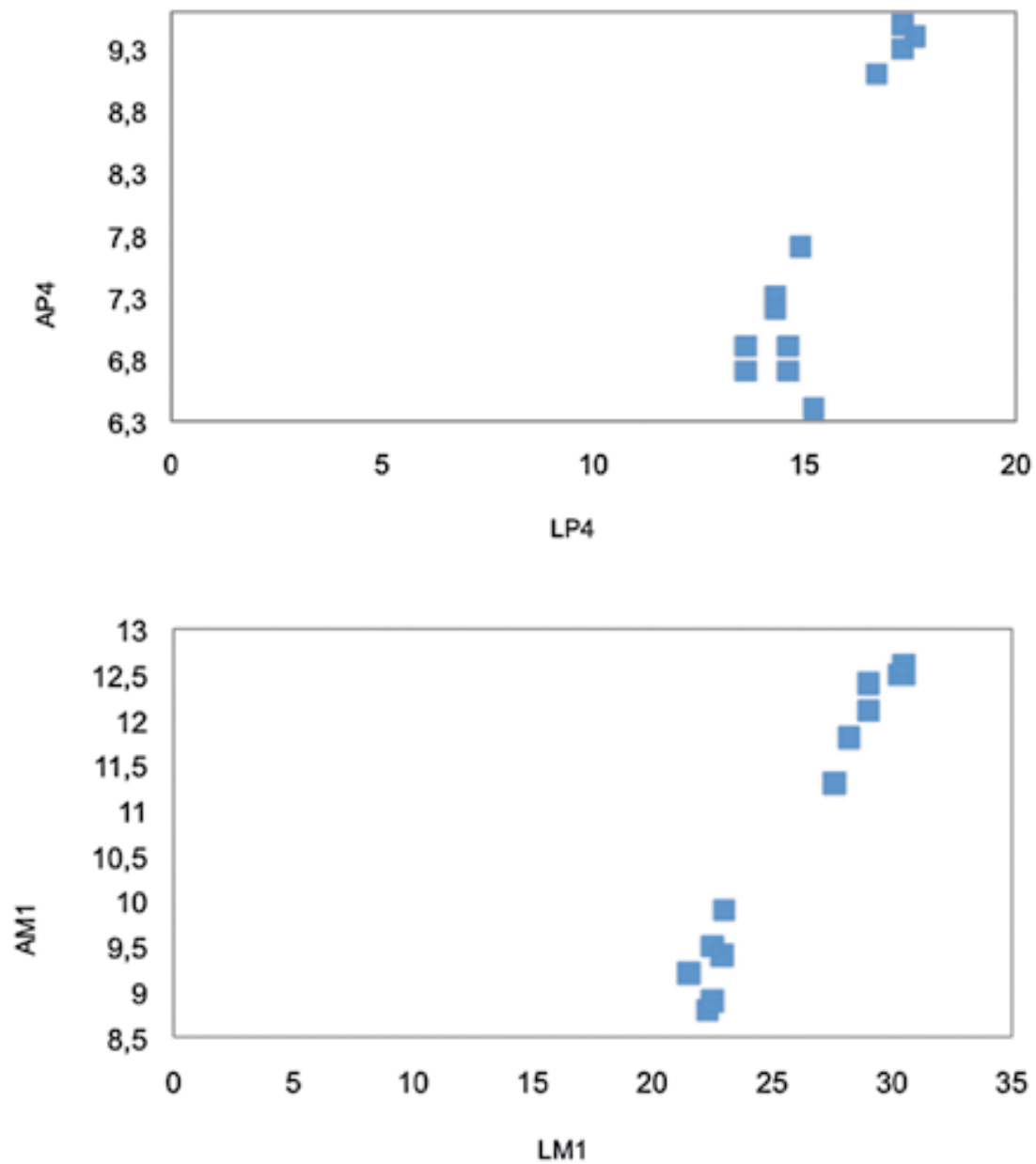

Fig. 20. Diagrama de dispersión de la anchura frente a la longitud del $\mathrm{M} / 1$ en lobo y en cuon. / Scatterplot of $M / 1$ breadth vs the $M / 1$ length measurements of wolf and cuon. 


\section{Esqueleto postcraneal}

Hay algunos elementos del esqueleto postcraneal que por sus dimensiones son atribuibles al cuon. Es el caso de un axis en la columna vertebral. En las extremidades anteriores corresponden a esta especie un resto de escápula, húmero, ulna y de los metacarpianos primero, segundo, cuarto y quinto respectivamente. De las patas posteriores hay un fémur, dos astrágalos, dos calcáneos y sendos metatarsianos tercero y cuarto. Pero una parte del los elementos postcraneales nos son susceptibles de atribución a nivel específico.

\section{Zorro \\ Vulpes vulpes}

El zorro es el carnívoro con mayor número de restos y uno de los posibles agentes acumuladores de huesos del yacimiento junto con el lobo y el cuon. Está presente en todos los sectores y niveles y sus muestras más numerosas proceden de la galería noroeste y de los niveles más antiguos del vestíbulo (Tabl. 31).

Desde el punto de vista anatómico predominan los elementos craneales (sobre todo por el elevado número de piezas dentarias sueltas) y los huesos más distales de las extremidades.

\begin{tabular}{|c|c|c|c|c|c|c|c|c|}
\hline & \multirow[t]{2}{*}{ Exterior } & \multirow[t]{2}{*}{ Galería NW } & \multicolumn{4}{|c|}{ Vestíbulo-Pasillo-Sala 1} & \multirow[t]{2}{*}{ Sala 2} & \multirow[t]{2}{*}{ Tota } \\
\hline & & & Epipal. & Mag. SF & Mag. Inf. & Solutrense & & \\
\hline Cráneo & & 3 & 6 & & 3 & 3 & & 7 \\
\hline Maxilar & & 8 & 1 & 2 & 1 & 8 & & 11 \\
\hline Dient. ais. sup. & 8 & 33 & 4 & 3 & 27 & 26 & 6 & 89 \\
\hline Mandíbula & 2 & 17 & 3 & 2 & 12 & 16 & 2 & 33 \\
\hline Dient. ais. inf. & 12 & 25 & 4 & 4 & 38 & 31 & 2 & 107 \\
\hline Vértebra & 3 & 26 & 2 & 4 & 16 & 26 & 1 & 88 \\
\hline Costilla & & 2 & & & & & 1 & 4 \\
\hline Escápula & 1 & 2 & & & 1 & 1 & & 4 \\
\hline Húmero & 1 & 4 & 2 & 2 & 4 & & 2 & 12 \\
\hline Radio & 1 & 8 & 4 & 2 & 5 & 3 & & 16 \\
\hline Ulna & & 7 & 2 & 1 & 1 & 2 & & 8 \\
\hline Carpo & & 1 & & & & 1 & & 27 \\
\hline Pelvis & & 1 & & & 1 & & 1 & 4 \\
\hline Fémur & 1 & 3 & 1 & 1 & 6 & 4 & & 13 \\
\hline Tibia & 1 & 10 & 3 & 1 & 6 & 4 & & 11 \\
\hline Peroné & & & & & & & & 2 \\
\hline Metacarpo & 3 & 7 & & & 2 & 5 & 1 & 26 \\
\hline Calcáneo & 1 & 6 & & & 6 & 3 & & 18 \\
\hline Astrágalo & & 2 & 1 & & & 1 & & 4 \\
\hline Resto tarso & & & & & & & & 5 \\
\hline Metatarso & 1 & 13 & 1 & & 1 & 8 & & 24 \\
\hline Metap. indet. & 3 & 5 & & & 2 & 7 & 1 & 15 \\
\hline Falange 1 & 3 & 14 & 4 & & 5 & 9 & 1 & 48 \\
\hline Falange 2 & 1 & & & & & & & 19 \\
\hline Falange 3 & & 1 & & & & & 1 & 20 \\
\hline Sesamoideo & & & & & 1 & & & 3 \\
\hline Total & 42 & 198 & 38 & 22 & 138 & 158 & 19 & 601 \\
\hline
\end{tabular}

Tabl. 31. Distribución anatómica de los restos de zorro. / Skeletal remain distribution of the fox.

Sus medidas aisladas (Anexo VI) constituyen por el momento la muestra osteométrica más rica de esta especie en el Paleolítico Cantábrico. Por esta razón se ofrecen los resúmenes estadísticos de las más frecuentes (Tabl. 32) con el fin de establecer las bases mínimas para la caracterización biométrica del zorro del Pleistoceno Superior del norte peninsular.

\section{Oso de las cavernas y Oso pardo Ursus spelaeus/Ursus arctos}

Al igual que en el cuon y en el lobo, la distribución anatómica de los restos de osos se ofrece conjuntamente ya que muchos huesos del esqueleto postcraneal no son susceptibles de atribución específica (Tabl. 33). 


\begin{tabular}{|c|c|c|c|c|}
\hline & $n$ & Variación & Media & s \\
\hline \multicolumn{5}{|c|}{ Maxilar: } \\
\hline LP4 & 24 & $9,4-15,8$ & 14,09 & 1,58 \\
\hline AP4 & 24 & $3,5-7,9$ & 6,25 & 1 \\
\hline LM1 & 14 & $9,0-10,4$ & 9,62 & 0,49 \\
\hline AM1 & 14 & $10,3-13,6$ & 11,61 & 0,9 \\
\hline LM2 & 10 & $5,2-10,6$ & 6,68 & 1,75 \\
\hline AM2 & 10 & $7,6-11,6$ & 8,86 & 1,43 \\
\hline \multicolumn{5}{|c|}{ Mandíbula } \\
\hline LP2 & 6 & $7,5-9,6$ & 8,56 & 0,8 \\
\hline AP2 & 5 & $3,0-3,6$ & 3,24 & 0,23 \\
\hline LP3 & 9 & $8,3-13,5$ & 9,52 & 1,49 \\
\hline AP3 & 9 & $3,2-8,3$ & 4,55 & 1,7 \\
\hline LP4 & 17 & 8,8-14,9 & 10,04 & 1,33 \\
\hline AP4 & 17 & $3,5-7,7$ & 4,32 & 0,91 \\
\hline LM1 & 30 & $14,2-17,6$ & 15,57 & 0,83 \\
\hline AM1 & 30 & 5,3-6,8 & 5,97 & 0,38 \\
\hline LM2 & 19 & $6,6-7,7$ & 7,21 & 0,26 \\
\hline AM2 & 19 & $4,5-6,0$ & 5,41 & 0,34 \\
\hline \multicolumn{5}{|c|}{ Húmero } \\
\hline LM & 3 & $116-129$ & 124,16 & \\
\hline Ap & 3 & $23,5-27,5$ & 25,33 & \\
\hline$A D$ & 3 & $7,5-8,8$ & 8,33 & \\
\hline $\mathrm{Ad}$ & 7 & $18,5-20,5$ & 19,51 & 0,7 \\
\hline \multicolumn{5}{|c|}{ Radio } \\
\hline LM & 4 & $112-121$ & 115,75 & \\
\hline Ap & 6 & $11,3-12,5$ & 11,76 & 0,43 \\
\hline$A D$ & 4 & $7,6-9,0$ & 8,35 & \\
\hline $\mathrm{Ad}$ & 8 & $14,4-16,3$ & 15,27 & 0,6 \\
\hline \multicolumn{5}{|l|}{ Ulna } \\
\hline EPA & 5 & $15,5-16,7$ & 16,12 & 0,46 \\
\hline EmO & 5 & $13,2-14,3$ & 13,76 & 0,43 \\
\hline LO & 4 & $13,2-14,2$ & 13,65 & 0,38 \\
\hline \multicolumn{5}{|c|}{ Fémur } \\
\hline $\mathrm{Ad}$ & 3 & $21,0-22,0$ & 21,5 & \\
\hline \multicolumn{5}{|c|}{ Tibia } \\
\hline LM & 2 & $143-147,5$ & 145,25 & \\
\hline Ap & 3 & $21,5-22,5$ & 22 & \\
\hline$A D$ & 2 & 8,3-9,5 & 8,9 & \\
\hline $\mathrm{Ad}$ & 8 & $13,6-17,7$ & 15,31 & 1,24 \\
\hline \multicolumn{5}{|c|}{ Astrágalo } \\
\hline LMI & 5 & $18,1-20,5$ & 19,12 & 0,63 \\
\hline \multicolumn{5}{|c|}{ Calcáneo } \\
\hline LM & 16 & $27,5-35,5$ & 32,19 & 2 \\
\hline \multicolumn{5}{|c|}{ Metatarso 2} \\
\hline LM & 6 & $54-61,5$ & 57,91 & 2,29 \\
\hline \multicolumn{5}{|c|}{ Metatarso 3} \\
\hline LM & 3 & $62,5-66,5$ & 4,83 & 1,69 \\
\hline \multicolumn{5}{|c|}{ Metatarso 4} \\
\hline LM & 2 & $48,5-61,5$ & 55 & \\
\hline
\end{tabular}

Tabl. 32. Resúmenes estadísticos de las medidas más frecuentes de zorro. / Univariate statistics of them measures more frequently of the fox. 


\begin{tabular}{|c|c|c|c|c|c|c|}
\hline & \multirow[t]{2}{*}{ Exterior } & \multirow[t]{2}{*}{ Galería NW } & \multicolumn{2}{|c|}{ Vestíbulo } & \multirow[t]{2}{*}{ Sala 2} & \multirow[t]{2}{*}{ Total } \\
\hline & & & Mag. Inf. & Solutrense & & \\
\hline Cráneo & & & & & 1 & 1 \\
\hline Maxilar & & & 1 & & & 1 \\
\hline Dient. ais. sup. & 10 & 1 & 8 & 2 & 25 & 46 \\
\hline Dient. ais. inf. & 9 & 1 & 2 & 3 & 19 & 34 \\
\hline Vértebra & & & & & 4 & 4 \\
\hline Costilla & 1 & & 1 & & 3 & 5 \\
\hline Húmero & & & & & 4 & 4 \\
\hline Ulna & & & & & 2 & 2 \\
\hline Carpo & & & & & 1 & 1 \\
\hline Pelvis & & & 1 & & 1 & 2 \\
\hline Fémur & & & 1 & & 1 & 2 \\
\hline Tibia & & & & & 1 & 1 \\
\hline Metacarpo & 2 & & & & 2 & 4 \\
\hline Calcáneo & & & & & 1 & 1 \\
\hline Falange 1 & 4 & & & & 4 & 8 \\
\hline Falange 2 & & & & & 1 & 1 \\
\hline Total & 26 & 2 & 14 & 5 & 70 & 117 \\
\hline
\end{tabular}

Tabl. 33. Distribución anatómica de los restos de oso. / Skeletal remain distribution of the bear

Las dos especies de oso desde el punto de vista espacial están ausentes en el pasillo y en la primera sala in- terior. Si atendemos a la cronología faltan en los niveles del final del Magdaleniense y en el Epipaleolítico.

\begin{tabular}{|c|c|c|c|c|c|c|c|c|c|}
\hline \multicolumn{10}{|c|}{ Maxilar } \\
\hline & LI1 & 10,4 & 11,5 & & & & & & \\
\hline & Al1 & 8,3 & 9,1 & & & & & & \\
\hline & $\mathrm{LI} 3$ & & & 13 & 14,4 & 13 & & & \\
\hline & $\mathrm{Al} 3$ & & & 14,3 & 13 & 12,7 & & & \\
\hline & LP4 & & & & & & 18,8 & 20 & \\
\hline & AP4 & & & & & & 12,8 & 14 & \\
\hline & LM2 & & & & & & & & 39,5 \\
\hline & ALM2 & & & & & & & & 20,5 \\
\hline & & & & & & & & & \\
\hline \multicolumn{10}{|c|}{ Mandíbula } \\
\hline & $\mathrm{LI} 1$ & 10 & 8,7 & 9,2 & & & & & \\
\hline & Al1 & 8 & 5,5 & 7,4 & & & & & \\
\hline & LP4 & & & & 14,5 & 15 & & & \\
\hline & AP4 & & & & 10,4 & 8,6 & & & \\
\hline & LM1 & & & & & & 31,5 & & \\
\hline & AM1 & & & & & & 14,5 & & \\
\hline & LM2 & & & & & & & 31,5 & \\
\hline & AM2 & & & & & & & 18,5 & \\
\hline & LM3 & & & & & & & & 26,5 \\
\hline & AM3 & & & & & & & & 19,7 \\
\hline & & & & & & & & & \\
\hline \multirow[t]{5}{*}{ Mc5: } & & & & \multicolumn{2}{|c|}{ Falange 1: } & & & & \\
\hline & LM & 73,5 & & & $\mathrm{LM}$ & 39 & & & \\
\hline & $A p$ & 18,7 & & & $A p$ & 21,5 & & & \\
\hline & $A D$ & 12,6 & & & $A D$ & 14,5 & & & \\
\hline & $\mathrm{Ad}$ & 16,8 & & & $\mathrm{Ad}$ & 15,1 & & & \\
\hline
\end{tabular}

Tabl. 34. Medidas aisladas de Ursus spelaeus. / Measures isolated from Ursus spelaeus. 


\begin{tabular}{|c|c|c|c|l|l|l|l|l|}
\hline \multicolumn{2}{|l|}{ Maxilar: } & & & & & \multicolumn{2}{l|}{ Mandíbula: } & \\
\hline & LI1 & 10 & 10,3 & & & & LI2 & 10 \\
\hline & Al1 & 7,7 & 7,8 & & & & Al2 & 7,8 \\
\hline & LI2 & 10,7 & 10,8 & & & & LP4 & 14,5 \\
\hline & Al2 & 9 & 9,3 & & & & AP4 & 8,9 \\
\hline & LI3 & & & & & & & \\
\hline & Al3 & & & & & & & \\
\hline & LM1 & 24,5 & 24,5 & & & & & \\
\hline & AM1 & 19,3 & 19,3 & & & & & \\
\hline & LM3 & & & 39,5 & & & & \\
\hline & AM3 & & & 20,5 & & & & \\
\hline
\end{tabular}

Tabl. 35. Medidas aisladas de Ursus arctos. / Measures isolated from Ursus arctos.

\section{Hiena de las cavernas Crocuta crocuta}

La hiena está presente con 14 restos y sólo aparece en el abrigo exterior y en la sala más profunda de Prai- leaitz I (Tabl. 36). Esta especie es típica del Paleolítico Medio Cantábrico estando a menudo asociada al oso de las cavernas. Sin embargo, pervive hasta el Magdaleniense en el yacimiento de Santa Catalina (CASTAÑOS, en prensa).

\begin{tabular}{|l|c|c|c|}
\hline & Exterior & Sala 2 & Total \\
\hline Maxilar & 2 & & $\mathbf{2}$ \\
\hline Dient. ais. sup. & & 1 & $\mathbf{1}$ \\
\hline Dient. ais. inf. & 2 & 2 & $\mathbf{4}$ \\
\hline Ulna & 1 & & $\mathbf{1}$ \\
\hline Metacarpo & 1 & 1 & $\mathbf{2}$ \\
\hline Calcáneo & 2 & & $\mathbf{2}$ \\
\hline Falange 1 & 1 & 1 & $\mathbf{2}$ \\
\hline Total & $\mathbf{9}$ & $\mathbf{5}$ & $\mathbf{1 4}$ \\
\hline
\end{tabular}

Tabl. 36. Distribución anatómica de los restos de hiena. / Skeletal remain distribution of the hyena.

\begin{tabular}{|l|c|l|l|l|l|l|l|l|l|l|}
\hline \multicolumn{2}{|l|}{ Maxilar: } & & & \multicolumn{2}{|l|}{ Mandibula: } & & & \multicolumn{2}{l|}{ Calcáneo: } & \\
\hline & LI3 & 9,6 & & & LC & 16,6 & & & LM & 60,5 \\
\hline & Al3 & 8,3 & & & AC & 13 & & & & \\
\hline & & & & & LP4 & 41 & & & & \\
\hline & & & & & AP4 & 20,3 & & & & \\
\hline
\end{tabular}

Tabl. 37. Medidas aisladas de Crocuta crocuta. / Measures isolated from Crocuta crocuta.

Sus escasas medidas (Tabl. 37) quedan dentro del dominio de variación de las publicadas en yacimientos coetáneos del norte peninsular.

\section{Pantera o Leopardo Panthera pardus}

La pantera o leopardo está representado con 30 restos que se extienden por la mayor parte del yacimiento. Sólo está ausente en la segunda sala interior (Tabl. 38).

Desde el punto de vista anatómico las regiones mejor representadas son la dentición, el carpo, el tarso y las falanges. La proporción de huesos largos es muy baja y están todos fragmentados. Se trata de un carnívoro de mediano tamaño cuya presencia en la Región Cantábrica se concentra en niveles del final del Paleolítico Medio e inicios del Paleolítico Superior. Probablemente el norte de la Península lbérica ha podido constituir uno de los últimos refugios de esta especie en Europa (SAUQUÉ, CUENCA-BESCÓS, 2013).

Las medidas obtenidas son escasas pero tienen su interés precisamente por los pocos datos osteométricos publicados de esta especie (Tabl. 39). Todas ellas entran 


\begin{tabular}{|l|c|c|c|c|c|}
\hline & Exterior & Galería NW & \multicolumn{2}{|c|}{ Vestíbulo-Pasillo } & Total \\
\hline & & & Mag. Inf. & Solutrense & \\
\hline Maxilar & 1 & 2 & & & $\mathbf{3}$ \\
\hline Mandíbula & & 2 & & & $\mathbf{2}$ \\
\hline Dient. ais. inf. & 2 & 2 & 1 & 1 & $\mathbf{6}$ \\
\hline Radio & & 1 & & & $\mathbf{1}$ \\
\hline Ulna & & 1 & & & $\mathbf{1}$ \\
\hline Carpo & 2 & & & 1 & $\mathbf{3}$ \\
\hline Pelvis & & & & 1 & $\mathbf{1}$ \\
\hline Tibia & & 1 & 1 & & $\mathbf{2}$ \\
\hline Metacarpo & & 2 & & & $\mathbf{3}$ \\
\hline Astrágalo & & & & & $\mathbf{1}$ \\
\hline Calcáneo & & 1 & & & $\mathbf{1}$ \\
\hline Falange 1 & 2 & & & & $\mathbf{2}$ \\
\hline Falange 2 & & & & & $\mathbf{2}$ \\
\hline Falange 3 & 1 & $\mathbf{1 3}$ & & & $\mathbf{3 0}$ \\
\hline Totales & $\mathbf{8}$ & & & & \\
\hline
\end{tabular}

Tabl. 38. Distribución anatómica de los restos de pantera o leopardo. / Skeletal remain distribution of the leopard.

\begin{tabular}{|l|c|c|c|c|c|c|c|c|c|c|c|}
\hline \multicolumn{2}{|l|}{ Maxilar: } & & & \multicolumn{2}{l|}{ Mandíbula: } & & & & & \\
\hline & LP4 & 25,8 & & & LC & 12,6 & & & & & \\
\hline & AP4 & 12,1 & & & AC & 9,5 & & & & & \\
\hline & & & & & LP3 & & & & 14,3 & & \\
\hline Mc3: & & & & & AP3 & & & & 7,4 & & \\
\hline & LM & 76,5 & & & LP4 & 18,7 & & & & 18,4 & \\
\hline & Ap & 13,8 & & & AP4 & 8,7 & & & & 9,2 & \\
\hline & AD & 9,9 & & & LM1 & 18,3 & 17,9 & 21,2 & & & \\
\hline & Ad & 14,3 & & & AM1 & 8,4 & 8,5 & 9,7 & & & \\
\hline & & & & & & & & & & & \\
\hline Astrágalo: & & & & Falange 1: & & & & & & \\
\hline & LM & 37,5 & & & LM & & & & & & \\
\hline
\end{tabular}

Tabl. 39. Medidas aisladas de Panthera pardus. / Measures isolated from Panthera pardus.

dentro de las publicadas en yacimientos coetáneos del País Vasco.

\section{Lince boreal y Lince de las cavernas Lynx lynx/Lynx spelaea}

Hay 73 restos de lince repartidos por casi todos los sectores del yacimiento (Tabl. 40). Esta muestra incluye elementos de lince boreal (Lynx lynx) y es probable que también de lince de las cavernas (Lyn spelaea).

La mayor parte de las medidas (Tabl. 41) entran dentro del dominio de dispersión del lince boreal. Pero no puede descartarse la presencia del lince de las cavernas, especie mal definida desde el punto de vista osteométrico.

\section{Gato montés Felis silvestris}

Se han recuperado cuatro restos de gato montés. Por un lado hay dos caninos superiores en el abrigo exterior y en la segunda sala respectivamente. Y en el Magdaleniense Inferior del vestíbulo una segunda falange y un segundo metacarpiano (LM 41). 


\begin{tabular}{|c|c|c|c|c|c|c|c|}
\hline & \multirow[t]{2}{*}{ Exterior } & \multirow[t]{2}{*}{ Galería NW } & \multicolumn{3}{|c|}{ Vestíbulo-Pasillo } & \multirow[t]{2}{*}{ Sala 2} & \multirow[t]{2}{*}{ Total } \\
\hline & & & Epipal. & Mag. Inf. & Solutrense & & \\
\hline Cráneo & & & 1 & & & & 1 \\
\hline Maxilar & & & & 1 & 1 & & 2 \\
\hline Dient. ais. sup. & 2 & & 2 & 3 & 2 & & 9 \\
\hline Mandíbula & & & 2 & & 1 & & 3 \\
\hline Dient. ais. inf. & & & & 1 & 1 & 1 & 3 \\
\hline Vértebra & & & & & 1 & & 1 \\
\hline Escápula & 1 & & & 1 & & & 2 \\
\hline Radio & & & & 1 & 2 & & 3 \\
\hline Ulna & 1 & & & & & & 1 \\
\hline Pelvis & & & & 1 & 1 & & 2 \\
\hline Fémur & & & & 1 & & & 1 \\
\hline Tibia & & & & & 1 & & 1 \\
\hline Metacarpo & & & & 2 & 6 & & 8 \\
\hline Calcáneo & & & 1 & & 1 & 1 & 3 \\
\hline Resto tarso & & & & 1 & & & 1 \\
\hline Metatarso & 1 & 1 & & & 5 & & 7 \\
\hline Falange 1 & & 2 & & 3 & 4 & & 9 \\
\hline Falange 2 & 2 & 1 & & 1 & 9 & & 13 \\
\hline Falange 3 & & & & 2 & 1 & & 3 \\
\hline Total & 7 & 4 & 6 & 18 & 36 & 2 & 73 \\
\hline
\end{tabular}

Tabl. 40. Distribución anatómica de los restos de lince. / Skeletal remain distribution of the lynx.

\begin{tabular}{|c|c|c|c|c|c|c|c|c|c|c|c|}
\hline \multicolumn{2}{|l|}{ Maxilar: } & \multirow[b]{2}{*}{10,8} & & \multicolumn{2}{|c|}{ Mandíbula: } & & & \multirow[b]{2}{*}{8,2} & & & \\
\hline & LP3 & & & & LC & & & & & & \\
\hline & AP3 & 5,3 & & & $A C$ & & & 6,1 & & & \\
\hline & LP4 & 18,3 & & & LM1 & 13,5 & 15,4 & & & & \\
\hline & AP4 & 9 & & & AM1 & 5,7 & 6,9 & & & & \\
\hline \multicolumn{2}{|l|}{ Radio: } & & & & & Ulna: & & & & & \\
\hline & LM & 181 & & & & & EPA & 19,7 & & & \\
\hline & $A p$ & 17,2 & 15,7 & 15,7 & & & $\mathrm{EmO}$ & 16,5 & & & \\
\hline & $A D$ & 12,7 & & & & & LO & 21 & & & \\
\hline & $\mathrm{Ad}$ & 25,5 & & & & & & & & & \\
\hline \multicolumn{2}{|c|}{ Metacarpo: } & 1 & 2 & 3 & 3 & 4 & 5 & 5 & & & \\
\hline & LM & 21 & 71 & 70 & 59 & 67,5 & 46 & 57 & & & \\
\hline & $A p$ & & 11 & 9 & 8,8 & 9,2 & 9,2 & 8,8 & & & \\
\hline & $A D$ & & 7,5 & 7,5 & 5,9 & 6,7 & 5,2 & 6 & & & \\
\hline & $\mathrm{Ad}$ & & 12 & 12 & 9,5 & 11,3 & 8,5 & 10 & & & \\
\hline \multicolumn{2}{|c|}{ Metatarso: } & 2 & 5 & & \multicolumn{2}{|c|}{ Falange 1: } & & & & & \\
\hline & LM & 88,5 & 79 & & & LM & $A p$ & $A D$ & $\mathrm{Ad}$ & LM & Ap \\
\hline & Ap & 10,3 & & & & 37 & 12 & 8 & 9,3 & 37 & 12 \\
\hline & $A D$ & 8 & & & & 37 & & 7,5 & 8,8 & 37 & \\
\hline & $\mathrm{Ad}$ & 12 & & & & 31 & 10,5 & 6,8 & 8,4 & 31 & 10,5 \\
\hline \multicolumn{12}{|c|}{ Falange2: } \\
\hline & LM & 26,5 & 28 & 19,7 & 21,5 & 26,5 & 27 & 28 & 24,5 & & \\
\hline & Ap & 8,8 & 10,3 & & & & & & & & \\
\hline & $A D$ & 5 & 5,8 & & & & & & & & \\
\hline & $\mathrm{Ad}$ & 7,7 & 8,8 & & & & & & & & \\
\hline
\end{tabular}

Tabl. 41. Medidas aisladas de los restos de lince. / Measures isolated from lynx. 


\section{Tejón Meles meles}

En el abrigo exterior hay un calcáneo y un astrágalo de tejón que son los únicos restos de esta especie en el yacimiento. Están fragmentados y por tanto no han proporcionado medida alguna.

\section{Turón \\ Mustela putorius}

El turón sólo está representado en el abrigo exterior con un canino superior cuya única información es la simple presencia de esta especie en el yacimiento.

\section{Armiño Mustela erminea}

Hay tres restos de armiño. Uno de ellos es un fémur completo (LM 35,5) procedente de la galería noroeste. Los otros dos corresponden al Epipaleolítico del vestíbulo: un fragmento de mandíbula derecha y otro de húmero. El primero conserva el M1 (LM 5,7; AM 2,7). El segundo es un fragmento distal (Ad 7,7).

\section{Comadreja Mustela nivalis}

El más pequeño de los mustélidos ha proporcionado cuatro restos. Dos fragmentos de húmero en cada uno de los niveles magdalenienses del vestíbulo y fragmentos de cráneo y mandíbula en la segunda sala. No hay medida alguna.

\section{7.- CONCLUSIÓN}

El análisis tafonómico de los restos de macromamíferos de Praileaitz I indica que la mayor parte de los mismos proceden de la actividad depredadora de distintos carnívoros, entre los que destacan los cánidos (lobo, cuon y zorro). La aportación de carácter antrópico a esta muestra es muy escasa y difícil de estimar.

Atendiendo a la información taxonómica y cronológica de los distintos sectores del yacimiento, se puede establecer una hipótesis respecto de la secuencia diacrónica de ocupación del mismo por distintos agentes tafonómicos. No obstante, habida cuenta del carácter de palimpsesto que algunos depósitos de la cavidad pueden tener, debe ser tomada con ciertas reservas.

Inicialmente la cavidad pudo servir como lugar de hibernación de osos durante el Paleolítico Medio utilizando la sala más profunda como sitio más adecuado para hacerlo. La mayor proporción de restos de oso de las cavernas de este sector y la datación de 51.000 años obtenida por racemización de aminoácidos para un canino de esta especie, pueden apoyar la existencia de esta primera ocupación. La presencia de hiena y de marmota son coherentes con esta cronología.

Hacia el final del Paleolítico Medio (Chatelperroniense) se produce la acumulación de restos del abrigo exte- rior situado junto a la entrada de la cavidad. Es probable que se trate del sector con menos actividad humana. Su escasa protección invita a pensar que ni siquiera es un cubil en sentido estricto, sino un lugar donde recalar durante unas horas al que se acarrean las presas para su consumo. Entre los herbívoros cazados destaca el sarrio que, a juzgar por otros yacimientos cantábricos coetáneos, parece tener su pequeña "edad de oro" en este momento. La presencia de los carnívoros de tamaño grande (oso de las cavernas, hiena y leopardo) justifica la estimable muestra de restos de grandes bóvidos.

A partir del Gravetiense se inicia una ocupación extensiva del interior de la cueva desde el vestíbulo hasta la sala más profunda. Al no tratarse de un lugar de habitación humana, el aporte de sedimento es mínimo y se producen simples depósitos de huesos sobre la superficie del suelo. No es por tanto difícil que las acumulaciones a lo largo del tiempo, tanto de carácter antrópico como de los distintos depredadores, estén a poca distancia estratigráfica. Parece que ya en esta ocupación sistemática de la cueva han desaparecido el oso de las cavernas y la hiena. El primero será sustituido por el oso pardo.

Al menos desde el Solutrense, a las aportaciones de origen animal se añaden evidencias de origen antrópico que van alternándose con las otras hasta el Epipaleolítico. Durante el Solutrense y Magdaleniense Inferior se produce el uso más intenso de la cueva por parte de las alimañas. Al inicio del Tardiglaciar ha desaparecido el leopardo y la utilización de la cavidad como cubil también desciende significativamente. Es posible que la presencia esporádica de humanos tuviese algo que ver con este fenómeno. La evolución posterior que se caracteriza por un abandono progresivo de la cueva, quizás fuese consecuencia de esta desafección por un antiguo refugio demasiado visitado ya por los competidores humanos.

En definitiva Praileaitz I es un ejemplo más de ocupaciones alternativas de humanos y depredadores animales. Se une a otros yacimientos relativamente próximos como Astigarraga, Ekain, Amalda, Zerratu, Labeko Koba y Lezetxiki. Todos estos ejemplos parecen confirmar un modelo general durante el Paleolítico Medio y Superior en el que los humanos van primero alternando y más tarde desplazando progresivamente de las cavidades cársticas a sus anteriores ocupantes.

\section{8.- AGRADECIMIENTOS}

En primer lugar agradecemos a X. Peñalver, director de la excavación su confianza al confiarnos el estudio de la macrofauna de este yacimiento. A la Diputación Foral de Gipuzkoa por el apoyo económico para la realización de este estudio durante las primeras campañas. A los dos revisores anónimos que con sus observaciones han permitido mejorar significativamente este trabajo. Jone Castaños es beneficiaria de una beca postdoctoral "Contratación para la especialización de personal investigador doctor" de la Universidad del País Vasco (UPV/EHU). 


\section{9.- BIBLIOGRAFÍA}

ALTUNA, J.

1978 Dimorphisme sexual dans le squelette postcéphalique de Capra pirenaica pendant le Würm final. Munibe 30, 201 214.

1990 Caza y alimentación precedente de Macromamíferos durante el Paleolítico de Amalda, en ALTUNA, J., BALDEÓN, A. \& MARIEZKUURRENA, K. (Eds.). Cueva de Amalda (Zestoa, País Vasco). Ocupaciones Paleolíticas y Postpaleoliticas. 149-192. (Sociedad de Estudios Vascos Serie B4).

1992 El medio ambiente durante el Pleistoceno Superior en la región Cantábrica con referencia especial a sus faunas de mamíferos. Munibe Antropologia-Arkeologia 44, 13-29.

1999 Mammals changes between the Dryas and the Holocene in Northern Spain, en BENECKE, N. The Holocene History of the European Vertebrate Fauna. Modern Aspects of Research. 1-8. (Archaologie in Eurasien 6).

ALTUNA, J., MARIEZKUURRENA, K.

1984 Bases de subsistencia de origen animal en el yacimiento de Ekain, en ALTUNA, J., MERINO, J.M. (Eds.). El yacimiento prehistórico de la cueva de Ekain (Deba, Guipúzcoa). 211-280. (Sociedad de Estudios Vascos Serie B1).

1985 Bases de subsistencia de los pobladores de Erralla: Macromamíferos, en ALTUNA, J. BALDEON, A. \& MARIEZKURRENA, K. (Eds.). Cazadores Magdalenienses en Erralla (Cestona, País Vasco). 87-111. (Munibe Antropologia-Arkeologia 37).

2000 Macromamíferos del yacimiento de Labeko Koba (Arrasate, País Vasco), en ARRIZABALAGA, A. \& ALTUNA, J. (Eds.). Labeko Koba (País Vasco). Hienas y Humanos en los albores del Paleolítico superior. 107-151. (Munibe Antropologia-Arkeologia 52).

ALVAREZ-LAÓ, D.

2014 The Jou Puerta cave (Asturias, NW Spain): a MIS 3 large mammal assemblage with mixture of cold and temperate elements. Palaeogeography, Palaeoclimatology, Palaeoecology 393, 1-19

ALVAREZ-LAÓ, D., RUIZ-ZAPATA, M.B., GIL-GARCÍA, M.J., BALLESTEROS, D., JIMÉNEZ-SÁNCHEZ, M.

2015 Palaeoenvironmetal research at Rexidora Cave: New evidence of cold and dry in NW Iberia during MIS 3. Quaternary International, 1-12.

BARROSO, C., RIQUELME, J. A., MOIGNE, A-M., BANES, M.

2006 Les faunes de grandes mammifères du Pléistocène superieur de la Grotte du Boquete de Zafarraya. Etude Paléontologique, Paléoécologique et Archéozoologique, en BARROSO RUIZ, C. \& LUMLEY, H. (Eds). La Grotte du Boquete de Zafarraya. 675-891. Málaga.

\section{BINFORD, L.}

1984 Faunal Remains from Klasies River Mouth. Academic Press. Orlando.
CASTAÑOS, J., CASTAÑOS, P. Y MURELAGA, $X$.

2006 Estudio osteométrico preliminar de los restos de ciervo (Cervus elaphus) del yacimiento paleontológico del Pleistoceno Superior de Kiputz IX (Mutriku, Gipuzkoa). Geogaceta 40, 163-166.

CASTAÑOS, J., ZULUAGA, M.C., ORTEGA, L.A., MURELAGA, X, ALONSO-OLAZABAL, A., ROFES, J. Y CASTAÑOS, P.

2014 Carbon and nitrogen stable isotopes of bone collagen of large herbivores from the Late Pleistocene Kiputz IX cave site (Gipuzkoa, north Iberian Peninsula) for palaeoenvironmental reconstruction. Quaternary International 339-340, 131-138.

CASTAÑOS, P

1988 Estudio de los restos de la cantera de Punta Lucero (Abanto y Ciérvana, Bizkaia). Kobie 17, 157-165.

2001 Estudio de la fauna del nivel 4 del denominado corte solutrense de Carballo, en MONTES, R. \& SANGUINO, J. (Eds.). La Cueva del Pendo. 153-159. Santander.

2009 Estudio arqueozoológico de los macromamíferos de Cobrante. Sautuola XV. 75-84.

CASTAÑOS, P., ALVAREZ, E.

2012 Nuevas aportaciones a las bases de subsistencia de origen animal durante el Gravetiense cantábrico, en DE LAS HERAS, C., LASHERAS, J.A., DE LA RASILLA, M. \& ARRIZABALAGA, A. (eds). Pensando el Gravetiense: nuevos datos para la Región Cantábrica en su contexto peninsular y pirenaico.301-317. (Monografías del Museo Nacional y Centro de Investigación de Altamira 23).

CASTAÑOS, P., MURELAGA, X., BAILÓN, S., CASTAÑOS, J., SÁEZ DE LA FUENTE, X. Y SUÁREZ, $O$.

2009 Estudio de los vertebrados del yacimiento de Lezikako Koba (Kortezubi, Bizkaia). Kobie Paleoantropología 28, 25-50.

DAVIS, S

1992 A rapid method for recording information about mammal bones from archaeoogical sites. London.

DELPECH, F.

1975 Les Faunes du Paléolithique Supérieur dans le Sud-Ouest de la France. Thèse. Université de Bordeaux I.

DRIESCH, A. V.D.

1976 Das Vermessen von Tierknochen aus vor und frühgeschichtliche Siedlunge. München.

MICHEL, P

2005 Un repaire würmien d'hyènes des cavernes : La Grotte d'Unikoté (Iholdy, Pyrénées-Atlantiques, France), en MONTES, R. \& LASHERAS, J.A. (Eds.). Actas de la reunión científica Neandertales cantábricos, estado de la cuestió. 131-150. (Museo de Altamira. Monografías 20). 
LÓPEZ, E.

2003 Paleontology and taphonomy of Pleistocene mammals of Galicia (NW Iberian Peninsula). Nova Terra 22.

PÉREZ-BARBERÍA, F.J.

1994 Determination of age in Cantabrian chamois (Rupicapra pyrenaica parva) from jaw tooth-row eruption and wear. Journal of Zoology 233, 649-656.

PÉREZ RIPOLL, M., MORALES PÉREZ, J.V., SANCHÍS SERRA, A., AURA TORTOSA, J. E., SARRIÓN MONTAÑANA, I.

2010 Presence of the genus Cuon in upper Pleistocene and initial Holocene sites of the Iberian Peninsula: new remains identified in archaeological contexts of the Mediterranean region. Journal of Archaeological Science 37, 437-450.
SAUQUÉ, V., CUENCA-BESCÓS, G.

2013 The lberian Peninsula, the last european refugium of Panthera pardus Linnaeus 1758 during the upper Pleistocene. Quaternaire 24 (1), 35-48.

STINER, M. C.

1991 Food Procurement and Transport by Human and NonHuman Predators. Journal of Archaeological Science 18, 455-482.

SUÁREZ-BILBAO, A., GARCÍA-IBAIBARRIAGA, N., CASTAÑOS, J., CASTAÑOS, P., IRIARTE, M.J., ARRIZABALAGA, A., TORRES, T., ORTIZ, J.E., MURELAGA, $X$.

2016 New Early Weichselian (MIS 5c) palaeontological assemblage from the Northern Iberian Peninsula. Palevol 15. DOl: 10.1016/j.crpv,2016.05.002. 
ANEXO I

Medidas aisladas de Capra pyrenaica Measures isolated Capra pyrenaica

\begin{tabular}{|c|c|c|c|c|c|c|c|c|c|c|c|}
\hline \multicolumn{12}{|c|}{ Mandíbula: } \\
\hline \multicolumn{2}{|c|}{ LP2-M3 } & 88 & 91,5 & 78 & LM3 & 29 & 24,5 & 27,5 & 31,5 & 28,5 & 27 \\
\hline \multicolumn{2}{|c|}{ LP2-P4 } & 27 & 27 & 24,5 & & & & & & & \\
\hline \multicolumn{2}{|c|}{ LM1-M3 } & 62 & 60,5 & 52,5 & LM3 & 31 & 27 & 23 & 25,5 & 24,5 & 25 \\
\hline & LM3 & 25 & 26 & 21,5 & & & & & & & \\
\hline & & $\mathrm{m}$ & $\mathrm{m}$ & $\mathrm{h}$ & LM3 & 28 & & & & & \\
\hline \multicolumn{2}{|c|}{ Escápula: } & & & & \multicolumn{2}{|c|}{ Húmero: } & & & & & \\
\hline & LMP & 38,5 & 39,5 & & & AT & 39 & 36,5 & 43 & 36,5 & \\
\hline & LS & 35,5 & 34,5 & & & & & $\mathrm{~h}$ & $\mathrm{~m}$ & $\mathrm{~h}$ & \\
\hline & AS & 26,5 & 27 & & & & & & & & \\
\hline & $\mathrm{LmC}$ & 26 & 26,5 & & Radio: & & & & & & \\
\hline & & $\mathrm{h}$ & $\mathrm{h}$ & & $A p$ & 42 & 36,5 & 39,5 & & & 41 \\
\hline & & & & & Asp & 41 & 34,5 & 38,5 & & & 39 \\
\hline \multicolumn{2}{|c|}{ Rótula: } & & & & $A D$ & & & & & & \\
\hline & LM & 36 & & & $\mathrm{Ad}$ & & & & 35,5 & 33,5 & \\
\hline & AM & 25 & & & & $\mathrm{~m}$ & $\mathrm{~h}$ & $\mathrm{~h}$ & & & $\mathrm{~m}$ \\
\hline & & & & & & & & & & & \\
\hline \multicolumn{12}{|c|}{ Metacarpo: } \\
\hline & LM & & & & & 131 & & 131,5 & 129 & 157,5 & \\
\hline & Ap & 33 & 36,5 & 31,5 & 31,5 & 29 & 29,5 & 29,5 & 29,5 & 34 & \\
\hline & $A D$ & & & & & 18,2 & & 18,5 & 17,8 & 21,5 & \\
\hline & $\mathrm{Ad}$ & & & & & 32 & & 32,5 & 32,5 & 38 & \\
\hline & $\mathrm{Ed}$ & & & & & 19,5 & & 19,5 & 19,4 & 21,5 & \\
\hline & & & & & & $\mathrm{h}$ & & $\mathrm{h}$ & $\mathrm{h}$ & $\mathrm{m}$ & \\
\hline & & & & & & & & & & & \\
\hline \multicolumn{12}{|c|}{ Fémur: } \\
\hline EC & 26,5 & 25,5 & 20,5 & 22 & 24,5 & & & & & & \\
\hline & & & & & & & & & & & \\
\hline \multicolumn{12}{|c|}{ Tibia: } \\
\hline \multirow[t]{2}{*}{$\mathrm{Ad}$} & 30,5 & 30,5 & 28 & 31 & & & & & & & \\
\hline & $\mathrm{h}$ & $\mathrm{h}$ & $\mathrm{h}$ & $\mathrm{h}$ & & & & & & & \\
\hline \multicolumn{12}{|c|}{ Astrágalo: } \\
\hline & LMl & 39 & 37 & 36 & 35,5 & 38 & 36,5 & 35 & 36 & 40 & 39 \\
\hline & $\mathrm{LMm}$ & 35,5 & 34 & 33,5 & 33 & 36 & 34,5 & 32 & 33 & 37,5 & 37 \\
\hline & $\mathrm{El}$ & 20,5 & 20,5 & 19,7 & 19,6 & 20,5 & 20 & 18 & 19,4 & 22,5 & 21,5 \\
\hline & $\mathrm{Ad}$ & & 24,5 & 22,5 & 22,5 & 23,5 & 22,5 & 22 & 22,5 & 26,5 & 26 \\
\hline & & $\mathrm{m}$ & $\mathrm{h}$ & $\mathrm{h}$ & $\mathrm{h}$ & $\mathrm{h}$ & $\mathrm{h}$ & $\mathrm{h}$ & $\mathrm{h}$ & $\mathrm{m}$ & $\mathrm{m}$ \\
\hline & LMI & 37 & 37 & 36,5 & 33,5 & 35,5 & 39,5 & 38 & 34,5 & 36,5 & 32,5 \\
\hline & $\mathrm{LMm}$ & 36 & 33,5 & 33,5 & 31,5 & 33 & 37 & 35 & 32 & 34,5 & 31,5 \\
\hline & $\mathrm{El}$ & 20 & 20 & 20 & 18,4 & 19,6 & 31,5 & 21,5 & 18,5 & 19,8 & 18,9 \\
\hline & $\mathrm{Ad}$ & 24,5 & 24,5 & 25 & 21,5 & 22 & 26 & 25 & 22 & 23,5 & 22 \\
\hline & & $\mathrm{h}$ & $\mathrm{h}$ & $\mathrm{h}$ & $\mathrm{h}$ & $\mathrm{h}$ & $\mathrm{m}$ & $\mathrm{h}$ & $\mathrm{h}$ & $\mathrm{h}$ & $\mathrm{h}$ \\
\hline & LMI & 35,5 & 39,5 & 36,5 & 38 & 36,5 & Calcán & & & & \\
\hline & $\mathrm{LMm}$ & 33 & 36,5 & 34,5 & 35 & 34,4 & & LM & 70,5 & 68 & 75 \\
\hline & $\mathrm{El}$ & 20 & 22,5 & 19,8 & 20,5 & 19,9 & & AM & 22,5 & 21 & 22,5 \\
\hline & $\mathrm{Ad}$ & 23,5 & 26,5 & 22 & 24 & 23,5 & & & $\mathrm{~h}$ & $\mathrm{~h}$ & $\mathrm{~h}$ \\
\hline & & $\mathrm{h}$ & $\mathrm{m}$ & $\mathrm{h}$ & $\mathrm{h}$ & $\mathrm{h}$ & & & & & \\
\hline & & & & & & & & & & & \\
\hline
\end{tabular}




\begin{tabular}{|c|c|c|c|c|c|c|c|c|c|c|}
\hline \multicolumn{11}{|l|}{ Centrotarsal: } \\
\hline AM & 29 & 29,5 & 34 & 32,5 & 35 & 33 & 30 & 31,5 & 29 & 28,5 \\
\hline & $\mathrm{h}$ & $\mathrm{h}$ & $\mathrm{m}$ & $\mathrm{h}$ & $\mathrm{m}$ & $\mathrm{m}$ & & $\mathrm{m}$ & $\mathrm{h}$ & $\mathrm{h}$ \\
\hline AM & 29 & 29,5 & 34 & 32,5 & & & & & & \\
\hline & $\mathrm{h}$ & $\mathrm{h}$ & $\mathrm{m}$ & $\mathrm{m}$ & & & & & & \\
\hline & & & & & & & & & & \\
\hline \multicolumn{11}{|l|}{ Metatarso: } \\
\hline LM & 135 & 171 & & 179 & & & 144,5 & & 167,5 & 192 \\
\hline $\mathrm{Ap}$ & 24,5 & 24 & 25,5 & 32 & & & 26,5 & 24,5 & 28 & 25 \\
\hline$A D$ & 15,7 & 15,2 & & 21 & & & 17 & & & 15,7 \\
\hline $\mathrm{Ad}$ & 30 & 31 & & 36 & 35,5 & 34,5 & 31,5 & & & 30 \\
\hline $\mathrm{Ed}$ & 17,6 & 18,6 & & 23 & 22 & 19,5 & 20,5 & & & 19,5 \\
\hline & $\mathrm{h}$ & $\mathrm{h}$ & & $\mathrm{m}$ & $\mathrm{m}$ & $\mathrm{m}$ & $\mathrm{m}$ & & & \\
\hline & & & & & & & & & & \\
\hline \multicolumn{11}{|l|}{ Falange 1: } \\
\hline Lmpe & 44 & 48 & 45 & 44,5 & 46 & 45,5 & 47 & 50,5 & 50 & 43 \\
\hline$A p$ & 15,3 & 17 & 16,1 & 14,6 & 15 & 15,8 & 14,7 & 16,5 & 17,1 & 17,1 \\
\hline$A D$ & 12,8 & 13 & 13,4 & 11,3 & 12,4 & 14 & 12,5 & 13,4 & 13,8 & 13,9 \\
\hline $\mathrm{Ad}$ & 14 & 15 & 15,8 & 13,6 & 13,8 & 15,6 & 14 & 16 & 16 & \\
\hline & & & & & & & & & & \\
\hline Lmpe & 43 & 46 & 44 & 51,5 & 43,5 & 41,5 & 43,5 & 41,5 & 45 & 42,5 \\
\hline$A p$ & 16,4 & 15,7 & 14,6 & 19 & 14,2 & 15,2 & 16,1 & 15,1 & 14,6 & 14,4 \\
\hline$A D$ & 13,2 & 12,4 & 11,6 & 14,5 & 11,2 & 12,4 & 12,9 & 12,4 & 11,6 & 11,6 \\
\hline $\mathrm{Ad}$ & 15,2 & 14,9 & 13 & 16,8 & 13,5 & 14,9 & 15 & 14,7 & 13,5 & 13,5 \\
\hline Impe & 415 & 49 & 495 & 47 & 52 & 49 & 43 & 465 & 515 & 445 \\
\hline$A p$ & 14,4 & 17,7 & 17,2 & 17 & 19 & 15,8 & 14,4 & 19,4 & 19,3 & 17,4 \\
\hline$A D$ & 13 & 14 & 13 & 14,4 & 16 & 12,7 & 11,3 & 15,2 & 15 & 13,8 \\
\hline $\mathrm{Ad}$ & 13,8 & 16 & 15,3 & 17,3 & 19 & 15,3 & 13 & 18 & 17,6 & 15,2 \\
\hline & & & & & & & & & & \\
\hline Lmpe & 44 & 43 & 47 & 44 & 47 & 46,5 & 46 & 46 & 42 & \\
\hline$A p$ & 15 & 16,5 & 18,3 & 15,5 & 19,6 & 15 & 15,2 & 16,7 & 10,8 & \\
\hline$A D$ & 12,3 & 14,2 & 14,6 & 12,4 & 15 & 12,2 & 12,2 & 14,2 & 13,2 & \\
\hline $\mathrm{Ad}$ & 13,8 & 16 & 17,4 & 14,2 & 18 & 13,9 & 13,8 & 16,2 & 14,9 & \\
\hline \multicolumn{11}{|l|}{ Falange 2: } \\
\hline LM & 28 & 28 & 22 & 28 & 26,5 & 25,5 & 26 & 24,5 & 26,5 & 30 \\
\hline$A p$ & 14,9 & 14,2 & 15 & 15,2 & 14,4 & 17,2 & 16,9 & 15,2 & 15,6 & 15 \\
\hline$A D$ & 11,3 & 11,7 & 10,6 & 11,3 & 10,6 & 10,3 & 12,7 & 11 & 11,2 & 11,6 \\
\hline $\mathrm{Ad}$ & 11,9 & & 12 & 11,3 & 11,6 & 13,8 & 13,6 & 11,5 & 11,5 & 12 \\
\hline LM & 28 & 30,5 & 26 & 28 & 26,5 & 27 & 30 & 30 & 28,5 & 29 \\
\hline$A p$ & 18 & 13,4 & 15,2 & 13,4 & 15,7 & 13,3 & 16 & 19 & 16,3 & 16,4 \\
\hline$A D$ & 12,2 & 8,6 & 11 & 10 & 10,9 & 10,2 & 11,5 & 13,7 & 10,8 & 11,4 \\
\hline $\mathrm{Ad}$ & 14 & 10,4 & & 10,8 & 11,3 & 11,1 & 12,9 & 14,6 & 12,2 & 12,3 \\
\hline LM & 29 & 31 & 30 & 31 & 26 & 30 & 27,5 & 29 & 26,5 & 27 \\
\hline $\mathrm{Ap}$ & 14,3 & 16,6 & 13,8 & 13,7 & 14 & 19,6 & 15,5 & 15 & & 13,4 \\
\hline$A D$ & 11 & 11,9 & 9,9 & 10 & 10,4 & 8,9 & 10,8 & 10,8 & 8,2 & 7,8 \\
\hline $\mathrm{Ad}$ & 11,3 & 12,2 & 11,3 & 11,3 & 10,5 & 15,5 & 11,6 & 11,4 & 10 & 10,1 \\
\hline LM & 29 & 27 & 28 & 29 & 29 & 29 & 27,7 & 25 & 25 & 27,5 \\
\hline $\mathrm{Ap}$ & 15,3 & 16,2 & 17,4 & 18,9 & 17,7 & 16,6 & 14,4 & 14,7 & 15 & 14,7 \\
\hline$A D$ & 10,8 & 12 & 12,3 & 13,3 & 13,3 & 12,5 & 11 & 11 & 10,9 & 11,3 \\
\hline $\mathrm{Ad}$ & 12,1 & 12,8 & 14,2 & 14 & 13,7 & 13 & 11,8 & 11,3 & 11,4 & 12,1 \\
\hline
\end{tabular}


ANEXO II

Medidas aisladas de Rupicapra pyrenaica Measures isolated Rupicapra pyrenaica

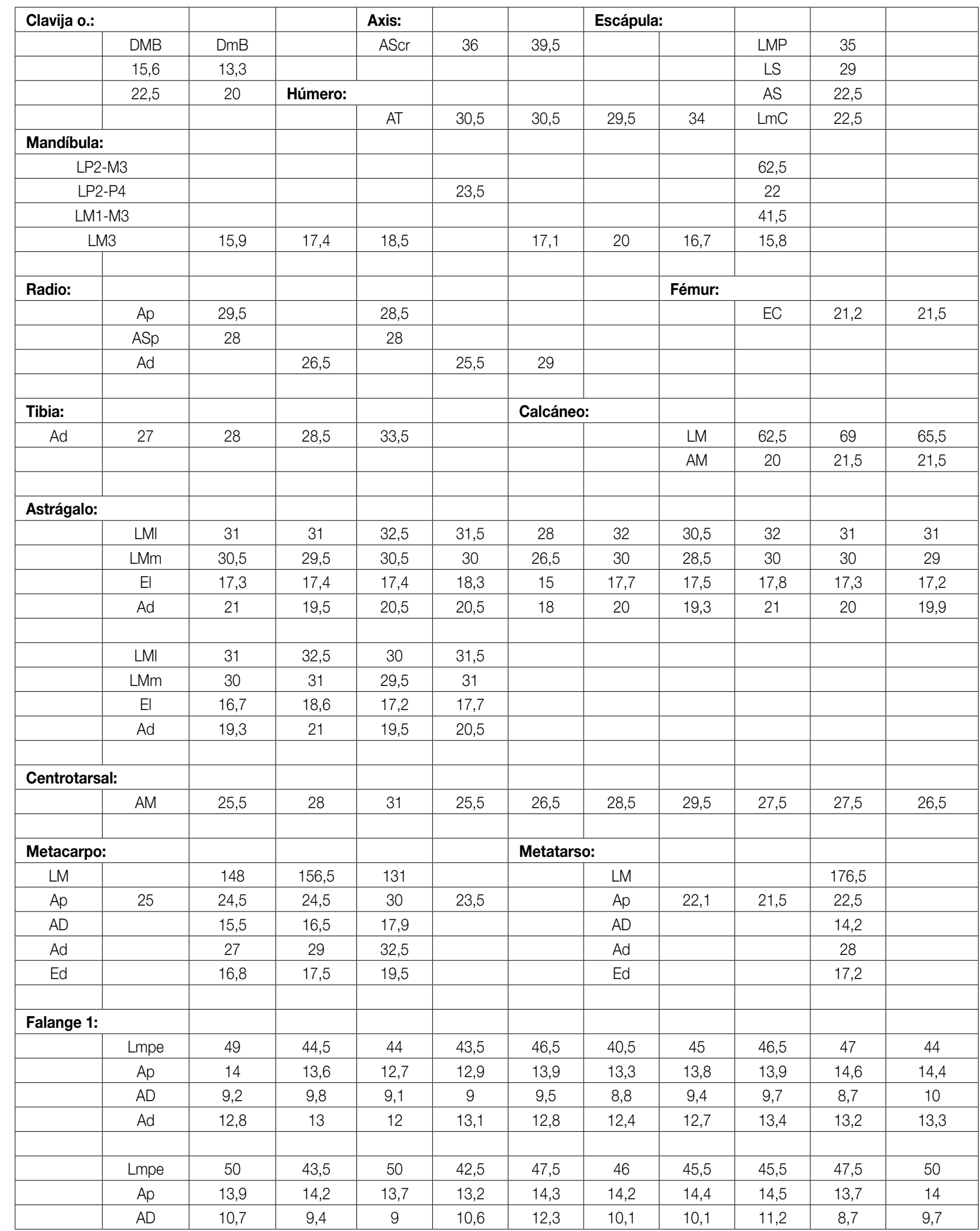




\begin{tabular}{|c|c|c|c|c|c|c|c|c|c|c|c|}
\hline & $\mathrm{Ad}$ & 13,2 & 12,8 & 12,6 & 13,1 & 14,3 & 13,9 & 13,8 & 12,4 & 12,7 & 12,8 \\
\hline & Lmpe & 49,5 & 43 & 49 & 43 & 50 & 46 & 43,5 & & & \\
\hline & $A p$ & 13 & 13,4 & & 13,2 & 15,2 & & 13,7 & & & \\
\hline & $A D$ & 8,9 & 9,6 & 9,2 & 9,4 & 10,6 & 8,4 & 9,6 & & & \\
\hline & $\mathrm{Ad}$ & 12,2 & 12,8 & 12,8 & 12,9 & 13,5 & 12,2 & 12,9 & & & \\
\hline \multicolumn{12}{|l|}{ Falange 2: } \\
\hline & LM & 31,5 & 27,5 & 33,5 & 27,5 & 28 & 31,5 & 26 & 30,5 & 28,5 & 29 \\
\hline & $A p$ & 13,6 & 13,8 & 12,9 & 12 & 13,4 & 11,5 & 13,6 & 14 & 13,7 & 12,5 \\
\hline & $A D$ & 9,2 & 8,5 & 8,4 & 8,1 & 9,4 & 8,6 & 10 & 10,2 & 8,3 & 8 \\
\hline & $\mathrm{Ad}$ & 10 & 9,8 & 9,7 & 9 & 10,2 & 9 & 10,3 & 11,7 & 10,3 & 9,7 \\
\hline & LM & 32 & 30,5 & 30 & 28 & 27,5 & 28 & 28,5 & & & \\
\hline & $A p$ & 13,2 & 12,6 & 12,5 & 13 & 13,6 & 12,3 & 12,3 & & & \\
\hline & $A D$ & 8,4 & 9,2 & 8 & 8,7 & 8,4 & 7,7 & 7,7 & & & \\
\hline & $\mathrm{Ad}$ & 10 & 9,9 & 10 & 13 & 10,4 & 10,2 & 9,6 & & & \\
\hline \multicolumn{12}{|l|}{ Falange 3: } \\
\hline & LSD & 38 & 31 & 35,5 & 31,5 & 35,5 & 33 & 34,5 & 31,5 & & \\
\hline & Ldo & 32 & 25 & 30,4 & 26 & 30 & 26,5 & 30 & 24,5 & & \\
\hline
\end{tabular}




\section{ANEXO III}

Medidas aisladas de Cervus elaphus

Measures isolated Cervus elaphus

\begin{tabular}{|c|c|c|c|c|c|c|c|c|c|c|}
\hline Mandíbula: & & & & Radio: & & & & Ulna: & & \\
\hline LM1-M3 & 73,5 & & & $A p$ & 45,5 & & & APC & 22,5 & \\
\hline \begin{tabular}{l|l} 
& LM3 \\
\end{tabular} & 32 & 26,5 & & ASp & 44 & & & & & \\
\hline AM3 & 14,4 & 9,9 & & $\mathrm{Ad}$ & & 49,5 & & & & \\
\hline & & +++ & & & & & & & & \\
\hline Metacarpo: & & & & & \multicolumn{2}{|c|}{ Astrágalo: } & & & & \\
\hline LM & 256 & & & & & LMI & 58,5 & 58,5 & 56 & 64 \\
\hline $\mathrm{Ap}$ & 47 & & & & & LMm & 54 & 56 & 53,5 & 59 \\
\hline$A D$ & 28 & & & & & El & 32 & 32 & 30,5 & 34,4 \\
\hline $\mathrm{Ad}$ & 44,5 & 47 & 44,5 & 42 & & $\mathrm{Ad}$ & 36,5 & 38 & 37,5 & 40,5 \\
\hline Ed & 31 & 29 & 30,5 & 27,5 & & & & & & \\
\hline & & & & & & & & & & \\
\hline Calcáneo: & & \multicolumn{2}{|c|}{ Centrotarsal: } & & & & & & & \\
\hline LM & 121 & & AM & 46 & 41 & 50,5 & 49 & 40 & 49 & \\
\hline AM & 37,5 & & & & & & & & & \\
\hline & & & & & & & & & & \\
\hline \multicolumn{11}{|l|}{ Falange 1: } \\
\hline Lmpe & 58,5 & 60,5 & 60,5 & 57 & 60,5 & 59,5 & 64,5 & 55,5 & 59,5 & 61 \\
\hline$A p$ & 22 & 23,5 & 24,5 & 22,5 & 22 & 23,5 & 23,5 & 22 & 23,5 & 23 \\
\hline$A D$ & 16,4 & 20,5 & 19,8 & 17,3 & 19,1 & 18,8 & 19,7 & 17 & 21 & 17,7 \\
\hline $\mathrm{Ad}$ & 21,5 & 22,5 & 22 & 21 & 22 & 23,5 & 23 & 21,5 & 22,5 & 23 \\
\hline Lmpe & 60 & 58,5 & 63 & 56,5 & 55 & 54 & 62 & 57,5 & 54,5 & \\
\hline$A p$ & 22 & 22,5 & 22,5 & 21,5 & 21,5 & 20,5 & 24 & 22 & 21 & \\
\hline$A D$ & 18,4 & 16,2 & 17,7 & 17,4 & 16,4 & 17 & 20 & 16,8 & 15,6 & \\
\hline $\mathrm{Ad}$ & 21,5 & 21,5 & 22,5 & & 20,5 & 19,8 & 22,5 & 21 & 19,3 & \\
\hline \multicolumn{11}{|l|}{ Falange 2: } \\
\hline LM & 45 & 44 & 45,5 & 43,5 & 43 & 43,5 & 43 & 46 & 40,5 & 45 \\
\hline Ap & 23,5 & 23 & 23,5 & 22,5 & 22,5 & 22,5 & 22 & 23 & 21,5 & 23 \\
\hline$A D$ & 18,8 & 17,3 & 17,7 & 15,3 & 17,3 & 19 & 15,6 & 17,2 & 15,8 & 18,4 \\
\hline $\mathrm{Ad}$ & 19,4 & 20,5 & 20 & 19,3 & 18,3 & 19,5 & 19 & 19 & 18,3 & 20 \\
\hline LM & 41,5 & 42 & 41 & 42,5 & 39,5 & 44,5 & 44 & 42,5 & 46 & 43,5 \\
\hline Ap & 22 & 21,5 & 19,8 & 21,5 & 20,5 & 24 & 22,5 & 23 & 23,5 & 21,5 \\
\hline$A D$ & 15,2 & 16 & 13,9 & 15,5 & 15,9 & 17,4 & 16,6 & 18,2 & 18,3 & 17 \\
\hline $\mathrm{Ad}$ & 19 & 17,9 & 17,7 & 19,3 & 17,2 & 21,5 & 19,2 & 21 & 19,6 & 18,4 \\
\hline
\end{tabular}


ANEXO IV

Medidas aisladas de Canis lupus

Measures isolated Canis lupus

\begin{tabular}{|c|c|c|c|c|c|c|c|c|c|c|c|}
\hline \multicolumn{12}{|c|}{ Maxilar: } \\
\hline & LC & 12,7 & 12,6 & 13,1 & 12,6 & 14,9 & 14,6 & 15 & & & \\
\hline & $A C$ & 8,3 & 8,2 & 9 & 8,8 & 9 & 9,5 & 10 & & & \\
\hline & LP3 & 17,9 & 17,8 & 15,5 & 15,5 & 15,5 & & LM1 & 15,9 & 17,2 & \\
\hline & AP3 & 8,5 & 8 & 6,9 & 6,2 & 6,4 & & AM1 & 18,4 & 21,2 & \\
\hline & & & & & & & & LM2 & 8,5 & & 9,1 \\
\hline & LP4 & 20 & 26 & 24,5 & 25,7 & 20,3 & & AM2 & 12,7 & & 13,6 \\
\hline & AP4 & 9,6 & 23,5 & 15,5 & 12,9 & 15,6 & & & & & \\
\hline \multicolumn{12}{|c|}{ Mandíbula: } \\
\hline \multicolumn{2}{|c|}{ LP1-M2 } & 92,5 & & & & & & & & & \\
\hline \multicolumn{2}{|c|}{ LP1-P4 } & 53 & & & & & & & & & \\
\hline \multicolumn{2}{|c|}{ LM1-M2 } & 41,5 & & & & & & & & & \\
\hline & LC & & & & 15,3 & 15,5 & & & & & \\
\hline & $A C$ & & & & 10,2 & 10,5 & & & & & \\
\hline & LP2 & 13,8 & & & & & 10,5 & 11,7 & & & \\
\hline & AP2 & 6,7 & & & & & 5,4 & 6,2 & & & \\
\hline & LP3 & 14,6 & & & & & & & 13,5 & 12,3 & 12,3 \\
\hline & AP3 & 7,4 & & & & & & & 6,6 & 5,6 & 6,3 \\
\hline & LP4 & 16,7 & 17,6 & 17,3 & & & & & & & \\
\hline & AP4 & 9,1 & 9,4 & 9,5 & & & & & & & \\
\hline & LM1 & 30,3 & 29 & 29 & & & & & & & \\
\hline & AM1 & 12,5 & 12,1 & 12,4 & & & & & & & \\
\hline & LM2 & 12,7 & 12,2 & 12 & & & & & & & \\
\hline & AM2 & 7,4 & 9,4 & 9,7 & & & & & & & \\
\hline & & & & & & & & & & & \\
\hline & LP4 & 16,7 & 17,6 & 17,3 & & & & & & & \\
\hline & AP4 & 9,1 & 9,4 & 9,3 & & & & & & & \\
\hline & LM1 & & & & 22,3 & 30,3 & 27,6 & 28,2 & 29 & 29 & 30,5 \\
\hline & AM1 & & & & 8,8 & 12,5 & 11,3 & 11,8 & 12,4 & 12,1 & 12,6 \\
\hline & LM2 & 12,2 & 12 & 11,3 & & & & & & & \\
\hline & AM2 & 9,4 & 9,7 & 8,8 & & & & & & & \\
\hline \multicolumn{2}{|l|}{ Atlas: } & & & & Axis: & & \multicolumn{2}{|c|}{ Escápula: } & & & \\
\hline & AM & 95 & & & AScr & 39 & & LMP & 39,5 & 41,5 & \\
\hline & AScr & 46,5 & 42,5 & & & & & LS & 34 & 35,5 & \\
\hline & Ascd & 36,5 & 34,5 & & & & & AS & 22 & 25 & \\
\hline & & & & & & & & $\mathrm{LmC}$ & 33 & 33,5 & \\
\hline \multicolumn{2}{|c|}{ Húmero: } & & & & \multicolumn{2}{|l|}{ Radio: } & & & & & \\
\hline & $\mathrm{Ad}$ & 45 & 36,7 & & & LM & 220,5 & 221 & & & \\
\hline & & & & & & Ap & 25,5 & 26,5 & 25 & & \\
\hline \multirow[t]{4}{*}{ Ulna: } & & & & & & $A D$ & 17,1 & 17,6 & & & \\
\hline & EPA & 31,5 & 25 & & & $\mathrm{Ad}$ & 32,5 & 33,5 & & 32 & \\
\hline & $\mathrm{EmO}$ & 26 & 22,5 & & \multicolumn{2}{|c|}{ Metacarpo: } & 1 & 1 & 1 & 1 & 1 \\
\hline & LO & 38,5 & 16,3 & & & LM & 28,5 & 30,5 & 30 & 28,5 & 25 \\
\hline \multicolumn{2}{|c|}{ Metacarpo: } & 2 & 2 & 2 & 2 & 2 & 2 & 3 & 3 & 3 & 3 \\
\hline & LM & 87 & 76,5 & 76,5 & 80 & 80,5 & 91,5 & 92 & 85 & 93 & 92,5 \\
\hline
\end{tabular}




\begin{tabular}{|c|c|c|c|c|c|c|c|c|c|c|c|}
\hline & Ap & 11,5 & 14,6 & 14,3 & 10,8 & 9 & 11,5 & 11,8 & 11,2 & 11,4 & 11,9 \\
\hline & $A D$ & 8,9 & 9 & 10 & 9 & 8,8 & 9 & 8,8 & 9,3 & 9,2 & 8,6 \\
\hline & $\mathrm{Ad}$ & 12,1 & 12 & 12 & 12,3 & 11,8 & 12,4 & 12,2 & 10,8 & 12,3 & 11,5 \\
\hline & & 3 & 4 & 4 & 4 & 5 & 5 & 5 & & & \\
\hline & LM & 79,5 & 92,5 & 87,5 & 92 & 73,5 & 76,5 & 76,5 & \multicolumn{2}{|l|}{ Fémur: } & \\
\hline & $A p$ & 9,9 & 11 & 10,5 & 10,6 & 14,7 & 14,6 & 14,3 & & $\mathrm{Ad}$ & 45 \\
\hline & $A D$ & 7,4 & 9,2 & 9 & 8,6 & 9,9 & 9 & 10 & & & \\
\hline & $\mathrm{Ad}$ & 11 & 11,6 & 12,6 & 11,9 & 12,7 & 12 & 17 & & & \\
\hline \multicolumn{12}{|l|}{ Astrágalo: } \\
\hline & LM & 32,5 & 37 & 28,5 & 33 & 35 & 26,3 & & & & \\
\hline \multicolumn{12}{|l|}{ Calcáneo: } \\
\hline & LM & 53 & 58,5 & 62 & 57,5 & 54 & & & & & \\
\hline & AM & 21 & 29,5 & 24,5 & 24 & & & & & & \\
\hline \multicolumn{2}{|l|}{ Metatarso: } & 2 & 3 & 3 & 4 & 4 & 4 & 4 & 5 & 5 & \\
\hline & LM & 82 & 99,5 & 98 & 97 & 102 & 102 & 87 & 91 & 90 & \\
\hline & $A p$ & 6,9 & 12,5 & 12 & 9,7 & 8,7 & 9 & 10,8 & 10,3 & & \\
\hline & $A D$ & 8,1 & 9 & 8,4 & 8,3 & 8,1 & 8 & 8,7 & 7,4 & 7,1 & \\
\hline & $\mathrm{Ad}$ & 10,6 & 11,2 & 11,6 & 12,4 & 12,4 & 11,2 & 10,7 & 11,1 & 11,4 & \\
\hline
\end{tabular}


ANEXO V

Medidas aisladas de Cuon alpinus

Measures isolated Cuon alpinus

\begin{tabular}{|c|c|c|c|c|c|c|c|c|c|c|c|}
\hline \multicolumn{12}{|l|}{ Maxilar: } \\
\hline & LC & 11,3 & & & & & & & & & \\
\hline & $A C$ & 7,4 & & & & & & & & & \\
\hline & LP3 & & 12,3 & 13,6 & & & & & & & \\
\hline & AP3 & & 6,2 & 6,6 & & & & & & & \\
\hline & LP4 & & & & 17,6 & & & & & & \\
\hline & AP4 & & & & 8,6 & & & & & & \\
\hline & LM1 & & & & & 12,5 & & & & & \\
\hline & AM1 & & & & & 15 & & & & & \\
\hline & & & & & & & & & & & \\
\hline \multicolumn{12}{|c|}{ Mandíbula: } \\
\hline \multicolumn{2}{|c|}{ LP1-M2 } & 71,5 & & & & & & & & & \\
\hline \multicolumn{2}{|c|}{ LP1-P4 } & 41,5 & & & & & & & & & \\
\hline \multicolumn{2}{|c|}{ LM1-M2 } & 31,5 & & & & & & & & & \\
\hline LC & & 11,5 & & 12,9 & & & & & & & \\
\hline$A C$ & & $7 ; 9$ & & 8,5 & & & & & & & \\
\hline LP2 & & 9,5 & & & & & & & & & \\
\hline AP2 & & 5 & & & & & & & & & \\
\hline LP3 & & & & & 11,3 & 11,2 & 11,8 & 10,7 & 11,5 & & \\
\hline AP3 & & & & & 5,6 & 5,8 & 5,8 & 5,3 & 5,5 & & \\
\hline LP4 & & 14,3 & 14,6 & & 14,3 & & & & & & \\
\hline AP4 & & 7,2 & 6,9 & & 7,2 & & & & & 13,6 & 14,6 \\
\hline LM1 & & 22,5 & 22,3 & & 23 & & & & & 6,7 & 6,7 \\
\hline AM1 & & & 8,8 & & 9,9 & & & & & & \\
\hline LM2 & & 8,1 & 8,9 & & & & & & & & \\
\hline AM2 & & 6,6 & 6,9 & & & & & & & & \\
\hline & & & & & & & & & & & \\
\hline LM1 & 13,6 & 14,3 & 14,9 & & & & & & Axis: & & \\
\hline AM1 & 6,9 & 7,3 & 7,7 & & & & & & Ascr & 32,2 & \\
\hline LM2 & & & & 22,2 & 22,5 & 21,5 & 22,9 & & & & \\
\hline AM2 & & & & 8,9 & 9,5 & 9,2 & 9,4 & & & & \\
\hline & & & & & & & & & & & \\
\hline \multicolumn{2}{|c|}{ Escápula: } & & & \multicolumn{2}{|l|}{ Húmero: } & & & Ulna: & & & \\
\hline & LMP & 33 & & & $\mathrm{Ad}$ & 34 & & EPA & 25 & & \\
\hline & LS & 29 & & & & & & $\mathrm{EmO}$ & 22,5 & & \\
\hline & AS & 18,4 & & & & & & LO & 16,3 & & \\
\hline & $\mathrm{LmC}$ & 27 & & & & & & & & & \\
\hline & & & & & & & & & & & \\
\hline \multicolumn{2}{|c|}{ Metacarpo: } & 1 & 2 & 4 & 5 & & \multicolumn{2}{|l|}{ Fémur: } & & & \\
\hline & LM & 18,6 & 64 & 75,5 & 60,5 & & & $E C$ & 19,3 & & \\
\hline & $A p$ & & 9,1 & 10,9 & 12,3 & & & & & & \\
\hline & $A D$ & & 8,4 & 7,7 & 8,4 & & \multicolumn{2}{|c|}{ Astrágalo: } & & & \\
\hline & $\mathrm{Ad}$ & & 11,4 & 10,4 & 11,7 & & & LM & 28,5 & 26,3 & \\
\hline \multicolumn{2}{|c|}{ Calcáneo: } & & & & \multicolumn{2}{|c|}{ Metatarso: } & 3 & 4 & & & \\
\hline & LM & 48,5 & 48,5 & & & LM & 86 & 81 & & & \\
\hline & AM & 22 & & & & $A p$ & 10,4 & 9,7 & & & \\
\hline & & & & & & $A D$ & 8,6 & 8,2 & & & \\
\hline & & & & & & $\mathrm{Ad}$ & 11,5 & 11 & & & \\
\hline
\end{tabular}


ANEXO VI

Medidas aisladas de Vulpes vulpes

Measures isolated Vulpes vulpes

\begin{tabular}{|c|c|c|c|c|c|c|c|c|c|c|c|}
\hline \multicolumn{12}{|l|}{ Maxilar: } \\
\hline & LC & 15 & 14,6 & & & & & & & & \\
\hline & $A C$ & 10 & 9,5 & & & & & & & & \\
\hline & LP3 & & & 8,6 & 8,9 & & & & & & \\
\hline & AP3 & & & 3 & 3,3 & & & & & & \\
\hline & LP4 & & & 14 & & 14,1 & 14 & 13,6 & 13,5 & 13,8 & 15 \\
\hline & AP4 & & & 5,7 & & 7,7 & 5,8 & 6,3 & 5,6 & 6 & 6,4 \\
\hline & LM1 & & & 9,2 & & 10 & 9 & 9 & 9,2 & 10,2 & \\
\hline & AM1 & & & 10,5 & & 11,8 & 10,7 & 11,4 & 10,8 & 11,9 & \\
\hline & LM2 & & & & & 5,8 & 5,6 & 5,2 & & & 5,5 \\
\hline & AM2 & & & & & 7,6 & 8 & 7,8 & & & 8,6 \\
\hline & LP4 & 14,7 & 13,9 & 15,3 & 14,1 & 13,4 & 15 & 14,7 & 15,8 & 13 & 15 \\
\hline & AP4 & 6,7 & 6,5 & 6,9 & 7,7 & 5,9 & 6,3 & 7 & 7,9 & 6,4 & 6,8 \\
\hline & LM1 & 10,4 & 9,7 & 9,5 & 10 & & & & & & \\
\hline & AM1 & 12,7 & 11,8 & 11,5 & 11,8 & & & & & & \\
\hline & LM2 & & 5,8 & 6,2 & 5,8 & & LM2 & 9,6 & 10,6 & 6,2 & 6,3 \\
\hline & AM2 & & 8,3 & 7,9 & 7,6 & & AM2 & 11,6 & 11,6 & 8 & 9,2 \\
\hline & LP4 & 15,6 & 15,5 & 15,5 & 14,7 & 13,3 & 15,7 & & & & \\
\hline & AP4 & 7,7 & 5,8 & 6,1 & 5,6 & 6,7 & 6,9 & & & & \\
\hline & & & & & & & & & & & \\
\hline & LM1 & 9,2 & 9,1 & 9,8 & 10 & 10,4 & & & & & \\
\hline & AM1 & 10,3 & 13,6 & 10,9 & 12,1 & 12,6 & & & & & \\
\hline & & & & & & & & & & & \\
\hline \multicolumn{12}{|c|}{ Mandíbula: } \\
\hline & LP2 & 7,5 & 7,8 & 9,6 & & 8,1 & & & & & \\
\hline & AP2 & 3 & 3 & 3,2 & & 3,4 & & & & & \\
\hline & LP3 & 8,3 & 8,6 & 10,1 & 9 & & 8,8 & & & & \\
\hline & AP3 & 3,3 & 3,2 & 3,5 & 3,3 & & 3,7 & & & & \\
\hline & LP4 & 9,4 & 8,8 & 10,5 & 8,8 & & 10,6 & 8,9 & 10,7 & & \\
\hline & AP4 & 3,8 & 3,6 & 4,4 & 3,8 & & 4,3 & 3,5 & 4,7 & & \\
\hline & LM1 & 14,4 & 14,3 & & 15,1 & 14,9 & 15,8 & 14,7 & 16,1 & 15,6 & 16,3 \\
\hline & AM1 & 5,3 & 5,5 & & 6,8 & 5,3 & 6 & 6,2 & 6,1 & 5,9 & 6,4 \\
\hline & LM2 & 6,6 & 7 & & 7,2 & 7,2 & 7,2 & 7,3 & 7,2 & 7 & 7,4 \\
\hline & AM2 & 5,7 & 5,5 & & 5,5 & 4,5 & 5,3 & 5,5 & 5,5 & 5 & 5,7 \\
\hline & & & & & & & & & & & \\
\hline & LP2 & 9 & & LP3 & 13,5 & 9,6 & 8,8 & 9 & & & \\
\hline & AP2 & 3,6 & & AP3 & 6,6 & 3,8 & 5,3 & 8,3 & & & \\
\hline & LP4 & 10 & 9,9 & 9,4 & 10 & 9,7 & 9,5 & 14,9 & 9,9 & 10 & 9,8 \\
\hline & AP4 & 4,7 & 4,2 & 4,2 & 4,4 & 3,7 & 4,4 & 7,7 & 4,2 & 4,2 & 3,7 \\
\hline & LM1 & 16,3 & & & & & & & & & \\
\hline & AM1 & 6,2 & & LM1 & 16 & 14,9 & 17,2 & 15,8 & 14,5 & 14,2 & 15,9 \\
\hline & & & & AM1 & 6,2 & 5,7 & 6,4 & 6,2 & 5,3 & 5,6 & 6 \\
\hline & LM1 & 14,9 & 15,9 & 15,2 & 17,6 & 15,5 & 15 & 16,1 & 16,6 & 15,6 & 16,6 \\
\hline & AM1 & 5,7 & 6 & 5,4 & 6,7 & 6,1 & 5,7 & 5,9 & 6,2 & 6,1 & 6,3 \\
\hline & LM1 & 14,6 & 16 & 15,5 & & & & & & & \\
\hline
\end{tabular}




\begin{tabular}{|c|c|c|c|c|c|c|c|c|c|c|c|}
\hline & AM1 & 5,8 & 6,2 & 6,1 & & & & & & & \\
\hline & LM2 & 6,8 & 7,3 & 7,2 & 7,7 & 7,5 & 7,5 & 7,5 & 7,2 & 6,9 & 7,4 \\
\hline & AM2 & 5 & 5,7 & 5,6 & 5,1 & 5,8 & 6 & 5,2 & 5,7 & 5,3 & 5,2 \\
\hline \multicolumn{2}{|l|}{ Atlas: } & & & Axis: & & & & \multicolumn{2}{|c|}{ Escápula: } & & \\
\hline & AScr & 25,5 & & AScr & 20,2 & 24,5 & 19,8 & & LMP & 18,3 & 18,7 \\
\hline & AScd & 21 & & & & & & & LS & 15,6 & \\
\hline & & & & & & & & & AS & 10,1 & \\
\hline \multicolumn{2}{|c|}{ Húmero: } & & & & & & & & $\mathrm{LmC}$ & 16,4 & \\
\hline & LM & 129 & 127,5 & 116 & & & & & & & \\
\hline & Ep & 27,5 & 25 & 23,5 & & & & & & & \\
\hline & $A D$ & 8,7 & 8,8 & 7,5 & & & & & & & \\
\hline & $\mathrm{Ad}$ & 20,5 & 19,5 & 18,5 & 18,8 & 19,4 & 19,4 & 20,5 & & & \\
\hline \multicolumn{12}{|c|}{ Radio: } \\
\hline & LM & 114 & 116 & 112 & 121 & & & & & & \\
\hline & $A p$ & 11,8 & 11,6 & 11,3 & 12,5 & 11,3 & 12,1 & & & & \\
\hline & $A D$ & 8,6 & 9 & 7,6 & 8,2 & & & & & & \\
\hline & $\mathrm{Ad}$ & 15,2 & 15,5 & 14,6 & 15,8 & & & 14,8 & 14,4 & 15,6 & 16,3 \\
\hline \multirow[t]{4}{*}{ Ulna: } & & & & & & & & Mc2: & & & \\
\hline & EPA & 16 & 16,7 & 16,6 & 15,8 & 15,5 & & & LM & 45,5 & \\
\hline & $\mathrm{EmO}$ & 13,7 & 14,2 & 13,4 & 14,3 & 13,2 & & & & & \\
\hline & LO & 13,2 & 13,4 & & 14,2 & 13,8 & & & & & \\
\hline \multirow[t]{2}{*}{ Mc4: } & & & & & & Mc5: & & & & & \\
\hline & LM & 45 & 45 & 50 & & & LM & 37,5 & 41 & 37,3 & \\
\hline \multicolumn{2}{|c|}{ Pelvis: } & & & & Fémur: & & & & & & \\
\hline & LA & 14,3 & 15,8 & & & EC & 12,5 & & & & \\
\hline & AA & 13,3 & 15,3 & & & $\mathrm{Ad}$ & & 21,5 & 21 & 22 & \\
\hline \multicolumn{12}{|l|}{ Tibia: } \\
\hline & LM & 143 & 147,5 & & & & & & & & \\
\hline & $A p$ & 21,5 & & 22,5 & 22 & & & & & & \\
\hline & $A D$ & 8,3 & 9,5 & & & & & & & & \\
\hline & $\mathrm{Ad}$ & 14,4 & 15,9 & & & 13,6 & 15 & 14 & 15,9 & 17,7 & 16 \\
\hline \multicolumn{12}{|c|}{ Astrágalo: } \\
\hline & LM & 18,1 & 20 & 19,4 & 18,8 & 19,3 & & & & & \\
\hline & & & & & & & & & & & \\
\hline \multicolumn{12}{|c|}{ Calcáneo: } \\
\hline & LM & 34,5 & 30,8 & 31,5 & 35,5 & 33,5 & 32 & 30 & 31,5 & 34,3 & 32 \\
\hline & LM & 33,5 & 33,5 & 27,5 & 34 & 30,5 & 30,5 & & & & \\
\hline \multicolumn{12}{|l|}{ Mt2: } \\
\hline & LM & 56,5 & 58,5 & 61,5 & 54 & 58 & 59 & & & & \\
\hline \multirow[t]{2}{*}{ Mt3: } & & & & & & Mt4: & & & & & \\
\hline & LM & 62,5 & 65,5 & 66,5 & & & LM & 48,5 & 61,5 & & \\
\hline
\end{tabular}


